\title{
THE INFLUENCE OF HYDROGEOMORPHOLOGY, SOIL REDOX CONDITIONS, AND SALINITY ON THE SPATIAL ZONING OF SALTGRASS, SALT RUSH, AND CATTAILS IN SCOTTS CREEK MARSH, SWANTON PACIFIC RANCH, CA.
}

\author{
A Thesis \\ presented to \\ the Faculty of California Polytechnic State University, \\ San Luis Obispo \\ In Partial Fulfillment \\ of the Requirements for the Degree \\ Master of Science in Agriculture \\ by \\ Mark D. Gormley
}

November, 2013 
(C) 2013

Mark D. Gormley

ALL RIGHTS RESERVED 


\section{COMMITTEE MEMBERSHIP}

TITLE:

AUTHOR:

DATE SUBMITTED:

COMMITTEE CHAIR:

COMMITTEE MEMBER:

COMMITTEE MEMBER:
The influence of hydrogeomorphology, soil redox conditions, and salinity on the spatial zoning of Saltgrass, Salt Rush, and Cattails in Scotts Creek Marsh, Swanton Pacific Ranch, CA.

Mark Gormley

November, 2013

Karen L. Vaughan, PhD

Assistant Professor of Soil Science

Chip Appel, PhD

Assistant Professor of Soil Science

Priya Verma, PhD

Assistant Professor of Environmental Science 


\begin{abstract}
The influence of hydrogeomorphology, soil redox conditions, and salinity on the spatial zoning of Saltgrass, Salt Rush, and Cattails in Scotts Creek Marsh, Swanton Pacific Ranch, CA. Mark D. Gormley

Scotts Creek Marsh (SCM) is a small coastal wetland ecosystem in Davenport, CA. The vegetation of SCM is dominated by three halophytic zones comprised of saltgrass, salt rush, cattails. The objectives of the study were (i) to investigate the variables that influence the zoning of the three dominant halophyte communities in SCM (ii) and to the test the effectiveness of Indicator of Reduction in Soil (IRIS) tubes to indicate the reduction of S. The study examined the following parameters from April 6 to July 21, 2013: (i) the HGM of Scotts Creek Marsh, (ii) soil oxidation and reduction (redox) conditions, and (iii) salinity. All three halophytes were well suited for anoxic, redox, and saline conditions by utilizing morphological adaptations (arenchyma, adventitious roots) to their root systems. The study concluded that the spatial zoning of the three dominate halophyte species within SCM was most likely due to slight differences in the water levels and salinity. The plants were distributed in an expected pattern; saltgrass occupying the areas with the highest water EC $(26.98 \mathrm{dS} / \mathrm{m})$ and elevation $(279.20 \mathrm{~cm})$. The salt rush zones had a mild average EC of $15.24 \mathrm{dS} / \mathrm{m}$ and elevation of $276.76 \mathrm{~cm}$. The cattails dominated the low average saline areas $(9.60 \mathrm{dS} / \mathrm{m})$ near the marsh channels with the elevation of $270.97 \mathrm{~cm}$. The IRIS tubes that were installed as indicators of both sulfur and iron reduction were effective. The 30 tubes that were withdrawn after the closure of Scott's Creek all had $>30 \%$ reduction of the $\mathrm{Fe}^{3+}$ paint. The analyzed data from the study suggests that changes to the HGM of SCM could potentially alter the ecology of the marsh. The results from the IRIS study seemed to indicate that they are effective at recording the reduction of sulfur.
\end{abstract}

Key Words: hydrogeomorphology, biogeochemistry, halophyte, spatial zoning, arenchyma, adventitious roots, sulfidization, Indicator of Reduction in Soil 


\section{TABLE OF CONTENTS}

LIST OF TABLES ........................................................ vii

LIST OF FIGURES ....................................................... viii

CHAPTER 1: Thesis Introduction ............................................... 1

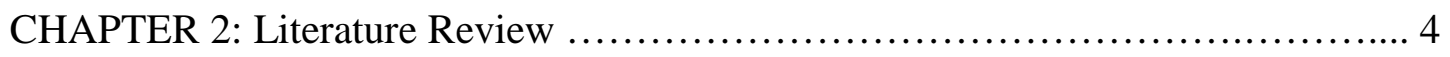

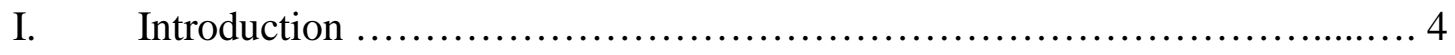

II. Hydrogeomorphology of Coastal Salt Marshes $\ldots \ldots \ldots \ldots \ldots \ldots \ldots \ldots \ldots \ldots \ldots . \ldots \ldots$

III. Physiochemical Environment ....................................... 14

IV. Oxidation and Reduction Chemistry................................. 16

V. Biogeochemical Cycles of Nitrogen, Iron, Manganese, and Sulfur .......... 23

VI. Factors Effecting Nutrient Cycling ..................................... 28

VII. Biotic Adaptations to Coastal Salt Marsh Environment .................... 28

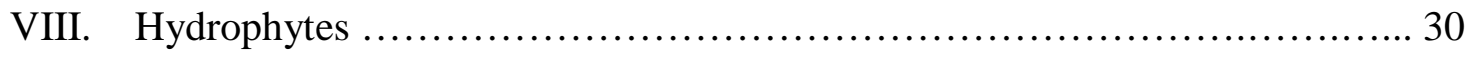

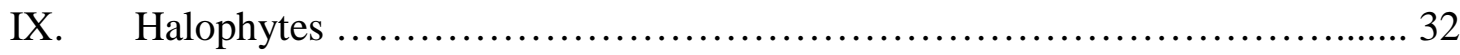

CHAPTER 3: The Influence of Hydrogeomorphology on Halophyte Zoning ........ 35

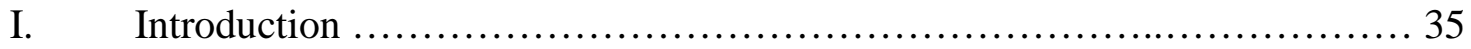

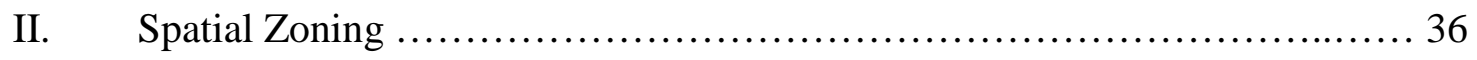

III. The Dominant Halophytic Vegetation of Scott's Creek Marsh ............... 39

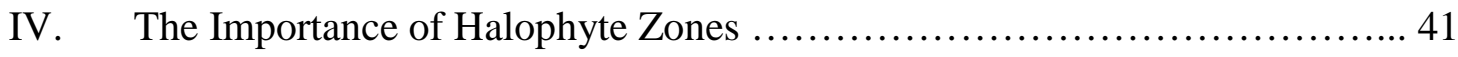

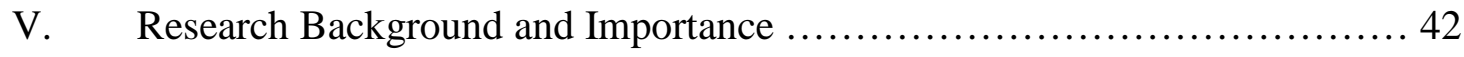

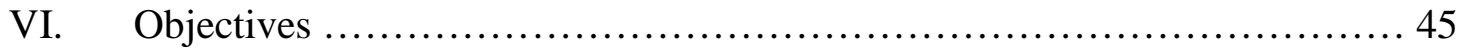

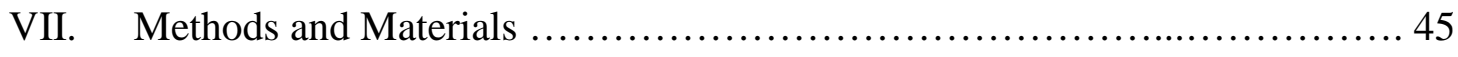

VIII. Results ......................................................... 48 


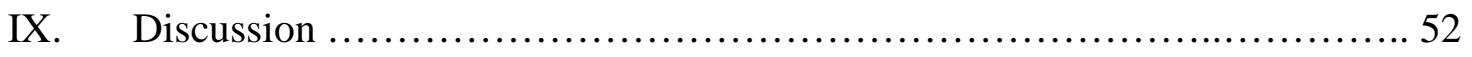

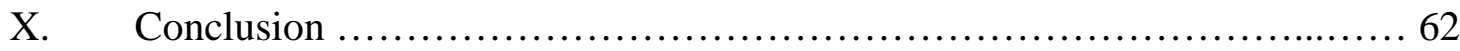

CHAPTER 4: The Investigation of Sulfate Reduction in Scotts Creek Marsh ......... 64

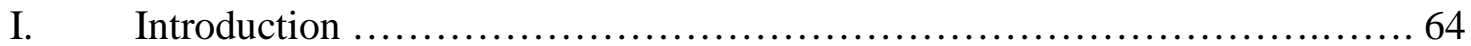

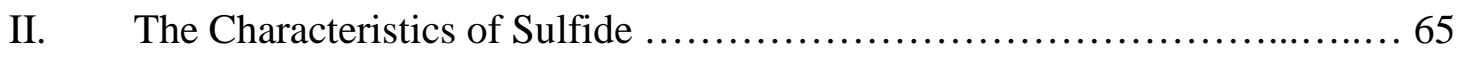

III. Problems Associated with the Reduction and Oxidation of Sulfur ............... 67

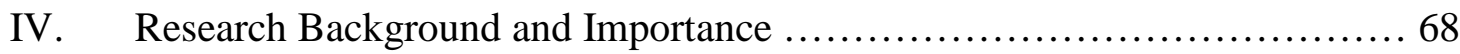

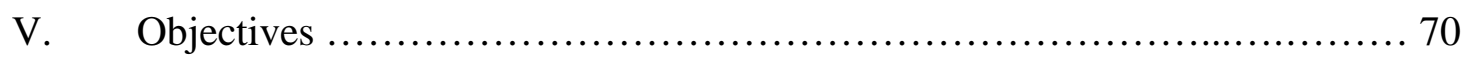

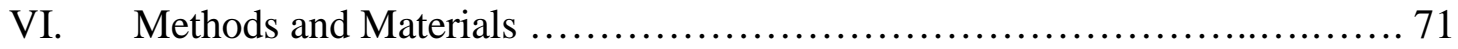

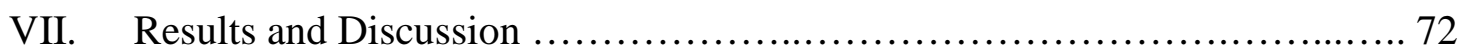

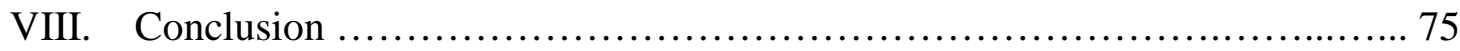

CHAPTER 5: Assessment of IRIS Tubes Using Adobe Photoshop CS 5.1 ........... 77

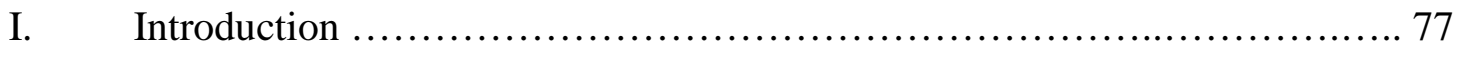

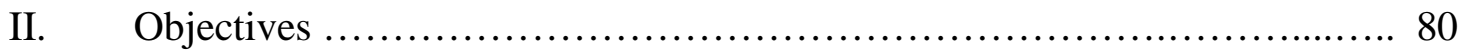

III. Methods and Materials .................................................. 80

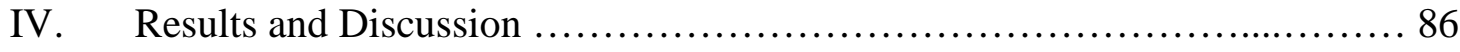

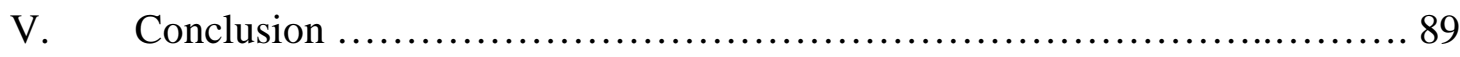

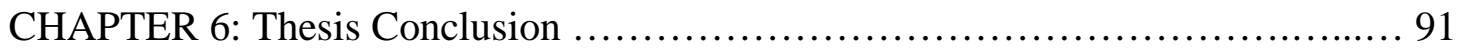

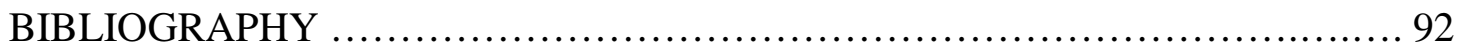




\section{LIST OF TABLES}

Table

1. The names, elevation, and locations of the three soil pits dug in Scotts Creek Marsh from 03/25/2013 - 03/28/2013

2. The names, locations, and elevations of each monitoring well installed at Scotts Creek Marsh from 03/25/2013 - 03/28/2013

3. The average daily water level from wells 1,2 and 3 in centimeters $(\mathrm{cm})$ from June 5 to June 11,2013

4. The average weekly significant wave height (WVHT), dominant period (DPD), mean wave direction (MWD), and low and high tides form June 1st to June 21st according to NOAA (2013) buoy $^{\dagger}$ data ............................. 49

5. Table 5. Soil profile descriptions for the saltgrass, salt rush, and cattail pits analyzed on 03/25/2013 according to the guide lines stipulated by USDA. (2012)

6. Table 6. Saltgrass salt rush, and cattail soil pit redoximorphic features according to the guide lines stipulated by the USDA (2012) 


\section{LIST OF FIGURES}

Figure

1. The location and distribution of the four major halophyte zones within Scotts Creek Marsh along with the locations of the study wells and soil pits. The map was created using a hand held GPS unit and aerial photographs provided by Swanton pacific Ranch

2. The black and white image shows the location and flow of Scotts Creek prior to the relocation of Route 1 and the construction of the bridge spanning the mouth of Scotts Creek. The current imagery shows the where Scotts Creek Marsh developed and the current location of Route 1, the bridge, and the levees along Scotts Creek

3. The daily average water temperature in degrees Celsius $\left({ }^{\circ} \mathrm{C}\right)$ for each well in Scotts Creek Marsh from April 6 to July 20, 2013

4. The daily average water electrical conductivity in $\mathrm{dS} / \mathrm{m}$ for each well in Scotts Creek Marsh from April 6 to July 20, 2013

5. The daily average precipitation in millimeters $(\mathrm{mm})$ based on NOAA, 2011 normalized and 2013 precipitation data from April 6 to July 21, 2011 normalized data was used since the 2012 data has not been compiled yet

6. Average daily gauge height in centimeters $(\mathrm{cm})$ of Scotts Creek from April 6 to July 21

7. Average daily low and high tides in meters (m) from buoy Station 46042,

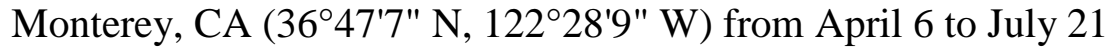
(NOAA, 2013), yellow lines indicate the full moons on April 25, May 25, and June 23

8. Average daily water level readings in centimeters ( $\mathrm{cm}$ ) for all three wells from April 6 to the 21 of July, yellow lines indicate the full moons on April 25, May 25, and June 23

9. The percent (\%) carbon (blue line) and \% nitrogen (orange line) by depths $(\mathrm{cm})$ for all three soil pits in Scotts Creek Marsh

10. Location of the IRIS installation sights within the Scotts Creek Marsh study area, Swanton Pacific Ranch, Davenport, California

11. The results of the all the IRIS tubes by week from April 6 - July 21, 2013 within the saltgrass zone, Swanton Pacific Ranch, Davenport California 
12. The results of the all the IRIS tubes by week from April 6 - July 21, 2013 within the salt rush zone Swanton Pacific Ranch, Davenport California

13. The results of the all the IRIS tubes by week from April 6 - July 21, 2013 within the cattail zone Swanton Pacific Ranch, Davenport California

14. Location of the IRIS installation sights within the Scotts Creek Marsh study area, Swanton Pacific Ranch, Davenport, California

15. To obtain total pixel count of the entire IRIS image, (i) open the histogram window by clicking on the windows tab and selecting the histogram option, (ii) the press ctl+A to select the entire image, (iii) the total pixel count is located in the histogram window

16. To identify the proper range of colors for oxidation and reduction, (i) open the color sampler tool, the color information window will open, (ii) identify the proper RGB value by gliding the eye dropper icon over the image and reading the value in the color information window, (iii) once proper value is identified, left click eye dropper and place marker, you can choose up to four .... 83

17. To obtain a more accurate representation of $S$ reduction, you can create a grey channel filter, (i) click the windows tab and select channel options, (ii) once the channel window is open, click on the channel options drop down, (iii) click split channel options, (iv) once the channel has been split, click merge channel, (v) a grey channel filter will be applied

18. Once the grey channel filter has been created, the color sampler and color range tools can be used for more accurate measurements

19. Once a color range has been established, the number of pixels within the color range can be quantified by using the color range selection tool, (i) click the selection tab and click the color range option, (ii) click on the initial color range identifier icon, (iii) glide mouse over the image and choose the desired RGB color by looking on the color information window or histogram window, once a desire value is found, click on the image to initialize the calibration, (iv) next click on the additions button and continue to add more colors within the desired RGB range, (v) once the total range of colors has been added, click OK to allow the program to select the desired pixels

20. The color range selection tool will select and highlight the pixels entered, the total number of selected pixels within the desired color range is found in the histogram window

21. The results of the all the IRIS tubes by week from April 6 - July 21, 2013 within the saltgrass zone, Swanton Pacific Ranch, Davenport California 87 
22. The results of the all the IRIS tubes by week from April 6 - July 21, 2013 within the salt rush zone Swanton Pacific Ranch, Davenport California .......... 87

23. The results of the all the IRIS tubes by week from April 6 - July 21, 2013 within the cattail zone Swanton Pacific Ranch, Davenport California

24. Comparison of the computer and student estimated total reduction (\%TotR) and oxidation (\%TotOx) of all IRIS tubes based on computer generated images .................................................... 8

25. Comparison of the computer and student estimated percent $\mathrm{Fe}^{3+}$ reduction (\%ReFe(III)) and S reduction (\%RS) of all IRIS tubes based on computer generated images 
Chapter 1: Thesis Introduction

Scotts Creek Marsh (SCM) is a coastal salt marsh located on Swanton Pacific Ranch in Davenport CA, approximately 100 km south of San Francisco (Hayes et al., 2008). During the 1940s, the construction of Route 1 along with levies to direct the flow of Scotts Creek created ideal conditions for the development of a coastal salt marsh. The presence, health, and productivity of SCM depends on its hydrogeomorphology and resultant biogeochemical processes. The combination of hydrology, climate, and geomorphology dictate the physiochemical status of SCM soils, which in turn, directly influences plant species composition and richness, primary productivity, organic accumulation, and nutrient cycling (Mitsch and Gosselink, 2007).

The importance of SCM for the survival of juvenile steelhead, Oncorhynchus mykissm, highlights the significance of this unique habitat. During the summer and fall, low flow rates of Scotts Creek and swell activities creates a sandbar that closes the mouth turning the salt marsh into an ephemeral lagoon (Hayes et al., 2008). The rise in water level increases fish habitat and catalyzes biogeochemical process that increase nutrient availability. A study conducted by Hayes et al. (2007) revealed that juvenile steelhead that inhabited SCM after the formation of the lagoon made up the vast majority of the fish who reached ocean entry size compared to the steelhead that inhabited other zones within the Scotts Creek watershed. Although the marsh/lagoon environment only comprises $5 \%$ of the total stream area, the marsh/lagoon is the most important habitat for the survival of steelhead within the Scotts Creek watershed (Hayes et al., 2007).

Recently, the California Department of Transportation (Caltrans) proposed the reconstruction of the bridge that spans the mouth of Scotts Creek due to its continued 
degradation. To accomplish their goals, modification of the hydrogeomorphology of SCM by Caltrans will be necessary. Any bridge reconstruction plan should take into consideration that changes to the landscape and hydrology of Scotts Creek could significantly alter the current ecology of SCM. Considering the ecological importance of SCM, research investigating the hydrogeomorphology and the resultant biogeochemistry of the marsh is necessary to develop a sustainable management plan that would allow for the improvement of the bridge while preserving the ecology. Although previous studies have investigated aspects of the marsh, there is very little data on how altering the hydrologic regime and modifying the landscape would impact the soil biogeochemical processes and plant communities of SCM.

The scope of the research project focused on the spatial zoning of plants within SCM and soil biogeochemical processes. Typically, halophytes are spatially distributed into distinct zones based on the adaptations developed by the plant to withstand environmental pressures. Therefore, the spatial distribution and concentration of plants can be used to observe and monitor any changes to the hydrology and landscape of SCM. Since the reduction of sulfates in coastal salt marshes drives much of the below ground energy production, the seasonal transformation of SCM into a lagoon provides an important opportunity to research the soil biogeochemistry.

The objectives of the study were (i) to investigate the zoning of the halophyte communities in SCM to better understand the effects the hydrogeomorphology of SCM may have on the ecosystem, (ii) to utilize Indicator of Reduction in Soil (IRIS) tubes to indicate whether the reduction of sulfates occurs in SCM during its lagoon phase, and (iii) test the effectiveness of IRIS tubes to accurately indicate the reduction of sulfate. 
The research hypotheses where (i) the salinity and hydrogeomorphology are the most significant factors influencing the spatial zoning of halophytes within SCM, (ii) the environmental conditions of SCM during its lagoon phase is ideal for the biologically mediated reduction of sulfate, and (iii) use of IRIS tubes is an effective way to indicate that the reduction of sulfates has occurred. 
Chapter 2: Literature Review

\section{Introduction}

Coastal salt marshes (CSM) are complex ecosystems that represent the convergence of terrestrial and aquatic systems. Since CSM have characteristics of both aquatic and terrestrial ecosystems, they are some of the most complex and productive ecosystems in the world (Mitsch and Gosselink, 2007). Yet, because of their complexity and diversity, CSM ecosystems can be hard to define and understand (Mitsch and Gosselink, 2007). Nevertheless, like all wetland ecosystems, CSM have three distinguishing features that can be used to understand and characterize them: (i) shallow water or saturated soils, (ii) the impedance of decomposition and subsequent organic matter accumulation, and (iii) animal and plant life specifically adapted to saturated conditions (Mitsch and Gosselink, 2007).

Tidal salt marshes (TSM) are typically found along intertidal shores in middle and high latitudes all over the world and the distribution of salt marshes can vary from narrow fringes on steep shorelines or large expanses that can cover several kilometers near river mouths, in bays, or on protected coastal plains and lagoons.However, within their geographic range, the physical features of tides, sediments, freshwater inputs, and shoreline structure determine the progress and distribution of CSM (Mitsch and Gosselink, 2000). Tidal salt marshes can be classified into two categories based on their process of development; (i) deltaic and (ii) reworked marine.

Most of the world's TSM are deltaic and form from riverine sediment deposits along low-energy river areas (Mitsch and Gosselink, 2007). Reworked marine TSM form from tidal and storm energies that translocate and manipulate sediments to build stable 
protected areas over time (Mitsch and Gosselink, 2007). Salt marsh development along marine-dominated coasts requires significant shelter to ensures that the rate of sedimentation is sufficiently greater than the rates of erosion due to wave and storm energies (Beeftink, 1977). These marshes typically develop at estuary mouths which have protective spits or bars that offer protection from waves and currents (Mitsch and Gosselink, 2007).

Marine dominated salt marshes are a development of tidal activity, sedimentation, freshwater input, and geomorphology (Mitsch and Gosselink, 2007). Coastal salt marshes are predominately intertidal because they are found in areas where occasional inundation occurs due to high tides; therefore, CSM are typically found in low-lying areas that are physically protected from severe hydrologic activities and climatic events. In order for CSM to develop adequate, protection from wave and storm energies is required to create a stable environment for plant growth. There are typically two types of marine-dominated salt marshes which are broadly classified based on how they are protected from sea energy; (i) protected bays and estuaries and (ii) spits, bars and islands.

When low gradient shorelines of bays and estuaries provide sufficient protection of riverine sediments from erosion and there is enough tidal influence to sustain a moderate to high salinity levels, marine-dominated salt marshes will develop. Coastal salt marshes can also form along marine-dominated coast lines where a bar, neck of land (spit) or island acts as both a sediment sink or trap and as a barrier to protect the marsh from the open sea. Naturally, CSM stability, once established, depends on the balance between the relative rates of two processes: sediment deposition (accretion), and surface subsidence due to abiotic and biotic factors (Mitsch and Gosselink, 2000). 
Biotic factors play a significant role in costal salt marsh stability; however, the abiotic factors play the most significant role. The morphology of a salt marsh directly influences the flow pattern, erosion, and deposition while climate influences the rates, degree, and frequency of flow, erosion, and deposition (Mitsch and Gosselink, 2007). Early development of marine-dominated salt marshes is typified by rapid sedimentation both vertically and laterally resulting in low-lying marshes (Mitsch and Gosselink, 2007). Sediments that build the foundation for CSM typically originate from upland runoff, marine reworking due to tidal and storm energies, and organic production within the marsh itself (Mitsch and Gosselink, 2007).

Both accretion and surface subsidence can occur at the same time and are at times co-dependent on each other and self-regulating (Mitsch and Gosselink, 2007). For example, the deposition of peat due to saturation and microbial anaerobic processes can raise the topography of a salt marsh. However, the rise in elevation lessens saturation and sedimentation increasing oxidation which leads to eventual subsidence due to the decomposition of organic matter (Anisfeld et al., 1999).

During later development, sedimentation usually slows down and is vertical since lateral deposition is checked by erosion on the seaward side until equilibrium between deposition and erosion is obtained (Mitsch and Gosselink, 2007). Like all wetlands, once the geomorphology has been established and stabilizes, the climate and resulting hydrology dictate the ecological services and functions of a CSM ecosystem (Mitsch and Gosselink, 2007). Hydrologic conditions are crucial for the persistence, maintenance, function, and structure of wetlands (Mitsch and Gosselink, 2007). Furthermore, hydrology influences major abiotic factors such as nutrient availability, soil redox 
potential, and salinity, which determine the development, concentration and distribution of wetland flora and fauna (Mitsch and Gosselink, 2000). Therefore, hydrology is the single most important factor in the establishment and maintenance of CSM and its biogeochemical processes (Mitsch and Gosselink, 2007).

Although climate and geomorphology dictate the parameters of a CSM existence, the starting point for all wetlands is hydrology, which, in turn, alters the physiochemical environment causing the adaptation of wetland biota (Mitsch and Gosselink, 2007). Furthermore, biota can alter both the hydrogeomorphology (HGM) (combination of hydrology, climate, and geomorphology), which collectively influences the functions of a wetland and physiochemical (physical and chemical properties) environment creating a feedback loop (Mitsch and Gosselink, 2007). Therefore, in order to gain a clear understanding of CSM ecosystem functions and processes, it is necessary to investigate the hydrogeomorphology, the resulting change in physiochemical environment, and the adaptations utilized by biota in order to survive within the ecosystem (Mitsch and Gosselink, 2007).

\section{Hydrogeomorphology of Coastal Salt Marshes}

Climate and geomorphology are the starting points for the hydrology of wetlands (Mitsch and Gosselink, 2007). The combination of hydrology, climate, and geomorphology, which collectively influences the functions of a wetland is known as hydrogeomorphology. Wetlands are common in areas where the climate is cool and wet compared to warm and dry climates . Cool, wet climates typically receive more annual precipitation and loss of water due to evaporation compared to aired climates (Mitsch and Gosselink, 2007). The geomorphology of wetlands directly influences the hydrology 
since steep terrains and uplifts typically tend to have fewer wetlands compared to flat or gently sloping landscapes (Mitsch and Gosselink, 2007). Furthermore, isolated wetlands such as vernal pools will have completely different hydrologic signatures compared to riverine or coastal wetlands simply due to their geographic location (Mitsch and Gosselink, 2007). The seasonal pattern of a wetlands water level is known as the hydroperiod or the hydrologic signature that helps to define a wetland (Mitsch and Gosselink, 2000).

The hydroperiod of a wetland is a unique characteristic that helps to delineate the rise and fall of surface and subsurface water while its yearly patterns can dictate the development of a wetland. Qualitatively, there are many different terms used to describe hydroperiods in an effort to define wetlands; however, in a broad sense most are classified based on whether they are tidally influenced or not. Hydroperiods can further be defined based on a wetlands flood duration (the amount of time that standing water present on a nonpermanently flooded or subtidal system) and flood frequency (the average number of times a wetland is flooded during a given period). Flood duration and frequency are used often to describe periodically flooded wetlands like coastal salt marshes and riparian wetlands (Mitsch and Gosselink, 2000).

Water levels for most wetlands typically are not stable and fluctuate daily/diurnally (tidal wetlands), annually/seasonally (high order riparian wetlands), and even unpredictably (wetlands in low-order streams and coastal wetlands with tidal actions) (Mitsch and Gosselink, 2000). Therefore, annual fluctuations in water levels for most wetlands are the norm, not the exception (Mitsch and Gosselink, 2000). Wetland hydroperiods with the greatest difference between high and low water levels are often 
caused by pulses or seasonal/periodic flooding (Junk et al., 1989). Hydrologic pulses are extremely important to many wetland ecosystems because they act as oxygen and nutrient subsidies that greatly enhance productivity (Junk et al., 1989). Furthermore, hydrologic pulses cleanse wetland systems by flushing away toxic byproducts of anaerobic respiration (Junk et al., 1989). Finally, highly productive pulse-fed wetlands play a critical role in exporting nutrients, energy, and biota to adjacent ecosystems (Junk et al., 1989).

Quantitatively, the hydroperiod is the sum of all inflows and outflows of a system as influenced by the terrain (surface landscape contours) and subsurface soil, geology, and groundwater conditions (Mitsch and Gosselink, 2000). The balance between the inflows and outflows of water define the water budget of a wetland while the topography, geology, soil, and conditions of the ground water define a wetland's capacity to store water (Mitsch and Gosselink, 2007). The water budget or the balance between inputs, outputs, and storage will dictate the presence or absence of a wetland and is qualitatively represented by Equation 1 where $P_{n}$ is the net precipitation, $S_{i}$ is the surface flow inputs, $G_{i}$ is the groundwater inputs, $E T$ is evapotranspiration, $S_{o}$ is surface flow out, $G_{o}$ is groundwater out, and depending on the wetland, $T$ represents tidal inputs and outputs (Mitsch and Gosselink, 2007).

$$
\Delta V / \Delta t=P_{n}+S_{i}+G_{i}-E T-S_{o}-G_{o} \pm T
$$

Wetlands most often occur in areas where precipitation is greater than the evapotranspiration and surface runoff (Mitsch and Gosselink, 2000). Wetland rich areas such as the eastern United States can have precipitation ranging from 10 to $40 \mathrm{~cm} / \mathrm{yr}$ (Woo and Winter, 1993). The western United States (west of the Mississippi) generally 
does not contain many wetlands since most of the region has an annual precipitation deficit ranging from -10 to -150 (Woo and Winter, 1993). However, exceptions to this general trend are wetlands with water budgets that rely heavily on surface inflows (riparian) and tides (coastal salt marshes) rather than local precipitation (Mitsch and Gosselink, 2000). Although there are a number of variables that influence the percentage of precipitation that becomes surface flow, the most important is climate (Mitsch and Gosselink, 2000).

In cool humid areas of Canada and the United States, on average, $60-80 \%$ of precipitation is converted to surface flow compared to warm dry areas that only convert 10 - 30\% precipitation to surface flow (Hare, 1980; Woo and Winter, 1993). Wetlands can be surface flow receiving systems (inflows), surface flow creating systems (outflow) or both since they are often integrated into a stream or river (Mitsch and Gosselink, 2000). There are several types of surface inflows a wetland can be subjected to; however, the two major types are channelized and nonchannelized flow (Mitsch and Gosselink, 2000). Overland flow is an influx of nonchannelized sheet surface water that usually occurs during or immediately after rainfall, spring thaw, or tidal rises in coastal wetlands (Mitsch and Gosselink, 2000). Wetlands that are part of an integrated drainage basin of a stream or river typically receive inflows via channelized streamflow for most of the year (Mitsch and Gosselink, 2000).

Wetlands that are not hydrologically connected to streams and rivers can also receive surface inflow due to seasonal or episodic pulses of flood flow (Mitsch and Gosselink, 2000). Many coastal saline and brackish wetland's are dependent upon surface runoff and pulses from adjacent bodies of water to supply nutrients, energy, and 
oxygen to help ameliorate the detrimental effects of salinity and anoxia. Although surface inflow is often difficult to calculate, it is one of the most important sources of water for a wetlands water budget. The precipitation that results in direct runoff, or quickflow, from a specific storm event can be determined as the product of the hydrologic response coefficient, average precipitation of the wetland, and the area of the watershed draining into the wetland (Mitsch and Gosselink, 2000). The influence of recharge and discharge on groundwater resources is often cited as an important function of wetland; however, this does not hold true for all wetlands (Siegal, 1988a).

Groundwater inflow occurs when the groundwater level of a wetland is hydrologically lower than the surrounding land (Mitsch and Gosselink, 2000). Tidal wetlands often receive significant amounts of groundwater inflows, which help to reduce soil salinity and moisture during low tides. Hydrologic inputs, such as floods, tidal pulses, precipitation, and surface and groundwater inflows, carry nutrients into and out of wetlands. The hydrologic flow of nutrients into and out of wetlands is an important determinant of productivity and decomposition. Therefore, the rate of nutrient cycling is tied to the frequency and duration of hydrologic inputs (Mitsch and Gosselink, 2000). In more open and tidally influenced wetlands, nutrient cycling is rapid compared to closed, precipitation dominated wetlands (Mitsch and Gosselink, 2000).

A major hydrologic feature of coastal wetlands is periodic and predictable tidal inundations (Mitsch and Gosselink, 2000). Tidal inundations are both a subsidy and stress on wetland ecosystems (Mitsch and Gosselink, 2000). Tides create environmental pressures or stress by increasing the salinity levels and creating anaerobic condition by way of submergence (Mitsch and Gosselink, 2000). However, tides are also nurturing by 
replenishing nutrients and oxygen into the tidal zone (Mitsch and Gosselink, 2000).

Furthermore, tides can significantly alter coastal landscapes and sediment patterns due to hydrologic motion. Tidal patterns vary greatly from coast to coast due to seasonal and diurnal patterns (Mitsch and Gosselink, 2000).

Since tides are influenced by the gravitational pull of the moon and to a lesser extent the sun; tides also have significant bimonthly patterns (Mitsch and Gosselink, 2000). During the spring tides, tides have the greatest amplitude because both the sun and moon are in line and pulling on the Earth's oceans (Mitsch and Gosselink, 2000). While during the neap tide, tides have their lowest amplitudes because the sun and moon are at right angles from each other (Mitsch and Gosselink, 2000). Spring tides most often occur during full and new moons, whereas first and third quarter moons are most likely to produce neap tides (Mitsch and Gosselink, 2000). Tides vary more locally than regionally primarily due to coastline configurations (Mitsch and Gosselink, 2000).

Tidal energy is a physical factor that influences a wide range of biological, physiographic, and chemical processes such as toxin removal, mineral and organic influx and efflux, sediment deposition and redox potential (Mitsch and Gosselink, 2000). These physical factors in turn influence the distribution, productivity, and density of the flora and fauna that live in CSM. The motion and energy of water can create spatial heterogeneity within a wetland ecosystem or create uniformed surfaces that encourage monospecific vegetative strands with little species richness. Flowing water renews minerals and buffers against anoxic conditions encouraging diversity and productivity. Hydrology is the main pathway through which nutrients are translocated, deposited, and transformed (Mitsch and Gosselink, 2000). Typically, the more open or accepting of 
hydrologic fluxes a wetland is, the more primary productivity occurs (Mitsch and Gosselink, 2000). For example, saltwater tidal marshes that have more frequent tidal activities and inundations are more productive than those that are occasional inundated (Steever et al., 1976).

A noted physiographic feature of CSM associated with tides are tidal creeks (Chapman, 1960). Tidal creeks function as important conduits created from preexisting sand flats with little peat (fibric organic material) that enables the transfer of material and energy between a marsh and its adjacent body of water (Redfield, 1972). Tidal creeks create unique vegetative zones and ecosystems that are intimately linked with their adjacent estuaries or bay's food chain (Mitsch and Gosselink, 2000). The salinity of tidal creeks are typically similar to the adjacent estuary and bay and their water depths are associated with tidal fluctuations (Mitsch and Gosselink, 2000). Tidal creek channels tend to be fairly stable because unlike a river, tidal creek channels have bidirectional flow and tend not to meander (Mitsch and Gosselink, 2000). Furthermore, continuous deposition of coarse grained minerals create elevated streamside levees along the banks of tidal creeks (Mitsch and Gosselink, 2000). Due to higher elevation, better drainage, and slightly larger nutrient inputs, tidal creek streamsides tend to have greater productivity of grasses (streamside effect) (Mitsch and Gosselink, 2000).

The hydrogeomorphology directly influences the physiochemical environment of CSM and is intimately tied to species composition and richness, primary productivity, organic accumulation and nutrient cycling (Mitsch and Gosselink, 2007). Minimally, the sustained saturation of CSM soils initiates soil biogeochemical processes that act as a natural selection tool excluding biota that cannot withstand anoxic and saline conditions 
(Mitsch and Gosselink, 2000). Even very slight changes to the hydrology of a wetland can cause massive changes in species composition, distribution, and productivity due to initially a change in soil aeration status (aerobic to anaerobic) (Brady and Weil, 2002). The aeration status of a soil influences many of the chemical processes that occur; thus, aeration greatly influences many soil physical properties as well (Brady and Weil, 2002).

\section{Physiochemical Environment}

Aeration involves the movement of gases into and out of a soil, the rate of gas exchange, the air filled porosity, the chemical composition of the air, and the chemical oxidation or reduction potential within the soil environment (Brady and Weil, 2002).The exchange of gases between a soil and the environment is facilitated by two mechanisms; (i) mass flow (the movement of nutrients with the flow of water to plant roots) and (ii) diffusion (the movement of atoms in a gaseous mixture or of ions in a solution, primarily as a result of their own random motion) (Brady and Weil, 2002). However, the process of diffusion has the greatest influence on the total gas exchange that occurs between a soil and the surrounding environment (Brady and Weil, 2002). The rate of gas diffusion is influenced by the moisture content, wind, and barometric pressures (Brady and Weil, 2002).

During the diffusion process, gas particles move in a direction determined by its own partial pressure or the pressure that a gas would exert if it alone was present in the volume occupied by the mixture (Brady and Weil, 2002). Although there is no overall

pressure gradient for the total mixture of gases, diffusion allows extensive gas movement from one area to another because there is a concentration gradient (partial pressure gradient) (Brady and Weil, 2002). Therefore, the exchange of $\mathrm{CO}_{2}, \mathrm{O}_{2}$, and $\mathrm{H}_{2} \mathrm{O}$ gas 
between a soil and the atmosphere will occur from areas of high concentrations (high partial pressure) to areas of low concentrations (low partial pressures) (Brady and Weil, 2002). In normal, well aerated soils, the exchange of gases is rapid enough to prevent a deficiency in $\mathrm{O}_{2}$ or a toxicity of $\mathrm{CO}_{2}$ (Brady and Weil, 2002). Oxygen availability in field soils is dependent on three variables; (i) soil macroporosity, (ii) soil water content, (iii) and $\mathrm{O}_{2}$ consumption by organisms (roots and microorganisms) (Brady and Weil, 2002). Poor soil aeration occurs when water occupies $80-90 \%$ of the soil pore space decreasing the availability of $\mathrm{O}_{2}$ within the top $150 \mathrm{~cm}$ of soil (Brady and Weil, 2002). Water occupation of soil pores prevents the exchange of gases between the soil and the atmosphere and reduces the amount of air storage within the soil matrix (Brady and Weil, 2002). A soil is considered water saturated or waterlogged when all or nearly all soil pores have been filled with water (Brady and Weil, 2002). Since water diffuses approximately 10,000 times slower into the soil solution compared to the soil atmosphere and as microorganism utilize the remaining dissolved oxygen, the soil environment can quickly turn anaerobic (Reddy and D’Angelo, 1994). Wetland soils are classified as hydric soils due to anaerobic conditions that developed as a result of prolonged saturation, flooding, or ponding during the growing season (USDA, 2010).

Hydric, or wetland soils, are the result of biogeochemical processes which occur due to the absence of $\mathrm{O}_{2}$ in the soil atmosphere or solution (Mitsch and Gosselink, 2007). The rate of oxygen depletion will vary depending on the temperature, the availability of organic substrates, and the chemical oxygen demand of reductants (Mitsch and Gosselink, 2007). Soil anaerobic conditions dramatically affect the ability of plants to function, the availability of nutrients, and the levels of toxic chemicals retained in the soil 
(Mitsch and Gosselink, 2007). Typically, a thin oxidized layer will from at the water-soil interface and along the surface of the plant root-soil interface (Patrick and Delaune, 1972; Gambrell and Partick, 1978). The thickness of the oxidized layer of soil varies depending on (i) the rate of $\mathrm{O}_{2}$ diffusion at the air-water interface, (ii) the presence and population of aerobic organisms present, (iii) the photosynthetic oxygen produced by algae in the water column, and (iv) the amount of mechanical activity in the system (Gambrell and Partick, 1978). Although it may be thin, the oxidized layer of soil is extremely important for the biogeochemical cycling of inorganic and organic material of a wetland (Gambrell and Partick, 1978).

\section{Oxidation and Reduction Chemistry}

The greatest impact that a change in soil aeration status has on wetland ecosystems is its impact on the oxidation and reduction (redox) states of chemical elements within the soil (Brady and Weil, 2002). A clear understanding and appreciation of the nature and properties of electron and proton flux in the soil system is necessary in order to understand the principles that underlie oxidation-reduction (redox) reactions in heterogeneous, multiphase soils and soil solutions (James and Bartlett, 2000). The close interrelationship between protons and electrons illuminates the reasoning behind why hydrogen ions $\left(\mathrm{H}^{+}\right)$and electron activities are master variables in soils (Sillén, 1967).

The energy required to release the $\mathrm{H}^{+}$ion (solvation enthalpy) is $-109 \mathrm{~kJ} \mathrm{~mol}^{-1}$ and once the proton has been released it migrates rapidly from one water molecule to another (James and Bartlett, 2000). The ephemeral nature of the hydronium ion enables it to be a powerful reducing agent with a potential of $-2.7 \mathrm{~V}$ relative to a standard hydrogen electrode (SHE, $\mathrm{H}^{+} / \mathrm{H}_{2}=0 \mathrm{~V}$ ) (James and Bartlett, 2000). The extremely large charge-to 
size ratio of electrons prevents them from persisting freely in an aqueous medium (James and Bartlett, 2000).

Soil treat the electron (e $\left.{ }^{-}\right)$, when considered as a soil species, can be viewed thermodynamically as a ligand, reactant, or product having negligible mass (Sposito, 1981). Although the $\mathrm{e}^{-}$is a carrier of negative electricity (negatively charged), it is not ionic (Thompson, 1923). Furthermore, the activity of an $\mathrm{e}^{-}$is similar to $\mathrm{H}^{+}$; measuring its concentration in mol L${ }^{-1}$ is undefinable (James and Bartlett, 2000). Therefore, when investigating the "activity" of e" in soils and natural waters, it ought to be viewed strictly from an energy function point of view such as "the ability to do work," "electric potential," and “electric pressure” (James and Bartlett, 2000).

Thermodynamic activity of both $\mathrm{H}^{+}$and $\mathrm{e}^{-}$are defined as the ratio of $\mathrm{H}^{+}$or $\mathrm{e}^{-}$ activity in a given system relative to its activity in standard state conditions (James and Bartlett, 2000). The standard conditions for $\mathrm{e}^{\mathrm{e}}$ are defined by the standard hydrogen electrode (SHE) where the partial pressure of $\mathrm{H}_{2}$ equals $1 \mathrm{~atm}$, temperature is $298 \mathrm{~K}$, and standard state of $\mathrm{H}^{+}$equals $1 M$ with an electrical potential of $0.00 \mathrm{~V}$ (Lindsay, 1979; Morgan and Stumm, 1996; Compton and Sanders, 1996).

The capacity factor for $\mathrm{e}^{-}$is known as the poise, which is the change in added equivalents of oxidants or reductants in order to bring about one unit change in pe or an Eh change of $59 \mathrm{mV}$ (James and Bartlett, 2000). The poise of soils are a central concept intimately tied to oxidation-reduction reactions and microbial metabolic processes (James and Bartlett, 2000). Therefore; quantifying redox potentials and estimates of poise must take into consideration biotic processes since the majority of soil redox reactions are governed by microbial respiration (James and Bartlett, 2000). Furthermore, the poise and 
pe of soils significantly differ from natural waters due to the redox reactions that occur across the colloid-solution interphase (James and Bartlett, 2000). Electron activity can also be defined as E(de) where $\mathrm{E}$ is potential and (de) is change in charge of the system (James and Bartlett, 2000). Finally, electron activity can also be defined as chemical work, $\mu(\mathrm{dn})$, where $\mu$ signifies chemical potential and (dn) is change in moles (Sposito, 1981).

Reduction reactions must be coupled with oxidation reactions since electrons are transferred from a reductant ( $\mathrm{e}^{-}$donors or reducing agents) to an oxidant ( $\mathrm{e}^{-}$acceptor or oxidizing agent) and do not exist freely in the soil solution (James and Bartlett, 2000). Knowledge of a coupled redox half-reaction provides the opportunity to predict the likelihood of a reaction occurring spontaneously by using the equilibrium constant (logK) (James and Bartlett, 2000). Based on the generic reduction half-reaction (Equations 1 and 2) the oxidant plus the number of electrons being transferred is equal to the reducants; therefore, the electron activity (e-) equals:

$$
\begin{aligned}
& \text { ox }+ \text { ne }^{-}=\text {red } \\
& \mathrm{e}^{-}=[(\mathrm{red}) / \mathrm{K}(\mathrm{ox})]^{1 / \mathrm{n}}
\end{aligned}
$$

Based on equations 1 and 2, the electron activity is a function of the ratio between reduced and oxidized species and the equilibrium constant (K) (James and Bartlett, 2000). The above equilibrium expressions can be fully written (Equation 4) and rearranged (Equation 5) to predict electron activity utilizing Gibbs free energy of formation $\left(\Delta \mathrm{G}_{\mathrm{f}}{ }^{\circ}\right)$ data once $\mathrm{K}$ has been calculated.

$$
\begin{aligned}
& \text { Aox }+\mathrm{Be}^{-}+\mathrm{CH}^{+}=\text {Dred }+\mathrm{EH}_{2} \mathrm{O} \\
& K=\frac{\left[(r e d)^{D}\left(H_{2} O\right)^{E}\right]}{\left[(o x)^{A}\left(e^{-}\right)^{B}\left(H^{+}\right)^{C}\right]}
\end{aligned}
$$


By taking the log of equation 5 and rearranging to solve for pe, the equation for a line of the pe-pH relationship can be obtained (Equation 6) where pe and $\mathrm{pH}$ are defined as the $\log \mathrm{e}^{-}$and $\mathrm{H}^{+}$activity (James and Bartlett, 2000).

$$
\left[\left(\frac{1}{B}\right) \log K-\left(\frac{D}{B}\right) \log (\text { red })+\left(\frac{A}{B}\right) \log (\text { ox })\right]-\left(\frac{C}{B}\right) p H=p e
$$

The equation for a straight line as derived above can be used to define individual pe-pH relationships where the log of $\mathrm{K}$ and the activities of oxidants and reductants define the $\mathrm{y}$ intercept and the ratio of $\mathrm{H}+$ to e- consumed determines the slope (James and Bartlett, 2000).

When plotted together, the lines can be used to predict whether a redox reaction would occur spontaneously. If one e- transfer $(\mathrm{B}=1)$ must be coupled with one proton consumption $(\mathrm{C}=1)$ and when $\mathrm{D}=\mathrm{A}$ and $(\mathrm{red})=(\mathrm{ox})$, then $\log \mathrm{K}$ is equal to the sum of pe and $\mathrm{pH}$ (Equations 7 and 8) (James and Bartlett, 2000). Finally, if the $\mathrm{pH}$ is equal to 0 , due to the SHE, the relationship between pe and $\log \mathrm{K}$ is achieved (Equation 8) (James and Bartlett, 2000).

$$
\begin{aligned}
& \mathrm{pe}+\mathrm{pH}=\log \mathrm{K} \\
& \mathrm{pe}=\log \mathrm{K}
\end{aligned}
$$

Based on Equations 7 and 8, the intimate relationship between pe and $\mathrm{pH}$ is highlighted demonstrating the activity of $\mathrm{H}^{+}$and $\mathrm{e}^{-}$cannot be separated when assessing the redox potential of soils (Lindsay, 1979). As electrons are transferred and the pe increases, the $\mathrm{pH}$ decreases in response (inverse relationship) until the system has achieved a state of equilibrium (James and Bartlett, 2000).The equilibrium condition of a soil; therefore, depends on pe and $\mathrm{pH}$ values, which represent the intensity measures of redox status (James and Bartlett, 2000). The change in pe plus $\mathrm{pH}$ per mole of electrons over the $\mathrm{H}^{+}$ 
transferred represents poise or buffering capacity of the system (Equation 9)(James and Bartlett, 2000).

$$
\Delta(\mathrm{pe}+\mathrm{pH}) / \Delta\left(\mathrm{mol} \mathrm{H}{ }^{+} \text {transferred }\right) \quad[9]
$$

Once $\mathrm{K}$ has been calculated, it can be combined with the Gibbs free energy equation where $\Delta \mathrm{G}_{\mathrm{r}}{ }^{\mathrm{o}}$ represents the Gibbs free energy of reaction under standard conditions (James and Bartlett, 2000).

$$
\Delta \mathrm{G}_{\mathrm{r}}{ }^{\mathrm{O}}=-\mathrm{RT} \ln \mathrm{K}
$$

A favorable reaction (large $+\mathrm{K}$ value or Large $-\Delta \mathrm{G}_{\mathrm{r}}{ }^{0}$ ) is associated with low electron activity or the reaction will occur at relatively low electron potentials (Equation 10) (James and Bartlett, 2000). Furthermore, K values can be related to thermodynamic electrochemical potential (Eh) using Equation 11 developed by Compton and Sander (1996) where $\mathrm{n}$ is the number of moles of $\mathrm{e}^{-}$transferred and $\mathrm{F}$ is Faraday's constant.

$$
\Delta \mathrm{G}_{\mathrm{r}}{ }^{\mathrm{o}}=-\mathrm{nF} \mathrm{Eh}
$$

Since equations 9 and 10 are used to express $\Delta \mathrm{G}_{\mathrm{r}}{ }^{\circ}$, we are able to derive Equation 12 by simply equating the two previous equations (Compton and Sanders, 1996).

$$
-\mathrm{nF} \text { Eh }=-\mathrm{RT} \ln \mathrm{K}
$$

Knowledge of $\mathrm{pH}$ and assuming $\mathrm{n}=1$, (red) $=(\mathrm{ox})$, pe $+\mathrm{pH}=\operatorname{logK}$, and the temperature is $298 \mathrm{~K}$, we can simplify Equation 13 to the following (Compton and Sanders, 1996):

$$
\text { Eh/0.059 = pe }
$$

It is important to note that calculating Eh requires knowledge of $\mathrm{pH}$, again demonstrating their interdependence (James and Bartlett, 2000). Furthermore, the thermodynamic derivation of $\mathrm{K}$ and its relationship to pe and $\mathrm{pH}$ is based on free energy of formation data for oxidants and reductants. Therefore, thermodynamics knowledge of 
redox reactions only provides information on the likelihood a reaction will allow the spontaneous transfer of electrons from a reductant to an oxidant (James and Bartlett, 2000). It does not provide information on the mechanisms or rates of reactions (James and Bartlett, 2000). Electron activities of a soil based on electrode potential only evaluates the ability of an electron to be transferred or do thermodynamic work; therefore, it does not provide a "concentration" of electrons in a soil solution (James and Bartlett, 2000). Kinetic derivations of thermodynamic parameters for redox reactions have been developed by Sparks (1985) and Harter and Smith (1981) as alternatives; unfortunately, they are seldom used due to difficulties obtaining rate coefficients for electron transfer processes and the irreversibility of most redox reactions (James and Bartlett, 2000).

The predictability of coupled redox reactions is extremely important in understanding biogeochemical processes in saturated soils (James and Bartlett, 2000). Heterotrophic microorganisms utilize organic compounds (electron donors) as energy sources and in doing so produce carbon dioxide $\left(\mathrm{CO}_{2}\right)$ and temporarily free electrons (James and Bartlett, 2000). Therefore, soil Eh is heavily dependent on the concentration of oxygen $\left(\mathrm{O}_{2}\right)$ because (i) it is a strong oxidizing agent or electron acceptor, (ii) $\mathrm{O}_{2}$ can oxidize both organic and inorganic substances, and (iii) all aerobic respiration requires $\mathrm{O}_{2}$ to serve as the principle electron acceptor (Equation 14)(Brady and Weil, 2002).

$$
\mathrm{O}_{2}+4 \mathrm{e}^{-}+4 \mathrm{H}^{+} \rightarrow 2 \mathrm{H}_{2} \mathrm{O}
$$

Microbes utilize $\mathrm{O}_{2}$ as their preferred electron acceptor; however, when soils become saturated, microorganisms are forced to utilize alternative electron acceptors in order to perform specific metabolic processes necessary for survival (James and Bartlett, 
2000). Based on their "ease of reduction" and their availability in the environment, microorganisms have a preference for alternative electron acceptors allowing for the predictability of coupled redox reactions in saturated soils (James and Bartlett, 2000). The order of preference based on pe values for alternative electron acceptors are $\mathrm{NO}_{3}{ }^{-}$ /N2, $\mathrm{MnO}_{2} / \mathrm{Mn}^{2+}, \mathrm{Fe}^{2+} / \mathrm{Fe}(\mathrm{OH})_{3}, \mathrm{SO}_{4}{ }^{2-} / \mathrm{H}_{2} \mathrm{~S}$ and $\mathrm{CO}_{2} / \mathrm{CH}_{4}$ (James and Bartlett, 2000). Once all of the dissolved oxygen has been consumed, nitrate $\left(\mathrm{NO}_{3}{ }^{-}\right)$will be reduced first to nitrite $\left(\mathrm{NO}_{2}{ }^{-}\right)$, then to nitrous oxide $\left(\mathrm{N}_{2} \mathrm{O}\right)$, and finally dinitrogen gas $\left(\mathrm{N}_{2}\right)($ Eq. 15$)$ (Mitsch and Gosselink, 2007).

$$
2 \mathrm{NO}_{3}+10 \mathrm{e}^{-}+12 \mathrm{H}^{+} \rightarrow \mathrm{N}_{2}+6 \mathrm{H}_{2} \mathrm{O} \quad \text { [15] }
$$

Once the redox potential of the soil has dropped to about $225 \mathrm{mV}$, the transformation of $\mathrm{Mn}^{4+}$ to $\mathrm{Mn}^{2+}$ begins to occur (Eq. 16) (Mitsch and Gosselink, 2007).

$$
\mathrm{MnO}_{2}+2 \mathrm{e}^{-}+4 \mathrm{H}^{+} \rightarrow \mathrm{Mn}_{2}^{+}+2 \mathrm{H}_{2} \mathrm{O}
$$

Following $\mathrm{Mn}^{4+}$, ferric iron will be reduced to ferrous iron at redox potentials between 100 to $-100 \mathrm{mV}$ (Eq. 170) followed by sulfate transformation between -100 to $-200 \mathrm{mV}$ (Eq. 18) (Mitsch and Gosselink, 2007).

$$
\begin{aligned}
& \mathrm{Fe}(\mathrm{OH})_{3}+\mathrm{e}^{-}+3 \mathrm{H} \rightarrow \mathrm{Fe}^{2+}+3 \mathrm{H}_{2} \mathrm{O} \\
& \mathrm{SO}_{4}{ }^{0}+8 \mathrm{e}^{-}+9 \mathrm{H}^{+} \rightarrow \mathrm{HS}^{-}+4 \mathrm{H}_{2} \mathrm{O}
\end{aligned}
$$

Finally, when redox potentials drop below $-200 \mathrm{mV}$, the organic substrates (carbon) or carbon dioxide will be reduced by soil microbes into low-molecular-weight compounds and methane gas (Eq.19) (Mitsch and Gosselink, 2007).

$$
\mathrm{CO}_{2}+8 \mathrm{e}^{-}+8 \mathrm{H}^{+} \rightarrow \mathrm{CH}_{4}+5 \mathrm{H}_{2} \mathrm{O}
$$

The utilization of alternative terminal electron acceptors (TEA) greatly impacts a major ecological function of wetlands; the biogeochemical cycling (BGCC) or the 
transformation and translocation of inorganic and organic chemicals as the result of physical, chemical, and biological processes (Mitsch and Gosselink, 2007). The Eh of a soil depends on the presence and redox state of TEA (oxidizing agent) and $\mathrm{pH}$ (James and Bartlett, 2000). Therefore, since each TEA is activated at specific Eh ranges and associated $\mathrm{pH}$ values, understanding soil redox reactions helps predict the chemical species present and in turn, the availability, mobility, and possible toxicity of various elements in soils (Brady and Weil, 2002). In coastal salt marshes, the redox condition of the soil has a great influence on the biochemical cycles of carbon, nitrogen, sulfur, iron and manganese (Mitsch and Gosselink, 2007).

\section{Biogeochemical Cycles of Nitrogen, Iron, Manganese, and Sulfur}

The nitrogen cycle is one of the most important biogeochemical cycles studied in wetlands because it appears in a number of oxidation states in wetlands, it is often the most limiting nutrient in wetlands (particularly in coastal systems), and the microbial activities in wetland ecosystems represents a significant way in which nitrogen is lost from the lithosphere to the atmosphere (Mitsch and Gosselink, 2007). Furthermore, since nitrates are the first alternative electron acceptor utilized by microbes once $\mathrm{O}_{2}$ has been depleted, nitrogen plays a critical role in the oxidation of organic matter in wetlands and in turn, the primary productivity (Mitsch and Gosselink, 2007).

The most common form of mineralized nitrogen found in wetland soils is the ammonium ion $\left(\mathrm{NH}_{4}{ }^{+}\right)$, which has an oxidation state of -3 (Mitsch and Gosselink, 2007). The nitrogen cycle is mediated by several biogeochemical processes and the presence of oxidized zones which dictate the transformation, translocation, and availability of nitrogen within a wetland ecosystem (Mitsch and Gosselink, 2007). Nitrogen 
mineralization is the biological transformation and release of organically bound nitrogen to $\mathrm{NH}_{4}{ }^{+}$due to microbial decomposition of simple soluble organic nitrogen (Mitsch and Gosselink, 2007). This pathway, often referred to as ammonification, can occur under anaerobic and aerobic condition (Mitsch and Gosselink, 2007). Ammonification (Eqs.20, 21) is often the precursor or primer for further nitrogen transformation (Mitsch and Gosselink, 2007).

$$
\begin{aligned}
& \mathrm{NH}_{2} \mathrm{CONH}_{2}+\mathrm{H}_{2} \mathrm{O} \rightarrow 2 \mathrm{NH}_{3}{ }^{+} \mathrm{CO}_{2} \\
& \mathrm{NH}_{3}+\mathrm{H}_{2} \mathrm{O} \rightarrow \mathrm{NH}_{4}^{+}+\mathrm{OH}^{-}
\end{aligned}
$$

Once $\mathrm{NH}_{4}{ }^{+}$is formed, the ion can take several pathways depending on the abiotic and biotic factors influencing the system (Mitsch and Gosselink, 2007). Depending on the soil structure and cation exchange capacity (CEC), long term immobilization can occur as $\mathrm{NH}_{4}{ }^{+}$is exchanged onto negatively charged soil particles (Mitsch and Gosselink, 2007). One would expect an excessive concentration of $\mathrm{NH}_{4}{ }^{+}$in wetland soils due to anaerobic conditions; however, several processes prevent this (Mitsch and Gosselink, 2007). Often $\mathrm{NH}_{4}{ }^{+}$is utilized by flora and fauna and synthesized back into organic matter and temporarily immobilized (Mitsch and Gosselink, 2007).

In coastal systems where the $\mathrm{pH}$ is $>8$, algae will convert $\mathrm{NH}_{4}{ }_{4}$ into ammonia $\left(\mathrm{NH}_{3}\right)$, which then volatilizes and is lost to the atmosphere (Mitsch and Gosselink, 2007). Furthermore, although the process is slow, diffusion of $\mathrm{NH}_{4}{ }^{+}$does occur from the reduced soil matrix (high concentration) to oxidized zones (around roots and top soil) (low concentration) further helping to mitigate any excess concentration of $\mathrm{NH}_{4}{ }^{+}$(Mitsch and Gosselink, 2007). Once $\mathrm{NH}_{4}{ }^{+}$does diffuse into oxidized layers, it goes through a process of oxidation known as nitrification converting $\mathrm{NH}_{4}{ }^{+}$into nitrate $\left(\mathrm{NO}_{3}{ }^{-}\right)($Mitsch 
and Gosselink, 2007). Nitrification is a two-step process facilitated first by Nitrosomonas sp. which converts $\mathrm{NH}_{4}{ }^{+}$into nitrite $\left(\mathrm{NO}_{2}{ }^{-}\right)$(Eq. 22) then Nitrobacter sp. converts $\mathrm{NO}_{2}{ }^{-}$to nitrate $\mathrm{NO}_{3}{ }^{-}$(Eq. 23) (Mitsch and Gosselink, 2007).

$$
\begin{aligned}
& 2 \mathrm{NH}_{4}^{+}+3 \mathrm{O}_{2} \rightarrow 2 \mathrm{NO}_{2}{ }^{-}+2 \mathrm{H}_{2} \mathrm{O}+4 \mathrm{H}^{+}+\text {energy } \\
& 2 \mathrm{NO}_{2}^{-}+\mathrm{O}_{2} \rightarrow 2 \mathrm{NO}_{3}{ }^{-}+\text {energy }
\end{aligned}
$$

Unlike $\mathrm{NH}_{4}{ }^{+}$which is a positively charged ion, nitrate $\left(\mathrm{NO}_{3}{ }^{-}\right)$carries a negative charge; therefore, it is highly mobile and not subject to immobilization by soil particles (Mitsch and Gosselink, 2007). If $\mathrm{NO}_{3}{ }^{-}$is not immediately assimilated by soil flora and fauna or leached, it can go through several different dissimilatory nitrogenous oxide reduction (not assimilated into a biological cell) pathways (Mitsch and Gosselink, 2007). Commonly, these pathways lead to the production of nitrous oxide $\left(\mathrm{N}_{2} \mathrm{O}\right)$ and dinitrogen $\left(\mathrm{N}_{2}\right)$ due to denitrification (Mitsch and Gosselink, 2007). Denitrification is a process carried out by facultative bacteria, which utilize $\mathrm{NO}_{3}{ }^{-}$as an alternative electron acceptor in order to complete necessary metabolic processes under anaerobic condition (Eq. 24) (Mitsch and Gosselink, 2007).

$$
\mathrm{C}_{6} \mathrm{H}_{12} \mathrm{O}_{6}+4 \mathrm{NO}_{3} \rightarrow 6 \mathrm{CO}_{2}+6 \mathrm{H}_{2} \mathrm{O}+2 \mathrm{~N}_{2}
$$

The process of denitrification is intimately linked to the production $\mathrm{NH}_{4}{ }^{+}$within the soil matrix and its diffusion into oxidized zones (Mitsch and Gosselink, 2007). Although the $\mathrm{NH}_{4}{ }^{+}$concentration gradient is often significantly high, since $\mathrm{NO}_{3}{ }^{-}$ diffusion rates are seven times faster than $\mathrm{NH}_{4}{ }^{+}$, the movement nitrogen in wetland soils is often dictated by the $\mathrm{NH}_{4}{ }^{+}$diffusion rate and its subsequent nitrification (Reddy and Patrick, 1984; Reddy and Graetz, 1988). When the nitrate-nitrogen supply is adequate, 
soil temperature appears to be the next significant factor affecting denitrification rates (Hernandez and Mitch, 2007).

Nitrogen fixation is the conversion of $\mathrm{N}_{2}$ into organic nitrogen due to microbial activities and the presence of the nitrogenase enzyme (Mitsch and Gosselink, 2007). Nitrogen fixation can occur under both aerobic and anaerobic conditions by bacteria, blue-green algae, and some actinomycetes within the overlying water, aerobic and anaerobic soils, as well as the rhizosphere (Mitsch and Gosselink, 2007). Since nitrogenase is limited by the presence of oxygen, nitrogen fixation typically occurs at higher rates in wetland soils which are typically saturated (Mitsch and Gosselink, 2007).

Iron and manganese follow nitrate on the preferred redox potential scale and are the two most abundant reduced elements found in wetland soils (Mitsch and Gosselink, 2007). Although manganese oxides $\left(\mathrm{MnO}_{2}\right)$ are reduced slightly ahead of iron oxides, both iron and manganese minerals are more soluble and readily available to organisms in in their reduced forms (ferrous iron and manganous) (Mitsch and Gosselink, 2007). Both reduced iron and manganese can accumulate to toxic levels in soils disrupting nutrient uptake by wetland plants (Mitsch and Gosselink, 2007). High concentrations of reduced iron will diffuse to oxidized zones of the rhizosphere becoming oxidized,m which leads to the immobilization of phosphorus and coating roots with iron oxides preventing nutrient uptake (Mitsch and Gosselink, 2007).

Sulfur is the $14^{\text {th }}$ most abundant element on the Earth's surface and is rarely present in low enough concentrations to be considered limiting to plant growth and development in wetlands (Mitsch and Gosselink, 2007). Like nitrogen, sulfur exists in several different redox states in wetlands and their transformation, translocation, and 
availability is mediated by microorganisms (Mitsch and Gosselink, 2007). Sulfur follows iron on the redox scale with reduction occurring at a range between -100 to $-200 \mathrm{mV}$ and the most common oxidation states are that of sulfides (2-) and sulfates $\left(6^{+}\right)$(Mitsch and Gosselink, 2007). Most sulfate reduction occurs as assimilatory sulfate reduction as obligate anaerobes such as desulfovibrio bacteria that utilize sulfates as alternative terminal electron acceptors (Eq. 27) (Mitsch and Gosselink, 2007).

$$
4 \mathrm{H}_{2}+\mathrm{SO}_{4}{ }^{2-} \rightarrow \mathrm{H}_{2} \mathrm{~S}+2 \mathrm{H}_{2} \mathrm{O}+2 \mathrm{OH}^{-}
$$

This pathway leads to the production of hydrogen sulfides and in general, saltwater wetlands tend to have higher rates of $\mathrm{H}_{2} \mathrm{~S}$ emissions ( $2700 \mathrm{mg} / \mathrm{L}$ ) compared to freshwater wetlands ( 10 mg/L) (Mitsch and Gosselink, 2007). Furthermore, in addition to $\mathrm{H}_{2} \mathrm{~S}$ release, coastal wetlands will also release organic sulfur compounds, especially dimethyl sulfides (DMS, $\left(\mathrm{CH}_{3}\right)_{2} \mathrm{~S}$ ) due to the decomposition of phytoplankton cells (Mitsch and Gosselink, 2007). The reduction of sulfates and subsequent concentration of sulfides, particularly in coastal wetlands, can lead to sulfide toxicity in wetland soils (Mitsch and Gosselink, 2007). Sulfide toxicity can inhibit both sulfur and metal micronutrients such as zinc $\left(\mathrm{Zn}^{2+}\right)$ and copper $\left(\mathrm{Cu}^{2+}\right)$ uptake in plants since sulfides will react quickly in solution to form precipitates (Mitsch and Gosselink, 2007).

Hydric soils, which contain high concentrations of $\mathrm{Fe}^{2+}$ can form ferrous sulfides, such as pyrite $\left(\mathrm{FeS}_{2}\right)$ when free sulfides in solution react with ferrous iron (Mitsch and Gosselink, 2007). The precipitation of pyrite can help mitigate, a wetland soil from sulfide toxicity (Mitsch and Gosselink, 2007). Finally, in wetlands such as coastal salt marshes, sulfur can play an important role in regulating the levels of organic carbon oxidation (Boon and Mitchell, 1995). In coastal salt marshes where the concentration of 
sulfur tends to be high, it has been suggested that sulfur-reducing bacteria inhibit the reduction of carbon substrates into methane (Boon and Mitchell, 1995).

\section{Factors Effecting Nutrient Cycling}

The intimate relationship between soil redox potential and biogeochemical cycling of nutrients is a limiting factor for primary production in coastal salt marshes because anoxic conditions can lead to the concentration of toxins, reduction in cellular respiration, and reduced nutrient availability (Mitsch and Gosselink, 2000). This is particularly true for inland salt marsh soils that have poor drainage and elevated levels of sulfide enhancing the effects of anaerobiosis. However, the most limiting factor in CSM productivity is the concentration of soluble salts.

Although coastal salt marshes are some of the most productive ecosystems in the world with an approximate annual production of plant material of 80 metric tons per hectare $\left(8,000 \mathrm{~g} / \mathrm{m}^{2} / \mathrm{yr}\right)$, to plants, the environment of a salt marsh is similar to that of a desert due to a challenging osmotic gradient caused by a concentration of dissolved salts (Mitsch and Gosselink, 2000). Even though water is plentiful in most salt marshes, plants are required to expend more energy to increase their internal osmotic concentration in order to obtain water. Therefore, the speciation, concentration, and distribution of plant's within a CSM will depend heavily on a plants ability to manage anoxic soil conditions, nutrient limitations and toxicity due to redox reactions, and salinity (Mitsch and Gosselink, 2007).

\section{Biotic Adaptations to Coastal Salt Marsh Environment}

Hydric soils are difficult mediums for organisms to live in due to anaerobic conditions (Mitsch and Gosselink, 2007). Plants that are not adapted to anoxic soil 
conditions must alter their metabolic processes occurring at the roots inhibiting proper aerobic metabolic functions under saturated conditions (Roberts, 1988). Forced to shift to anaerobic metabolism, plant energy production is significantly reduced hindering nutrient uptake and cell division and growth (Roberts, 1988). Under normal conditions, plant cells utilize oxygen in the electron transport chain as the primary terminal acceptor to produce ATP (energy) during the oxidation of nicotinamide adenine dinucleotide (NAD) (Mendelssohn et al., 1982). However, without oxygen, plant cells are forced into fermentation or glycolysis, significantly reducing ATP production since NAD is not oxidized while also creating toxins in the form of acetaldehyde and ethanol (Mendelssohn et al., 1982). Ultimately, the dramatic drop in energy production along with the buildup of toxic by-products from anaerobic respiration causes cytoplasmic acidosis and eventual plant death (Vartapetian, 1988).

When soils are flooded, most plants will reduce the amount of water intake to minimize damage to plant cells (Mitsch and Gosselink, 2007). Although there may be an abundance of water in a flooded environment, because of the decrease in water uptake, plants will show similar symptoms as drought stricken plants such as decreased $\mathrm{CO}_{2}$ uptake and transpiration, closed stomata, and wilting (Mitsch and Gosselink, 2007). Saturated soil conditions also trigger the biochemical reduction of iron, manganese, and sulfur into more toxic soluble forms and can prevent proper nutrient uptake (Ernst, 1990). Grosse and Meyer (1992) demonstrated that under saturated conditions, plants will experience a $20 \%$ nitrate, $30 \%$ potassium, and $70 \%$ phosphate drop in uptake under saturated conditions. How plants adapt to saturated environments varies; however, in general, plants can tolerate the stress or regulate their activities to avoid or minimize the 
effects of anoxic conditions through physiological and structural changes (Larcher, 2003).

\section{Hydrophytes}

Plants with the ability to survive in hydric soils are known as hydrophytes (Mitsch and Gosselink, 2007). All hydrophytes have developed morphological features that enable them to withstand anoxic conditions by transferring atmospheric $\mathrm{O}_{2}$ into the root zone or by increasing growth in aerobic zones (Larcher, 2003). In response to flooding, hydrophytes will develop air spaces called arenchyma that enables $\mathrm{O}_{2}$ to diffuse from aerial portions of the plant to the anoxic root zone (Larcher, 2003). The transport of oxygen from the atmosphere to the rhizosphere is known as radial oxygen loss (ROL) (Armstrong et al., 1996). In response to flooding, hydrophytes will develop air spaces called arenchyma that enables $\mathrm{O}_{2}$ to diffuse from aerial portions of the plant to the anoxic root zone (Larcher, 2003).

The ability to directly transport oxygen into the rhizosphere can help mediate metal mobility and activity by altering the electric potential (Eh) and $\mathrm{pH}$ (Armstrong et al., 1996; Jun-Xing et al., 2012). Experiments conducted by Jun-Xing et al. (2012) indicated that ROL from wetland plants decreased the $\mathrm{pH}$, increased the Eh, decreased the concentration Fe (II), and immobilized $\mathrm{Zn}$ and $\mathrm{Pb}$. Among the four plants that they tested, the plant with the greatest below ground root production had the most iron plaque (redox concentration) and ability to immobilize heavy metal. On average, up to $60 \%$ of the volume of the roots of hydrophytes is made up of arenchyma compared to only 2 to 7 \% for flood-intolerant plants (Larcher, 2003). As well, some hydrophytes will develop root systems above the anoxic zone known as adventitious roots (McLeod et al. 1988). 
Hypoxic root tissues will produce ethylene, which initiates the production of adventitious roots along the stem directly above the anoxic zone (McLeod et al. 1988). Many hydrophytes will also reduce root growth and focus their energy on stem elongation to avoid variable flood levels (McLeod et al. 1988). The transfer of $\mathrm{O}_{2}$ to the roots creates a micro-aerobic rhizosphere mitigating the effects of anoxia (Larcher, 2003).

On average, up to $60 \%$ of the volume of the roots of hydrophytes is made up of arenchyma compared to only 2 to $7 \%$ for flood-intolerant plants (Larcher, 2003). Some hydrophytes have the ability to use solar energy (heat) to create a "thermal pump," which facilitates "pressurized gas flow" increasing the flow of $\mathrm{O}_{2}$ into the rhizosphere (Darcy 1980, 1981; Grosse et al. 1998). A temperature gradient is established as sun light heats the interior environment of the stem of a plant while the exterior temperature remains the same creating an internal pressure gradient that forces gas downward towards the roots (Dacey, 1980, 1981; Brix et al. 1992; Grosse et al. 1998). In addition to adjusting to anoxic conditions, hydrophytes must develop adaptations to overcome the toxic byproducts of anaerobic respiration and difficulties with nutrient absorption (Mitsch and Gosselink, 2007). Anoxic conditions force microbes to reduce nutrients in the soil matrix altering their availability while creating toxic byproducts like reduced iron, manganese, and sulfur (Mitsch and Gosselink, 2007).

Iron, manganese, and sulfur are reduced to more soluble and toxic species that are more readily absorbed by plants (Mitsch and Gosselink, 2007). In coastal wetlands where there is an abundance of sulfur, sulfide toxicity due to biochemical reduction is a major obstacle for plants (Goodman and Williams, 1961; Koch and Mendelssohn, 1989). The 
chemical structure and activity of sulfide allows it to easily enter plants where it restricts alcohol dehydrogenase (ADH) from catalyzing the final step in alcohol fermentation (Koch et al., 1990). Since hydrophytes have the ability to transfer oxygen to the rhizosphere, they can mitigate many of the chemical challenges of hydric soils (Ernst, 1990). The oxidized rhizosphere of hydrophytes allows for the oxidation of ammonium into nitrate making it more plant available while also oxidizing toxic reduced species such as iron, manganese, and sulfur (Ernst, 1990). Many hydrophytes can sequester reduced iron, manganese, and sulfur within cell vacuoles or transfer them to senescing tissue where they cannot disrupt metabolic activities (Ernst, 1990). IX. Halophytes

In addition to an anoxic environment, coastal wetland plants must also adapt to osmotic fluctuations due to increased soluble salt concentrations (Mitsch and Gosselink, 2007).Under normal conditions the osmotic concentration of a plant cell cytoplasm is greater than the surrounding medium (Mitsch and Gosselink, 2007). The concentration gradient allows water to freely flow into plant cells maintaining enough turgor pressure to support its structure (Mitsch and Gosselink, 2007). However, an increase in soluble salt concentrations of the soil environment will, (i) significantly decrease the available water for plants, and (ii) force water to move out of the plant cell causing rapid dehydration (Mitsch and Gosselink, 2007). Without a mechanism to actively remove salts from the cytoplasm, over time, plant cells will leak $\mathrm{Na}^{+}$into the cytoplasm where it can accumulate to toxic levels (Mitsch and Gosselink, 2007).

Plants that can survive in high saline environments, such as CSM, are known as halophytes (Mitsch and Gosselink, 2007). Halophytes have been traditionally defined as 
plants that can complete their life cycle in a medium with a salt concentration of at least $200 \mathrm{M} \mathrm{NaCl}$ (Colmer and Flowers, 2008). Like arid environments, the high salinity of coastal hydric soils reduces the available water (Black, 1973; Fitter and Hay, 1987). Therefore, most halophytes utilize the C4 biochemical pathway during photosynthesis since it (i) utilizes less water and (ii) is a more efficient biochemical pathway for carbon fixation and photorespiration (Black, 1973; Fitter and Hay, 1987). Instead of producing a three carbon phosphoglycerate, $\mathrm{C}_{4}$ plants produce four carbon compounds oxaloacetate and malate as a result of $\mathrm{CO}_{2}$ incorporation (Black, 1973; Fitter and Hay, 1987).

Halophytes can internally regulate the concentration of salts within the cytoplasm or they have developed morphological adaptations to mitigate the effects of high soluble salt concentrations (Mitsch and Gosselink, 2007). Instead of trying to fight against the concentration gradient, many halophytes simply increase the salt concentration within the cytoplasm by transforming soluble salts into organic molecules and incorporating them into the structure of the cytoplasm (Mitsch and Gosselink, 2007). Halophytes can also regulate salt concentrations via exclusion or salt secretion (Mitsch and Gosselink, 2007). Many halophytes thicken or alter their exodermis and periderm to act as a physical barrier protecting the inner cortex of roots from salt (Mitsch and Gosselink, 2007). The uptake of salt by halophytes is restricted to the $3^{\text {rd }}$ and $4^{\text {th }}$ order terminal roots helping to mitigate the quantity of salt that is allowed to enter the plant (Mitsch and Gosselink, 2007). Finally, many halophytes, particularly salt marsh grasses and mangroves, can excrete excess salt from their leaves by way of specialized salt glands (Mitsch and Gosselink, 2007). The salt glands of halophytes actively secrete ions from leaves to help maintain 
the ionic balance between di- and monovalent ions throughout the plant (Mitsch and Gosselink, 2007). 
Chapter 3: The Influence of Hydrogeomorphology on Halophyte Zoning

\section{Introduction}

Coastal salt marshes are complex wetland ecosystems that are among the most fertile habitats on earth and provide more ecosystem services to coastal population than any other environment (Gedan et al., 2009). Coastal salt marshes are predominately intertidal and are found in low-lying areas that are physically protected from severe hydrologic activities and climatic events (Mitsch and Gosselink, 2007). To understand

why coastal salt marshes are some of the most productive ecosystems in the world, it is necessary to investigate their hydrogeomorphology and resultant biogeochemical processes (Mitsch and Gosselink, 2007).

Hydrogeomorphology is defined as the combination of climate, hydrology, and geomorphology which alters the aeration status of coastal salt marsh soils. In turn, the sustained saturated soil conditions acts as the catalysis which initiates the biologically mediated reduction of critical nutrients such as carbon, nitrogen, and phosphorus. The biogeochemical transformation and translocation of nutrients dictates the productivity of a costal salt marsh and the environmental pressures that select only specialized plants and organism adapted to the environment (Mitsch and Gosselink, 2007).

The productivity of tidal marshes can vary regionally due to climatic differences and nutrient availability (Mitsch and Gosselink, 2007). Energy balance in coastal salt marshes depends heavily on below-ground production and anaerobic reduction of sulfur (Koch, 1990). Sulfur additions, losses, transformations, and translocations play a critical role in coastal salt marshes. Sulfur typically acts as the primary electron acceptor in reduced coastal salt marsh soils; therefore, a major portion of the below-ground flow of 
energy cycles through reduced sulfur compounds mediated by soil microbes (Rabenhorst et al., 2010). However, the intimate relationship between soil redox potential and biogeochemical cycling of nutrients can be a limiting factor for primary production in coastal salt marshes as well. Anoxic conditions can lead to the concentration of toxins, retardation of cellular respiration, and reduced nutrient availability (Mitsch and Gosselink, 2007).

The most limiting factor in coastal salt marsh productivity; however, is the concentration of soluble salts in the soil medium (Mitsch and Gosselink, 2007). Coastal salt marsh soils are similar to desert soils due to a challenging osmotic gradient caused by a concentration of dissolved salts. Even though water is plentiful in most salt marshes, coastal salt marsh plants are required to expend more energy to increase their internal osmotic concentration in order to obtain water compared to plants in non-saline environments (Mitsch and Gosselink, 2000). Therefore, the speciation, concentration, and distribution of plants within a coastal salt marshes depends heavily on a plants ability to manage anoxic soil conditions, nutrient limitations and toxicity due to redox reactions, and salinity (Mitsch and Gosselink, 2007). Halophytes are plants with the ability to survive flooded environments and high saline soils (Mitsch and Gosselink, 2007).

\section{Spatial Zoning}

Coastal salt marsh flora are typically structured into highly specific zones in tune with tidal and salinity fluctuations, alternating drying and submergence, and daily and seasonal temperature shifts (Craft, 2001). Halophytes have developed adaptations to overcome anoxia, the toxic byproducts of anaerobic respiration, difficulties with nutrient absorption, and salinity (Craft, 2001). All halophytes have evolved morphological 
features that enable them to withstand anoxic conditions. Some halophytes can transfer atmospheric oxygen into the root zone or avoid anoxic conditions by increasing root growth in aerobic zones (Larcher, 2003).

Soil anoxic conditions are the result of sustained soil saturation that depletes oxygen levels due to microbial metabolic activities (Colmer and Flowers, 2008). Anoxic conditions force microbes to utilize nitrogen, manganese, iron, sulfur, and carbon as alternative terminal electron acceptors to complete necessary metabolic activities (Colmer and Flowers, 2008). The use of alternative terminal electron acceptors transforms them into their reduced forms in the soil matrix altering their availability while creating toxic byproducts (Mitsch and Gosselink, 2007).

Nitrate, the primary available form of nitrogen for plants, is the preferred terminal electron acceptor for soil microbes after oxygen has been depleted from the soil environment (Mitsch and Gosselink, 2007). Therefore, nitrogen is often the most limiting nutrient in coastal salt marsh soils since nitrate is a highly mobile negatively charged ion. If it is not leached from the system, then it is often utilized as a terminal electron acceptor and generally leaves the system as dinitrogen gas. The use of iron, manganese, and sulfur as alternative electron acceptors by soil microbes transforms these nutrients into more soluble forms that are more readily absorbed by plants (Mitsch and Gosselink, 2007). Although iron, manganese, and sulfur are essential plant nutrients, most plants only need a small concentration for proper growth and development (Brady and Weil, 2002). High concentrations of reduced iron, manganese, and sulfur can be toxic to plants since they do not have the ability to prevent these species from entering through mass flow and adsorption (Mitsch and Gosselink, 2007). 
Halophytes must also adapt to osmotic fluctuations caused by increased soluble salt concentrations in coastal environments (Mitsch and Gosselink, 2007). Under normal conditions the osmotic concentration of a plant cell cytoplasm is greater than the surrounding medium (Mitsch and Gosselink, 2007). The concentration gradient allows water to freely flow into plant cells maintaining enough turgor pressure to support its structure (Mitsch and Gosselink, 2007). However, an increase in soluble salt concentrations of the soil environment can, (i) significantly decrease the available water for plants, and (ii) force water to move out of the plant cell causing rapid dehydration (Mitsch and Gosselink, 2007). Without a mechanism to actively remove salts from the cytoplasm, over time, plant cells will leak sodium into the cytoplasm where it can accumulate to toxic levels (Mitsch and Gosselink, 2007).

Halophytes can internally regulate the concentration of salts within the cytoplasm or they have developed morphological adaptations to mitigate the effects of high soluble salt concentrations (Mitsch and Gosselink, 2007). Instead of trying to fight against the concentration gradient, many halophytes simply increase the salt concentration within the cytoplasm by transforming soluble salts into organic molecules and incorporating them into the structure of the cytoplasm. Halophytes can also regulate salt concentrations via exclusion or salt secretion (Mitsch and Gosselink, 2007). Many halophytes thicken or alter their exodermis and periderm creating a physical barrier that protects the inner cortex of roots from excess salt. Some halophytes, particularly salt marsh grasses and mangroves, can excrete excess salt from their leaves by way of specialized salt glands (Mitsch and Gosselink, 2007). 
The salt glands of halophytes actively secrete ions from leaves to help maintain their internal osmotic gradient (Mitsch and Gosselink, 2007). Furthermore, not only is nitrogen the most limiting nutrient in coastal salt marsh soils, nitrogen plays a critical role in regulating salt stress. Without nitrogen, plants are unable to produce compatible organic solutes which help to maintain internal water balance (Storey and Jones, 1977). The production of nitrogen-based proline and glycinebetaine is known to consume approximately $20 \%$ of plant nitrogen (Storey et al., 1977). In addition, many plants utilize nitorgen to regulate their photosynthetic use of water (Chavas et al., 2009; Martin et al., 2010). However, not all plants rely on nitrogen to regulate consumption and balance of water (Flowers, 1985).

The efficiency of C4 plants to maximize their water use enables them to not have to rely on nitorgen to regulate water use and balance (Markino et al., 2003). On average, C4 plants use approximately 5 - 9\% of their leaf nitrogen during photosynthesis compared to $20-30 \%$ required by C3 plants (Markino et al., 2003). However, research on Distichlis spicata (saltgrass) a C4 plant, suggested that although saltgrass did not necessarily use nitrogen to regulate water during photosynthesis, saltgrass did incorporate nitrogen to help mitigate the effects of increased salinity (Ryan and Boyer, 2012).

\section{The Dominant Halophytic Vegetation of Scott's Creek Marsh}

Like most coastal salt marsh ecosystems the vegetation of SCM is typically dominated by salt tolerant grasses and rushes that develop distinct identifiable zones known as spatial zoning (Fig. 1). Scotts Creek Marsh has several halophyte zones; however, three plant species dominate the landscape; (i) Typha latifolia (ii) Distichlis spicata, and (iii) Juncus lesueurii. The broadleaf cattail or Typha latifolia is a perennial 
rhizomatous obligate wetland monocot that usually blooms during the months of May and June (USDA, 2006). Cattails are usually found in or near water and can tolerate flooded conditions, reduced environments, and moderate salinity. Typha latifolia has the ability to clone itself and produce seeds making them aggressive in both fresh and salt water wetlands. Ecologically, the broadleaf cattail is an important plant due to its natural ability to adsorb and chelate metal (phytoremediation) micronutrients that have accumulated to toxic levels (Lyubenova et al., 2013). Typha latifolia is an extremely efficient C3 plant that tends to focus its energy on above ground production and its organic matter typically contains a high carbon to nitrogen ratio (USDA, 2006).

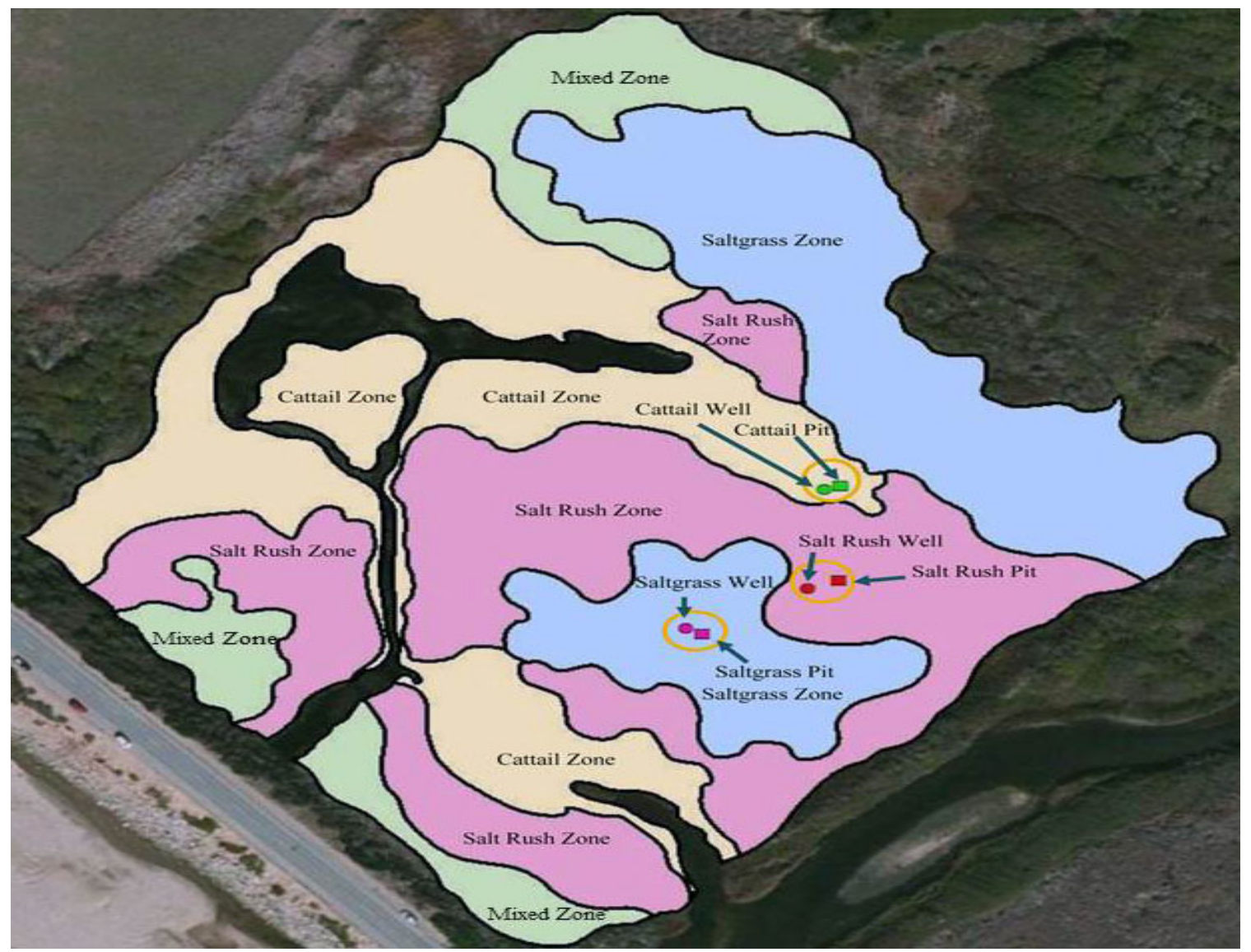

Figure 1. The location and distribution of the four major halophyte zones within Scotts Creek Marsh along with the locations of the study wells and soil pits. The map was created using a hand held GPS unit and aerial photographs provided by Swanton pacific Ranch 
Distichlis spicata, commonly known as saltgrass, is a glabrous perennial with scaly rhizomes (Kubitzk, 1998). Saltgrass are facultative wetland plant that can be found growing on wet soils, in shallow waters, even submerged (Kubitzk, 1998). It is a common coastal salt marsh plant that usually inhabits the upper/high marsh where water level can vary 5 to $15 \mathrm{~cm}$ above the surface of the soil (USDA, 2005). Since saltgrass utilizes the C4 photosynthetic pathway, it is suitably adapted for dry climates and saline environments (USDA, 2005). Furthermore, saltgrass leaves have specialized salt glands to help actively secrete ions from leaves to help maintain an internal osmotic balance (Mitsch and Gosselink, 2007).

The salt rush or Juncus lesueurii is a perennial rhizomatous facultative wetland plant that can tolerate flooded conditions and mild salinity (USDA, 2003). Salt rush are commonly found starting in Central California up to British Columbia, typically in seasonally flooded wetlands. Salt rush leaves are tough enabling them to withstand many insect problems and their extensive rhizomatous root system allows them to withstand drought and flooded conditions (USDA, 2003).

\section{The Importance of Halophyte Zones}

The significance of halophytes within SCM cannot be underestimated. Halophytes create beneficial microenvironments through shade, nutrient recycling, organic subsidies, and sequestration of toxins (Sousa et al., 2010; Pilon-Smits, 2005; Hacker and Bertness, 1995). The sequestration and retention by plant incorporation of nitrogen and phosphorus greatly impacts their availability in interstitial water reducing eutrophication and helping to improve soil and water quality (Sousa et al., 2010). It is well known that 
cattails are extremely effective as phytoremediators or plants that have the ability to remediate toxins, especially heavy metals (Pilon-Smits, 2005).

The physical and chemical created by halophytes can have a positive effect on other plant species and animals by creating more tolerable microenvironments (Hacker and Bertness, 1995). A study investigating the relationship between Juncus gerardi and Iva frutescens demonstrated that when Juncus was removed from an experimental plot, the Iva population suffered greatly from increased salinity due to greater evaporation rates (Hacker and Bertness, 1995). The evaporation rates increased since the shade and ground cover provided by the Juncus were removed (Hacker and Bertness, 1995).

Finally, spatial zoning of halophytes provides insight into the environmental pressures dictating the overall health of a coastal salt marsh, it is used as a biological indicator of ecosystem function. Large-scale changes to the spatial zoning of halophytes help identify disturbances to ecology of a coastal salt marsh. A study conducted by Ryan and Boyer (2012) investigated the effects of increased nitrogen and salinity on growth and distribution of Salicornia virginica. The study concluded that, Salicornia virginica, a plant found throughout SCM, will dominate salt marsh environments when excess nitrogen is added to the system (Ryan and Boyer, 2012). Therefore, close monitoring of the halophyte zones will enable natural resource managers to observe natural and anthropogenic changes within SCM.

\section{Research Background and Importance}

Scotts Creek Marsh (SCM) is a coastal salt marsh located on Swanton Pacific Ranch in Davenport CA, approximately 100 km south of San Francisco (Fig. 2). During the 1940s, the construction of Route 1 (Pacific Highway) along with levies to direct the 
flow of Scotts Creek created ideal conditions for the development of a coastal salt marsh.

Over time, an intertidal grassland developed due to tidal activity, sedimentation, freshwater input, geomorphology, and biological processes. Historically, during the summer and fall, low flow rates of Scotts Creek and swell activities creates a sandbar which closes the mouth of the creek turning the salt marsh into an ephemeral lagoon (Hayes et al., 2008). The rise in water level and heightened nutrient availability due to biogeochemical processes creates ideal environments for both terrestrial and aquatic organisms.
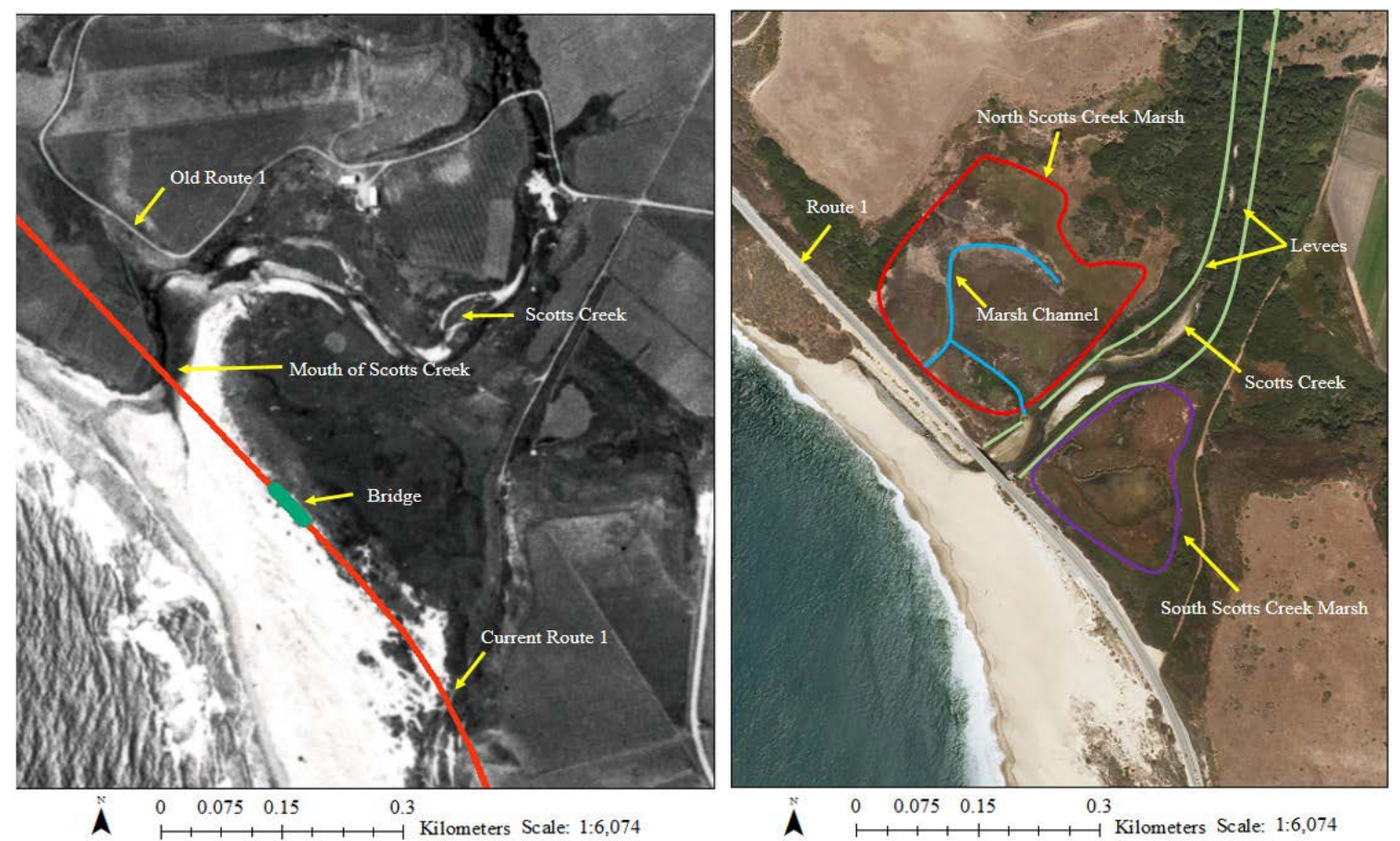

Figure 2. The black and white image shows the location and flow of Scotts Creek prior to the relocation of Route 1 and the construction of the bridge spanning the mouth of Scotts Creek. The current imagery shows the where Scotts Creek Marsh developed and the current location of Route 1, the bridge, and the levees along Scotts Creek

Like all wetland ecosystems, the presence, health, and productivity of SCM depends on the hydrogeomorphology and resultant biogeochemical processes (Mitsch and Gosselink, 2007). The combination of hydrology, climate, and geomorphology dictate the physiochemical status of wetland soils, which in turn, directly influences plant 
and animal species composition and richness, primary productivity, organic matter accumulation, and nutrient cycling (Mitsch and Gosselink, 2007). The importance of SCM for the survival of juvenile steelhead Oncorhynchus mykiss highlights the significance of this unique habitat.

A study conducted by Hayes et al. (2007) revealed that juvenile steelhead that inhabited SCM after the formation of the lagoon made up the vast majority of the fish who reached ocean entry size compared to the steelhead that inhabited other zones within the Scotts Creek watershed. Although the marsh/lagoon environment only comprises 5\% of the total stream area, the estuary is the most important habitat for the survival of steelhead within Scotts Creek watershed. They attributed the significant growth differences to the high biologic productivity and increased wetland habitat of SCM in its lagoon phase. Clearly, SCM is an important habitat worthy of investigation and conservation.

Recently, the California Department of Transportation (Caltrans) has decided that the bridge spanning the mouth of Scotts Creek along Route 1 must be replaced due to its continued degradation. To achieve their goals, changes to the hydrology of Scotts Creek and the geomorphology of the marsh would be required by Caltrans. Any bridge reconstruction plan should consider that any changes to the hydrogeomorphology of SCM would alter the soil biogeochemistry which, in turn, would change the overall ecology of the system. Given the little information available about SCM and its importance as a critical habitat, research was necessary to help develop a management plan that would improve the bridge and preserve the current ecological conditions of the marsh. Because coastal salt marsh ecosystems are extremely complex, the scope of the 
research focused on halophyte zoning since the spatial distribution and concentration of coastal salt marsh plants can be used to observe and monitor any changes to the hydrogeomorphology and biogeochemistry of SCM.

\section{Objectives}

The objective of the study was to investigate the zoning of the halophyte communities within SCM by researching the hydrogeomorphology and biogeochemistry of the marsh. The research hypothesis was salinity and hydrogeomorphology were the most important factors influencing the spatial zoning of halophytes within SCM.

\section{Methods and Materials}

Scotts Creek Marsh (SCM) is a small coastal wetland ecosystem located at the end of Scotts Creek watershed on Swanton Pacific Ranch in Davenport, California. It is located at $37^{\circ} 2^{\prime} 29.96 " \mathrm{~N}$ and $122^{\circ} 13^{\prime} 44.23^{\prime \prime} \mathrm{W}$. Geologically, SCM lies on the Salinian structural block bounded by Sur-Nacmiento and the San Andreas faults (Stanley, 1984). The Salinian block consists of mostly Cretaceous quartz diorite covered by Mesozoic arkosic sandstone of the Santa Maria Formation, which itself is covered by the upper Miocene Santa Cruz mudstone (Brabb, 1989; Stanley, 1984). The watershed is approximately $70 \mathrm{~km}^{2}$ and consists of three main tributaries, Little, Big, and Mill Creeks (Hayes et al., 2008).

Located within the Major Land Resource Area, 4B (Coastal Redwood Belt), the streams that make up the upper portions of the watershed are typically high gradient with extensive coastal redwood (Sequoia sempervirens) canopies (Hayes et al., 2008; USDA, 2010). The lower portions of the watershed consist of low gradient streams with overstory canopy consisting of alders (Alnus sp.) and understory dominated by willows 
(Salix sp.) (Hayes et al., 2008). The mean annual precipitation for Davenport, California is $801 \mathrm{~mm}$ (32 inches) and the mean annual maximum and minimum temperatures are 20 ${ }^{\circ} \mathrm{C}\left(68^{\circ} \mathrm{F}\right)$ and $8{ }^{\circ} \mathrm{C}\left(47^{\circ} \mathrm{F}\right)$ respectively (NOAA, 2013). During the driest months of the year, decreased flow rates of Scotts Creek, and continuous wave energies can close the mouth of the creek forming an ephemeral lagoon (Hayes et al., 2008). The marsh will remain flooded until Scotts Creek can exert enough pressure to break the sand bar.

According to the Soil Survey of Santa Cruz County, California (Bowman and Estrada, 1980), the research area can be found in Section 19, Township 10 South Range 3 West and the dominant soil types for the marsh are Map Unit 103, Aquents (77\%) and Map Unit 171, the Soquel loam (23\%). To investigate the properties of the soils within SCM and collect samples for analysis, three sites were chosen within the study area to conduct our investigation. Site locations were chosen based on the type of vegetative cover and with minimal environmental impact in mind (Fig. 1).

Elevation data for each site was collected with a TOPCON GTS-250 Series Total Station using bench mark 3652 located in the Davenport quadrangle with a geographic position of $37^{\circ} 02^{\prime} 25.74^{\prime \prime} \mathrm{N}$ and $122^{\circ} 13^{\prime} 44.22^{\prime \prime} \mathrm{W}$ and an elevation of $8 \mathrm{~m}$ (NOAA, 2013). Complete soil profiles to a depth of $150 \mathrm{~cm}$ were dug at each site and named salt grass soil pit, salt rush soil pit, and cattail soil pit (Fig. and Table 1). The names, locations, and elevations for each soil pit are listed in Table 1. Soil profile descriptions were completed following the technical guidelines specified in the Field Book for Describing and Sampling Soils version 3.0 
Table 1. The names, elevation, and locations of the three soil pits dug in Scotts Creek Marsh from 03/25/2013 - 03/28/2013

\begin{tabular}{cccc}
\hline Soil Pit & Elevation $^{\dagger}$ & \multicolumn{2}{c}{ Location $^{\ddagger}$} \\
\hline Name & $\mathrm{cm}$ & ---- Lat.---- & ---Long.--- \\
\hline Saltgrass & 279 & $37^{\circ} 2^{\prime} 31.02^{\prime \prime}$ & $122^{\circ} 13^{\prime} 43.42^{\prime \prime}$ \\
Salt Rush & 277 & $37^{\circ} 2^{\prime} 31.56^{\prime \prime}$ & $122^{\circ} 13^{\prime} 42.13^{\prime \prime}$ \\
Cattail & 271 & $37^{\circ} 2^{\prime} 32.61^{\prime \prime}$ & $122^{\circ} 13^{\prime} 42.17^{\prime \prime}$ \\
\hline
\end{tabular}

† Bench Mark 3652, Davenport Quadrangle, NAVD 88

$\ddagger^{\circ}=$ Degrees, ' $=$ Minutes, “ = Seconds

(USDA, NRCS 2012). Soil samples were collected from each horizon of every pit dug and transported to a lab. To test for the presence of inorganic carbon, three drops of $1 M$ $\mathrm{HCl}$ acid was applied to both on field and laboratory samples. Laboratory soil samples were dried, sieved using a $2 \mathrm{~mm}$ sieve, crushed, and then run through an Elementar VarioMax CNS analyzer.

Monitoring wells were installed using the guidelines specified by Sprecher (2008) in locations near the soil pits so that disturbance did not interfere with the data collected from the wells (Fig. 1 and Table 2). Like the soil pits, the wells were named based on which halophyte zone it was located in: saltgrass, salt rush, and cattail wells respectively. Once all wells were installed, a Decagon CTD sensor measuring water level, electrical conductivity (EC), and temperature was placed in each well at a depth of $140 \mathrm{~cm}$ below the soil surface. The sensors were then connected to a Decagon EM50 data logger to record data every 30 minutes from April 6 to July 21 2013. Data were downloaded and daily averages were calculated.

Table 2. The names, locations, and elevations of each monitoring well installed at Scotts Creek Marsh from 03/25/2013 - 03/28/2013

\begin{tabular}{cccc}
\hline Monitoring Wells & Elevation $^{\dagger}$ & Location $^{\ddagger}$ \\
\hline Name & $\mathrm{cm}$ & ----- Lat.----- $^{\prime}$ & --Long.--- $^{\circ}$ \\
\hline Saltgrass & 279 & $37^{\circ} 2^{\prime} 31.10^{\prime \prime}$ & $122^{\circ} 13^{\prime} 43.56^{\prime \prime}$ \\
Salt Rush & 277 & $37^{\circ} 2^{\prime} 31.52^{\prime \prime}$ & $122^{\circ} 13^{\prime} 42.44^{\prime \prime}$ \\
Cattail & 271 & $37^{\circ} 2^{\prime} 32.61^{\prime \prime}$ & $122^{\circ} 13^{\prime} 42.28^{\prime \prime}$ \\
\hline
\end{tabular}

† Bench Mark 3652, Davenport Quadrangle, NAVD 88

$\ddagger^{\circ}=$ Degrees, ' $=$ Minutes, “ $=$ Seconds 


\section{Results}

The total precipitation that fell during the course of the study was $321 \mathrm{~mm}$ (13 in). The closure of SC created a natural flood event that maintained saturated soil conditions starting on June 8. The water level data collected from each well indicated that there was a sharp jump in the water level from June 8 to June 9 (Table 3). The average daily water level at each well from June 8 to July 21 was $16.79 \mathrm{~cm}(0.55 \mathrm{ft}$.) at the saltgrass well, $17.11 \mathrm{~cm}(0.56 \mathrm{ft}$.$) at the salt rush well, and 29.71 \mathrm{~cm}(0.97 \mathrm{ft}$.$) at the cattail well. The$ differences between the two days were $39.15 \mathrm{~cm}, 32.64 \mathrm{~cm}$, and $18.94 \mathrm{~cm}$ respectively for each well (Table 3).

Buoy data of the average significant wave height (AWVHT), average dominant wave period (ADPD), and tides during the first, second, and third weeks were classified (Table 4). The condensed soil profile data and redoximorphic features collected from the saltgrass, salt rush, and cattail soil pits are provided in tables 5 - 10. The EC and temperature of the ground water stayed relatively consistent even after the mouth of Scotts Creek closed and the marsh became a large lagoon. Temperature of the soils as expected slowly increased due to the seasonal transition (Fig. 3). All three wells went through the same transitions starting at $11{ }^{\circ} \mathrm{C}$ (Saltgrass), $12{ }^{\circ} \mathrm{C}$ (Salt Rush), and $12{ }^{\circ} \mathrm{C}$ (Cattail) and rising to a high of $14{ }^{\circ} \mathrm{C}$ (Saltgrass), $13{ }^{\circ} \mathrm{C}$ (Salt Rush), and $13{ }^{\circ} \mathrm{C}$ (Cattail).

The average water temperature of the wells, $13{ }^{\circ} \mathrm{C}$ (Saltgrass), $13{ }^{\circ} \mathrm{C}$ (Salt Rush), and 13 ${ }^{0} \mathrm{C}$ (Cattail), showed little variability for the duration of the study.

The well EC for each site was slightly variable; rising and falling but the general trend was a steady increase as the study progressed (Fig. 4). Originally, the saltgrass well started off at $26 \mathrm{dS} / \mathrm{m}$, dropped slightly and after the 1st of June gradually increased 
finishing at $29 \mathrm{dS} / \mathrm{m}$. The salt rush well's daily averages remained the most consistent out of the three. The salt rush well started off at $13 \mathrm{dS} / \mathrm{m}$, rising to its highest of $16 \mathrm{dS} / \mathrm{m}$ on the 22nd of April before descending and evening out at a consistent $15 \mathrm{dS} / \mathrm{m}$. Like the two previous wells, the cattail well started at $11 \mathrm{dS} / \mathrm{m}$ but quickly decreased to as low as $8 \mathrm{dS} / \mathrm{m}$ on the 6th of June and then rose and stabilized to almost its original value coming in at $10 \mathrm{dS} / \mathrm{m}$.

Table 3. The average daily water level from wells 1,2 and 3 in centimeters $(\mathrm{cm})$ from June 5 to June 11,2013

\begin{tabular}{cccc}
\hline Date & Saltgrass Well & Salt Rush Well & Cattail Well \\
\hline $6 / 5 / 2013$ & -73.40 & -56.43 & -38.22 \\
$6 / 6 / 2013$ & -75.88 & -52.56 & -32.62 \\
$6 / 7 / 2013$ & -77.56 & -46.72 & -24.03 \\
$6 / 8 / 2013$ & -37.19 & -31.21 & -3.88 \\
$6 / 9 / 2013$ & 1.96 & 1.43 & 15.07 \\
$6 / 10 / 2013$ & 8.49 & 9.23 & 21.33 \\
$6 / 11 / 2013$ & 12.99 & 13.06 & 25.15 \\
\hline
\end{tabular}

Table 4. The average weekly significant wave height (WVHT), dominant period (DPD), mean wave direction (MWD), and low and high tides form June $1^{\text {st }}$ to June $21^{\text {st }}$ according to NOAA (2013) buoy $^{\dagger}$ data

\begin{tabular}{cccccc}
\hline Dates & WVHT (m) & DPD (s) & MWD (deg.) & Low Tide (m) & $\begin{array}{c}\text { High Tide } \\
(\mathrm{m})\end{array}$ \\
\hline $6 / 1-6 / 7$ & 2.21 & 7.56 & 283.65 & 0.09 & 0.40 \\
$6 / 8-6 / 14$ & 2.64 & 7.58 & 290.61 & 0.11 & 0.39 \\
$6 / 15-6 / 21$ & 1.69 & 5.39 & 292.83 & 0.11 & 0.40 \\
\hline † Buoy Station 46042, Monterey, CA (NOAA, 2013) & & &
\end{tabular}


Table 5. Soil profile descriptions for the saltgrass, salt rush, and cattail pits analyzed on 03/25/2013 according to the guide lines stipulated by USDA. (2012)

\begin{tabular}{|c|c|c|c|c|c|c|c|c|}
\hline \multirow{3}{*}{ Horizon } & \multicolumn{6}{|c|}{ Saltgrass } & \multirow{2}{*}{\multicolumn{2}{|c|}{ Roots }} \\
\hline & Depth & Color & Texture & Clay & $\mathrm{EC}^{\dagger}$ & Temp. & & \\
\hline & $\mathrm{cm}$ & Moist & Class & $\%$ & $\mathrm{dS} / \mathrm{m}$ & C & Amt. $^{\ddagger}$ & $\operatorname{Size}^{\S}$ \\
\hline A1 & $0-9.5$ & 10YR2/1 & - & - & 0.33 & 11.7 & $\mathrm{C}$ & $\mathrm{M}-\mathrm{C}$ \\
\hline A2 & $9.5-25$ & 7.5 YR3/1 & SIL & 25 & 1.47 & 10.4 & $\mathrm{C}$ & $\mathrm{M}-\mathrm{C}$ \\
\hline $\mathrm{AB}$ & $25-33$ & 7.5 YR3/1 & SIL & 15 & 1.9 & 10.4 & $\mathrm{C}$ & $\mathrm{M}-\mathrm{C}$ \\
\hline Bt1 & $33-55$ & 7.5YR2.5/1 & SICL & 30 & 3.9 & 10.6 & C & M-C \\
\hline Bt2 & $55-94$ & $5 Y 3 / 1$ & SICL & 32 & 6.99 & 10.6 & $\mathrm{C}$ & $\mathrm{M}-\mathrm{C}$ \\
\hline Bt3 & $94-150$ & $2.5 \mathrm{~N}$ & SICL & 32 & 7.04 & 10.6 & M & F-M \\
\hline \multicolumn{9}{|c|}{ Salt Rush } \\
\hline Oe & $0-5$ & 10YR3/2 & - & - & 0.62 & 11.11 & $\mathrm{C}$ & F-C \\
\hline $\mathrm{A} 1$ & 9-May & 10YR3/3 & SICL & 31 & 0.96 & 11.67 & $\mathrm{C}$ & F \\
\hline A2 & 27-Sep & 10YR3/2 & SIL & 22 & 2.63 & 10.83 & $\mathrm{~F}$ & VF-VC \\
\hline A3 & $27-61$ & 10YR3/1 & SIL & 20 & 3.16 & 11.4 & $\mathrm{~F}$ & C \\
\hline $\mathrm{AB}$ & $61-79$ & 5 Y2.5/1 & SIL & 18 & 4.7 & 11.4 & $\mathrm{~F}$ & $\mathrm{C}$ \\
\hline Bt1 & $79-112$ & $2.5 \mathrm{~N}$ & SICL & 30 & 4.7 & 11.4 & F & VF \\
\hline Bt2 & $112-150$ & $2.5 \mathrm{~N}$ & SICL & 35 & 5.4 & 11.3 & - & - \\
\hline \multicolumn{9}{|c|}{ Cattail } \\
\hline Oe & $0-3$ & $2.5 Y 2.5 / 1$ & & & 0.07 & 18.8 & $\mathrm{C} / \mathrm{M}$ & F-M-VC \\
\hline A1 & 7-Mar & $2.5 Y 2.5 / 2$ & SIL & 25 & 1.52 & 19.7 & $\mathrm{C} / \mathrm{M}$ & F-M \\
\hline A2 & Jul-37 & $5 Y 3 / 1$ & SIL & 27 & 2.09 & 13.8 & - & - \\
\hline Bt1 & $37-86$ & $5 Y 3 / 2$ & SICL & 32 & 2.02 & 13.8 & - & - \\
\hline Bt2 & $86-126$ & $2.5 \mathrm{~N}$ & SICL & 35 & 2.97 & 11.7 & - & - \\
\hline C & $126-150$ & - & CB & 5 & - & - & - & - \\
\hline
\end{tabular}

† Electrical Conductivity

$\ddagger$ The average quantity (number) of roots from five representative areas along a horizontal plane $\mathrm{C}=$ Common (2), $\mathrm{M}=$ Many (3)

$\S$ The average root diameter from a $1 \mathrm{~cm}^{2}$ or $1 \mathrm{dcm}^{2}\left(\mathrm{dm}^{2}=\right.$ a square that is $10 \mathrm{~cm}$ on a side) area, $\mathrm{F}=$ fine $\left(1\right.$ to $\left.<2 \mathrm{~cm}, 1 \mathrm{~cm}^{2}\right), \mathrm{M}=$ medium $\left(2\right.$ to $\left.<5 \mathrm{~mm}, 1 \mathrm{dcm}^{2}\right)$, and $\mathrm{C}=$ coarse $\left(5\right.$ to $\left.<10 \mathrm{~mm}, 1 \mathrm{dcm}^{2}\right)$ 
Table 6. Saltgrass salt rush, and cattail soil pit redoximorphic features according to the guide lines stipulated by the USDA (2012)

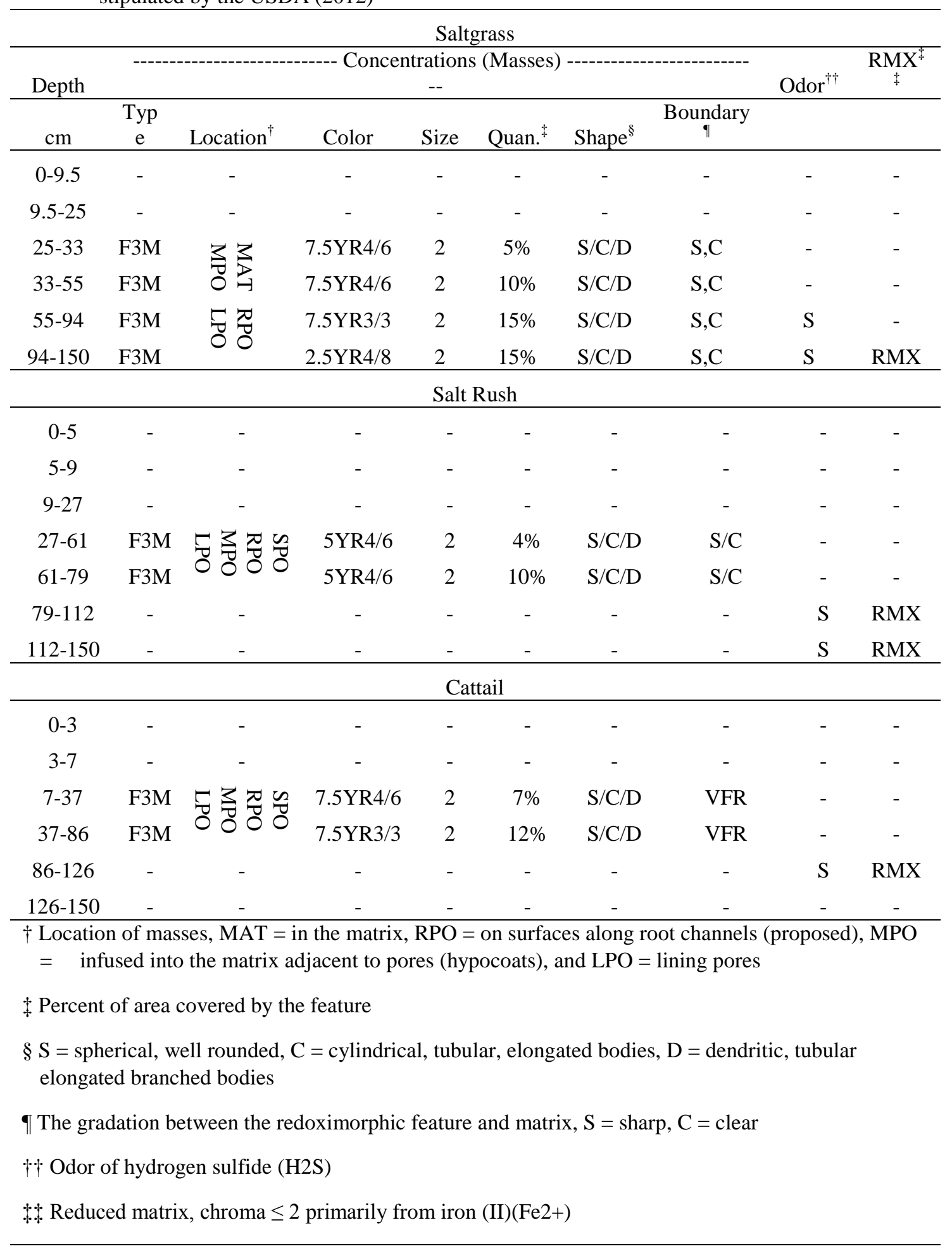




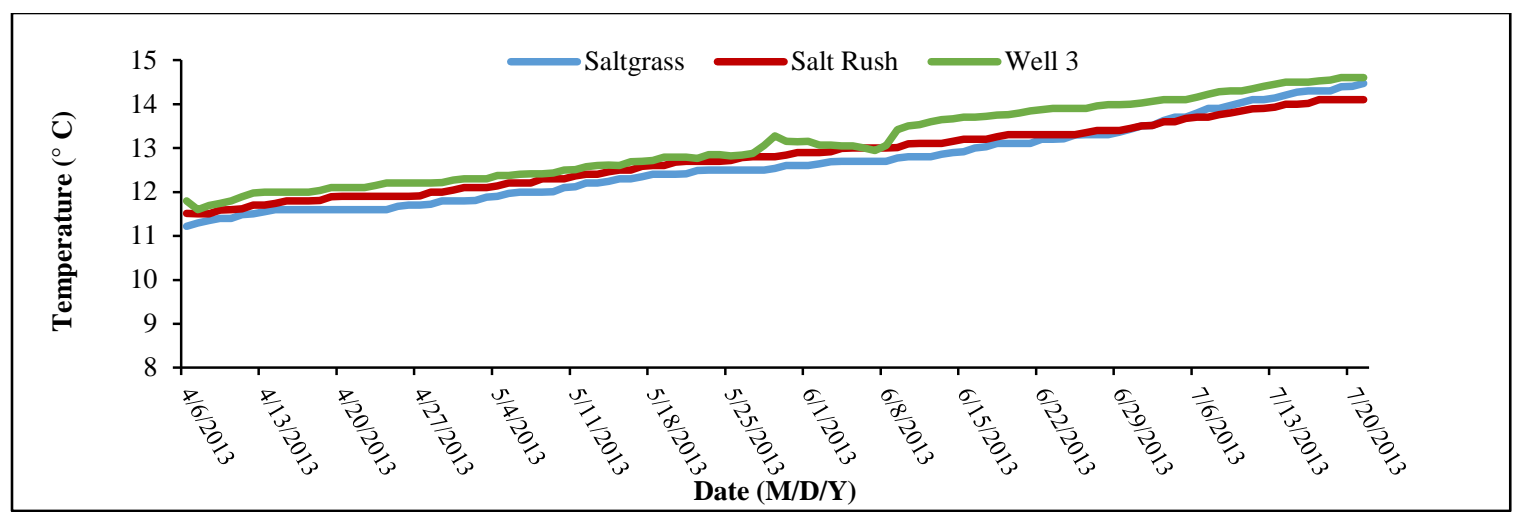

Figure 3. The daily average water temperature in degrees Celsius $\left({ }^{\circ} \mathrm{C}\right)$ for each well in Scotts Creek Marsh from April 6 to July 20, 2013

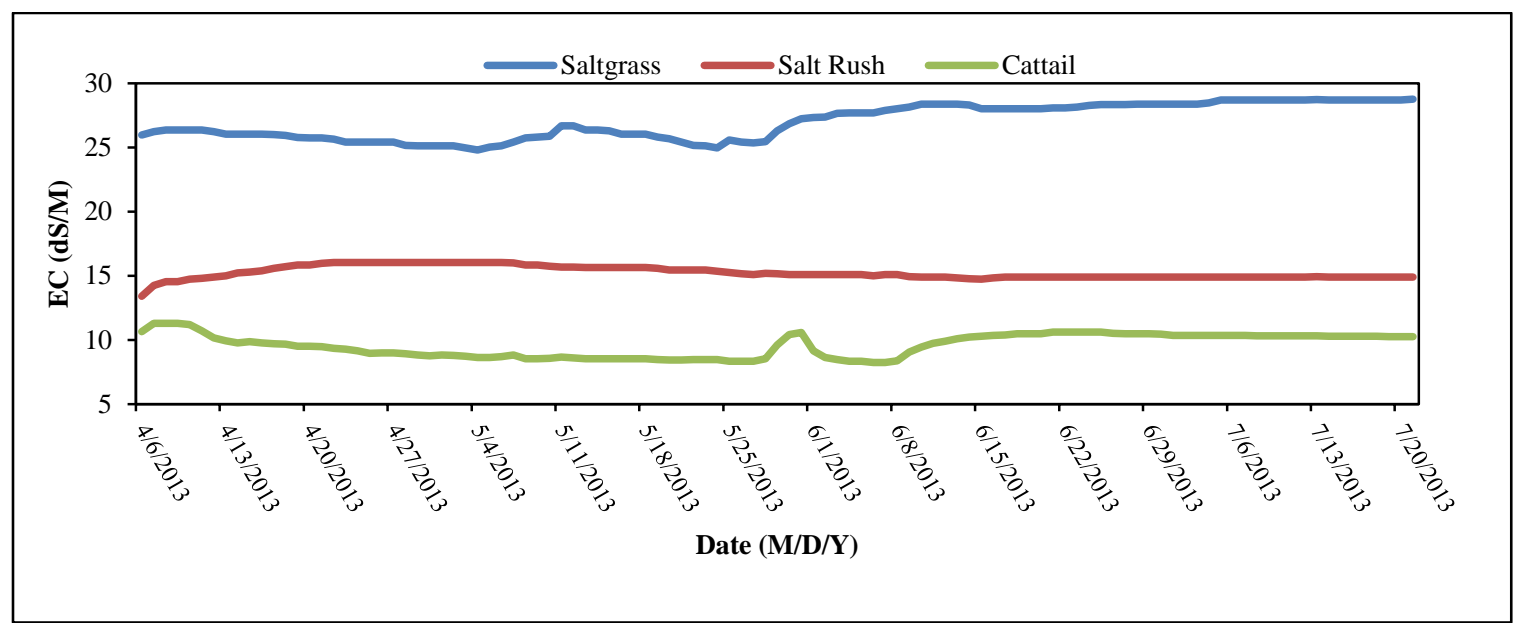

Figure 4. The daily average water electrical conductivity in $\mathrm{dS} / \mathrm{m}$ for each well in Scotts Creek Marsh from April 6 to July 20, 2013

\section{Discussion}

The 2013 daily average precipitation results indicated that during the course of our study, the precipitation was lower than the normalized data for the same dates in 2011 (Fig. 5). There was a difference of 1445 mm (57 in.) when comparing 2013 precipitation to the precipitation in 2011 (Fig. 5). The daily gauge data averages of Scotts Creek indicated that the low precipitation during the study reduced the flow rate of Scotts Creek facilitating the closure of the mouth (Fig. 6). Analyzed buoy, well, and gauge data suggested that there was no major weather or tidal event that closed Scotts Creek (Table 4, Fig. 7). Isolated tide and wave data from the week leading up to the flood event, the 
week of the flood event, and the week after indicated that there was no hydrologic event that caused the closure of the mouth. The average wave height before the flood was 2.21 m, during $2.64 \mathrm{~m}$, and $1.69 \mathrm{~m}$ the week after (Table 4). Isolated tide averages the week before, during, and week after indicated no big increase or decrease (Table 4).

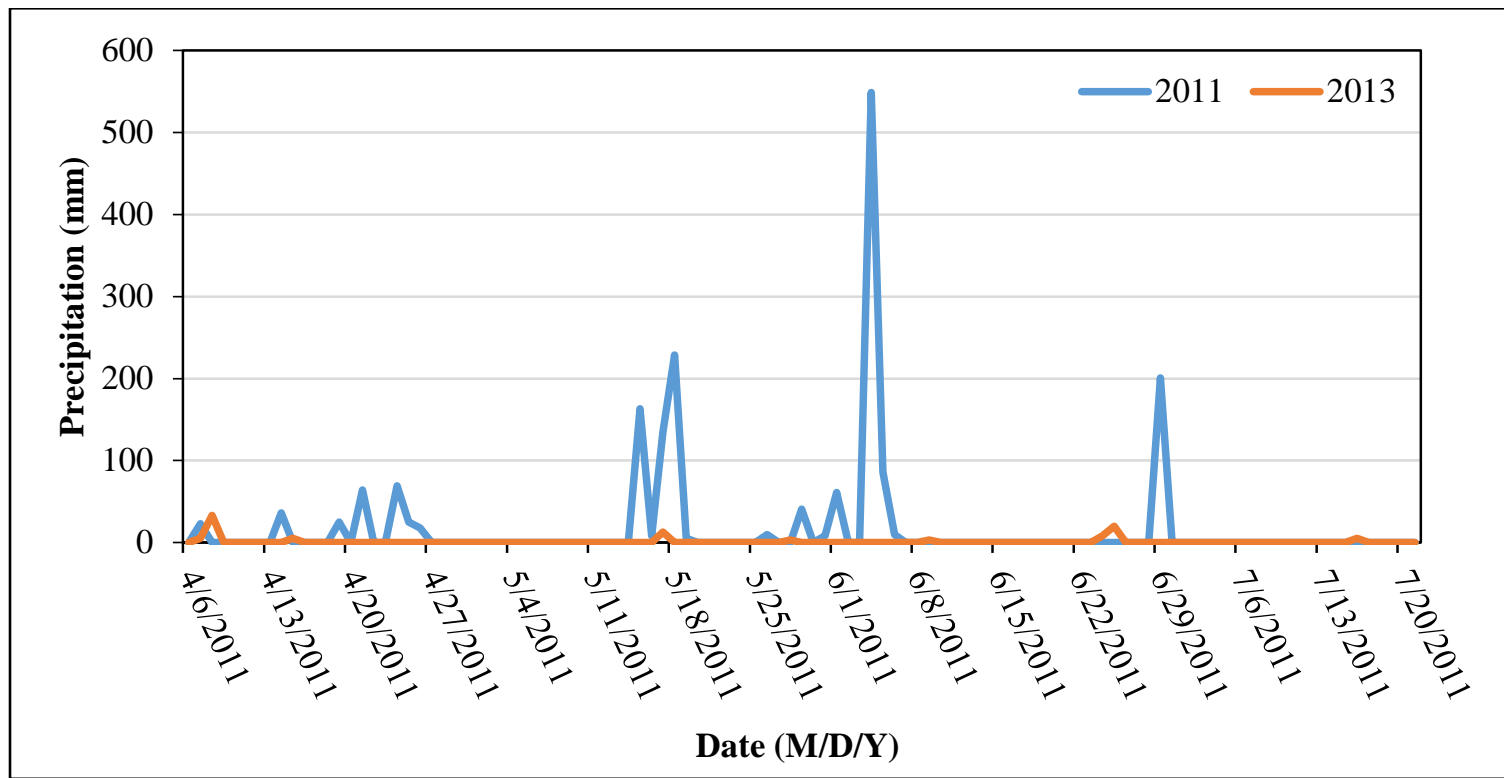

Figure 5. The daily average precipitation in millimeters (mm) based on NOAA, 2011 normalized and 2013 precipitation data from April 6 to July 21, 2011 normalized data was used since the 2012 data has not been compiled yet

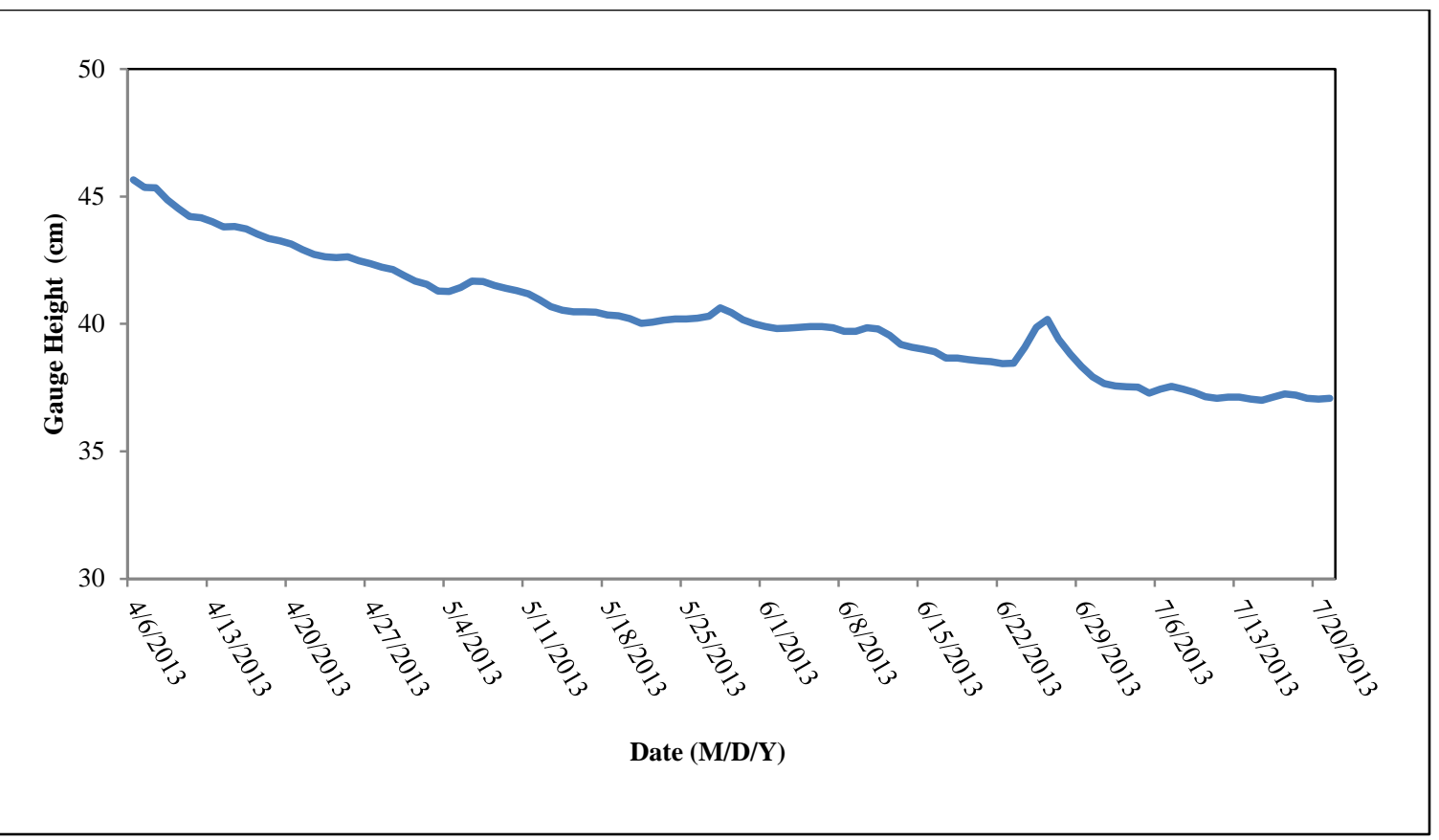

Figure 6. Average daily gauge height in centimeters (cm) of Scotts Creek from April 6 to July 21 


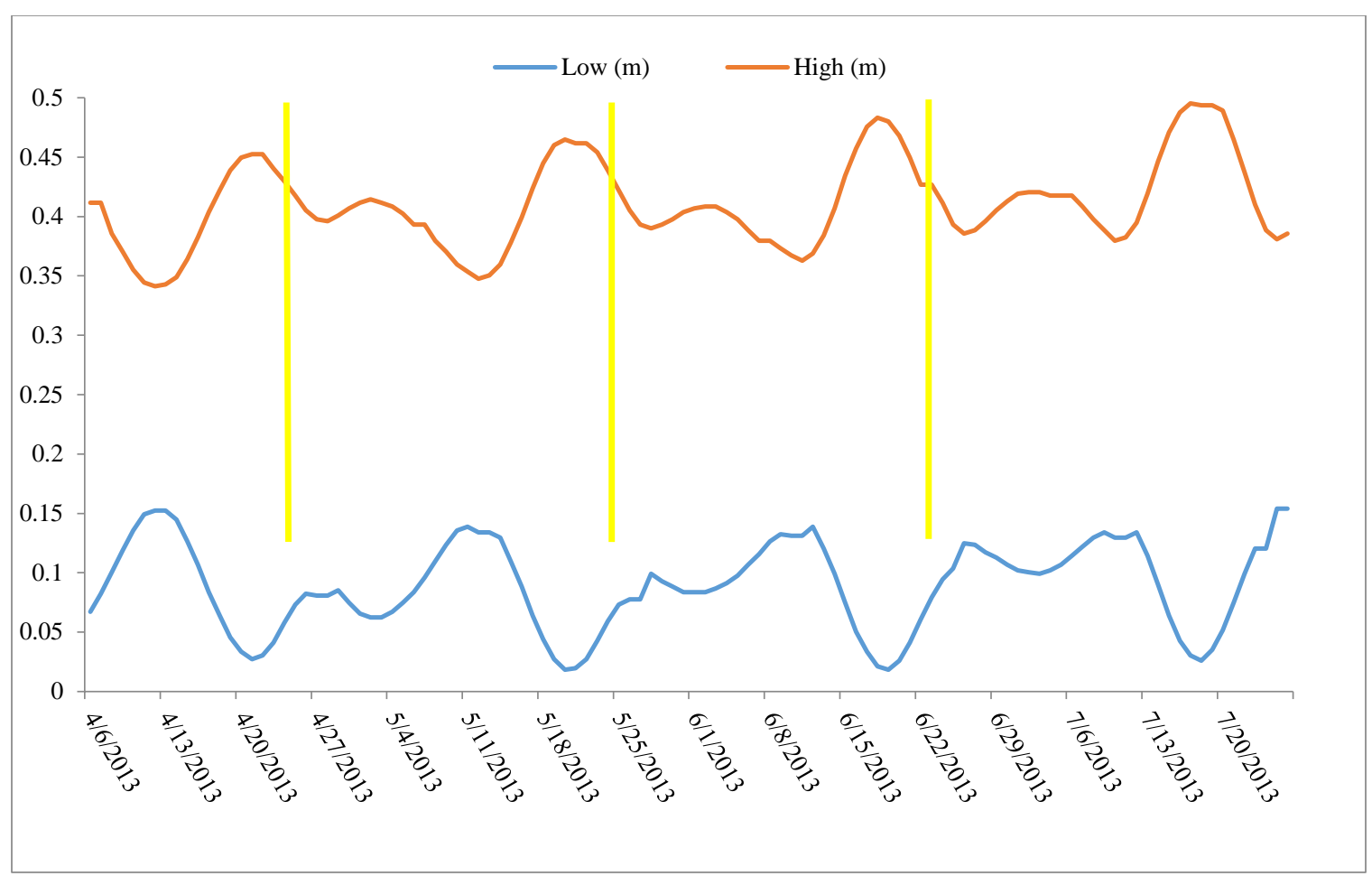

Figure 7. Average daily low and high tides in meters (m) from buoy Station 46042, Monterey, CA (3647'7" N, 122 $28^{\circ} 9^{\prime \prime} \mathrm{W}$ ) from April 6 to July 21 (NOAA, 2013), yellow lines indicate the full moons on April 25, May 25, and June 23

The wave direction could have played a more important role rather than the wave height and tides in the formation of the lagoon. The average wave direction from the 7 to the 11 of June (two days before and two days after the closure of SCM) was $257^{\circ}$ approximately parallel to the shoreline. Instead, low annual rain fall and the resulting low flow rates of Scotts Creek led to the gradual buildup of the sand bar closing the mouth of the creek early in the summer and allowing for a long, sustained period of soil saturation.

The closure of the mouth had no bearing on the overall salinity levels of the well water according to our data. Since salt water is denser than fresh water, the fresh water will sit on top of the saline water. During years of high precipitation when the lagoon forms, the fresh water will push the salt water out through the bottom of the sand bar. The low 2013 precipitation could have resulted in equilibrium between fresh and salt water since not enough fresh water was present to displace the saline water. Furthermore, it is 
possible since SCM sits on top of an old sand dune which was leveled to create Route 1 that saline water present in SCM was due to below ground salt water intrusion (Fig. 2).

The high saturated hydraulic conductivity of sand particles and proximity of the ocean could allow salt water to move along a concentration gradient into SCM. Even with enough fresh water to push out the saline water, salt water could still be present due to the concentration gradient and the movement of salt water from below. The initial results from the water level data seems to indicate there is a tidal influence even when the mouth of SC is closed. Close examination of the averaged daily water level shows a monthly pattern associated with the phases of the moon (Figs. 7, 8). The full moons on the 25 of April, the 25 of May, and the 23 of June coincided with increases in the water level of SCM. However, the analyzed data also indicated that the rise in water level did not persistent and will subsided after a few days.

All three vegetation types were able to tolerate the flooded soil environment and the resultant anoxic conditions. The soil profiles illuminated the morphological adaptations of saltgrass, salt rush, and cattail communities within SCM. The saltgrass soil profile verified that saltgrass expends energy in root growth verses vertical production by pumping atmospheric oxygen into the root system to avoid anoxic soil conditions via arenchyma (Larcher, 2003). The abundance of healthy roots as far down as $150 \mathrm{~cm}$ along with the presence of redoximorphic iron films in the rhizosphere indicated that saltgrass is well suited for flooded conditions (Table 6). 


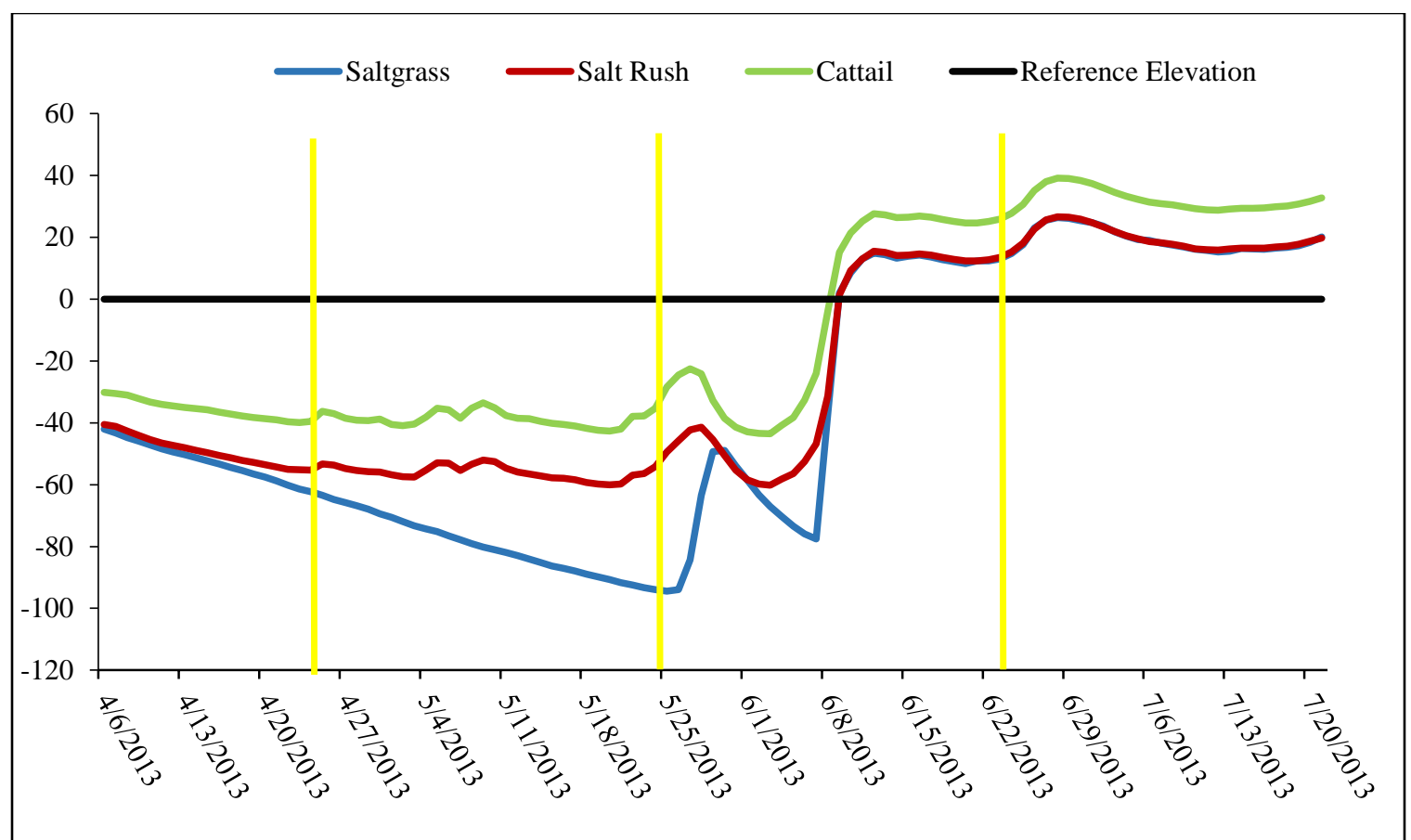

Figure 8. Average daily water level readings in centimeters (cm) for all three wells from April 6 to the 21 of July, yellow lines indicate the full moons on April 25, May 25, and June 23

Assessment of the data indicated that cattails survive flooded environments by doing the opposite of saltgrass; they utilize adventitious roots that allow them to create an extensive horizontal vegetative mat. The adventitious roots utilized by cattails allow them to focus their energy on above ground shoot and leaf production and is the reason why the root system was shallow only reaching a depth of approximately $7 \mathrm{~cm}$ (Table 6). The salt rush plant community is a hybrid of cattail and saltgrass. The salt rush community appeared to utilize both arenchyma and adventitious roots to survive flooded soil conditions. Although the roots of the salt rush soil profile were not as thick and numerous as those found in the saltgrass profile, they did extend down to a depth of approximately $112 \mathrm{~cm}$ (Table 6). All three plant species have thick protective tissue roots for protection from anoxic soil conditions. 
The soil within each vegetative zone were classified as fine silty, mixed, mesic, Cumulic Haploaquolls. The cation exchange capacity (CEC) class was unfortunately not tested during the study. Due to the annual flood and fluctuating water table of Scotts Creek Marsh, the soil moisture regime was considered aquic and the close proximity to the ocean helps to maintain a mesic soil temperature regime of 8 to $<15{ }^{\circ} \mathrm{C}$ (USDA, NRCS, 2010). None of the samples taken directly from the pits or those brought back to the lab effervesced when $1 M \mathrm{HCl}$ acid was applied. The results of the carbon analysis showed that the cattail and the salt rush soil pits had O horizons with a total \% organic carbon content of 19.70 and 18.32 (Fig. 9). Respectively, the surface horizon of the saltgrass soil pit did not meet the minimum \% organic carbon requirement $(>12 \%)$ to be considered an O horizon.

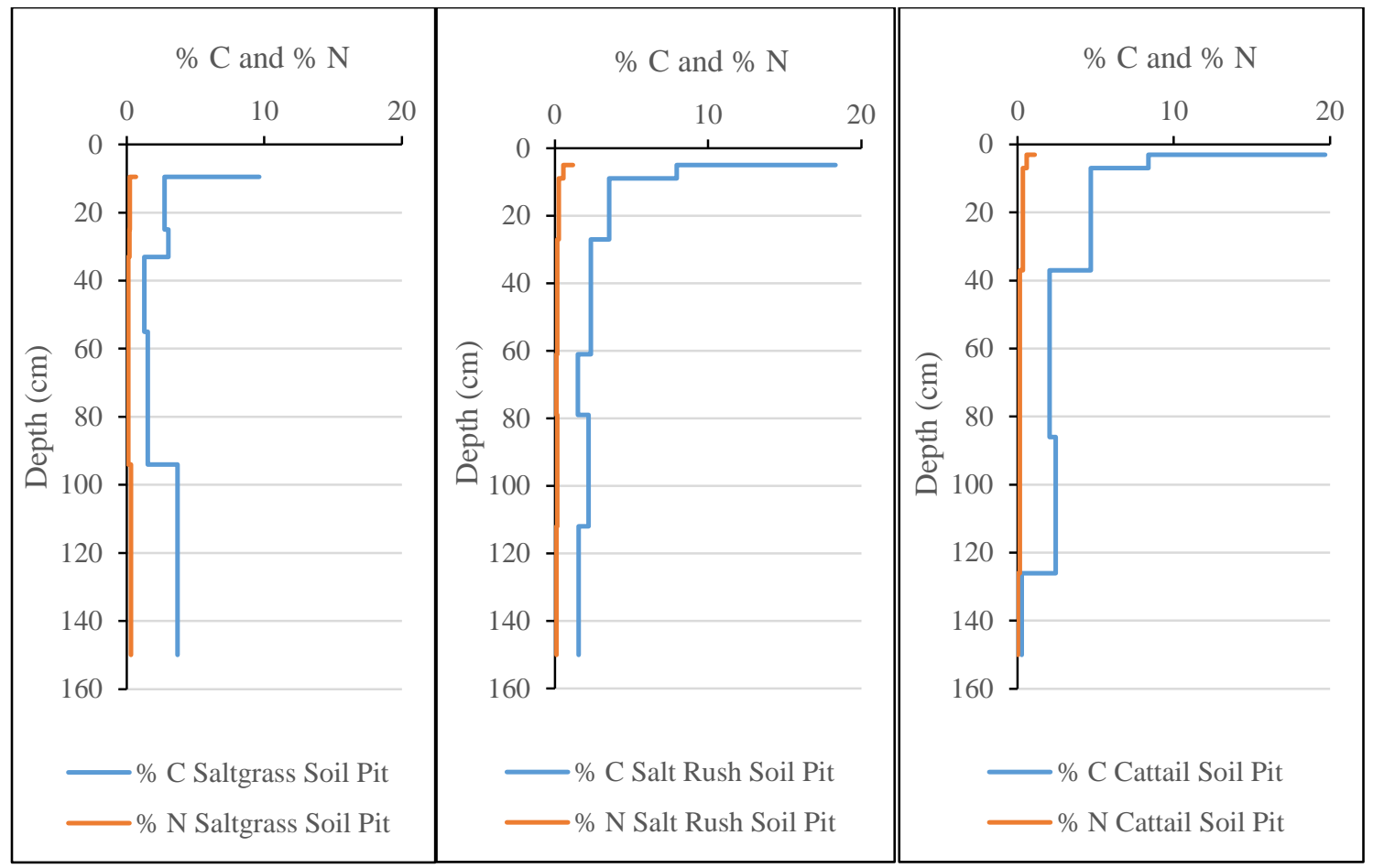

Figure 9. The percent (\%) carbon (blue line) and \% nitrogen (orange line) by depths (cm) for all three soil pits in Scotts Creek Marsh 
The soils we investigated all had mollic epipedons because of the percent $\mathrm{C}$ content (>0.6\%), color, thickness ( $25 \mathrm{~cm}$, no underlying diagnostic horizons), and the epipedon is moist for at least 90 days out of the year when the soil temperature at $50 \mathrm{~cm}$ was $\geq 5{ }^{\circ} \mathrm{C}$ (USDA, 2010). Due to the high salinity, mollic epipedon, and $\mathrm{pH}$ greater than 6 , it was assumed that the base cation saturation was greater than $50 \%$. All three soil profiles were dominated by silt loam or silty clay loam textures with the exception of the last horizon of the cattail pit which was a C horizon with a mix of sand, gravel, and cobbles (cobbly, $\geq 15 \%$ but $<35 \%$ cobbles).

The soils at the saltgrass and salt rush soil pits were classified as cumulic because they meet the following requirements: organic-carbon content of $\geq 0.3 \%$ at a depth of 125 $\mathrm{cm}$ below the first mineral horizon and a slope less than 25\% (Fig. 9) (USDA, 2010). The cattail pit qualified as cumulic based on its slope $(<25 \%)$ and variable decreases in organic-carbon content in-between 25 to $125 \mathrm{~cm}$ of the soil profile (Fig. 9) (USDA, 2010). Unlike, the cattail and salt rush, saltgrass clearly spends most of its energy on below ground root production as evident in the carbon analyses and soil profiles (Table 6, Fig. 9). The cattail and salt rush soil surface horizons were high in organic matter because they spend their energy on shoot and leaf production. The organic matter accumulates as the dead plant matter falls to the surface and then is saturated before it can be decomposed by soil microbes and soil fauna.

The soil profiles offered interesting clues into the redoximorphic conditions of the soils investigated. The high organic matter and the presence of redoximorphic features in the lower horizons of each soil pit suggested that seasonally saturated conditions do occur in SCM. The absence of depletions along with information gathered from the monitoring 
wells suggest that reduced and oxidized conditions occur rapidly. The reduced soil horizons could not have formed without sustained soil saturation due to changes in the water level as evident in the locations of the reduced matrixes found in all three soil pits.

The saltgrass pit had a reduced matrix in the last horizon from 95 to $150 \mathrm{~cm}$ (Table 6). The salt rush pit had two reduced horizons starting from 80 to $150 \mathrm{~cm}$ and the cattail pit had one from $80-112 \mathrm{~cm}$ (Table 6). The presence of reduced matrixes towards the bottom of each soil pit suggested the lower soil horizons would continue to experience sustained saturated conditions even after the mouth of SCM opens. Initially, $\mathrm{H}_{2} \mathrm{~S}$ could not be detected by smell; however, once the reduced matrixes of all three profiles were exposed, $\mathrm{H}_{2} \mathrm{~S}$ was detected.

Redox concentrations were found at each soil pit (Table 6). Since none of the redox concentrations evaluated were cemented, they were categorized as masses. The most redox concentrations were found in the saltgrass pit, then the salt rush pit, and the cattail pit had the least amount (Table 6). The majority of the redox concentrations were located around soil pores, root pores, and around the rhizosphere environment (Table 6). Only the saltgrass soil pit had masses in the surrounding soil matrix (Table 6). Clearly the different root adaptations each species exhibited had a great impact on the quantity, concentration, and distribution of the soil redox feature we found. All three species of plants we investigated utilize arenchyma to promote radial oxygen loss in the rhizosphere. The redox masses were only present in saturated horizons where halophyte roots were pumping oxygen into the soil matrix (Table 6).

Despite the presence of redoximorphic features in all three soil pits, only the cattail soil be considered a hydric or wetland soil by the current standards established by 
the National Technical Committee for Hydric Soils (NTCHS). The cattail soil met the F6 or dark surface horizon greater than $10 \mathrm{~cm}$ thick and found in the first $30 \mathrm{~cm}$ of the surface field indicator. Based on the following conditions, other two soils did not meet the technical standard: (i) depth of redox concentrations, (ii) lack of thick enough mucky horizon, (iii) no gleyed horizon due to color, (iv) $\mathrm{H}_{2} \mathrm{~S}$ is only discernible in the lowest horizons, and (v) lack of depletions (UDSA, NRCS, 2010). More research is necessary to determine whether the soils within SCM meet the qualifications of a hydric soil based on field indicators due to conservation and legal problems associated wetlands.

The water salinity data collected from the wells were different from the data we collected from the soil profiles. The analysis of the soil profile data suggested the ability of the soils to buffer the concentration of soluble salts was high. It is possible that the soil texture and seasonal fresh water flushing of the soils could help lower soil salinity levels; however, more research is needed for a definitive answer. The field EC and soil temperature trends were consistent with what we expected.

Interpretation of all three well data suggested that there was a relationship between the salinity and the spatial distribution of the three plants investigated. The plants were distributed in an expected pattern with saltgrass occupying the area with the highest well salinity and cattails dominating the low saline areas near the marsh channels. The ability of salt rush to withstand mild salinity was supported by the data since they occupied moderately saline areas. It appears that both the salt rush and cattail utilize thick lateral adventitious roots to physically avoid fluctuating salt concentrations. Based on the analysis of the water temperature data collected from the wells, the temperature was not a 
limiting factor in biological activities since it never reached the biological zero temperature of $5{ }^{\circ} \mathrm{C}$ during the course of the study (Rabenhorst, 2005).

The high carbon content of the soils investigated during the study was expected (Fig. 9). The presence of such high concentrations of carbon is reflective of the seasonal flood patterns and plant development. Analysis of the data indicated that the percent carbon at each pit was influenced by previous alluvial depositions supporting the notion that the soils have cumulic characteristics (Fig. 9). The unpredictable changes in the percent carbon with depth supports the notion that vegetation was buried due to large hydrologic flood events.

The soil samples that had the highest percent carbon were the ones collected in the cattail zone (Fig. 9). The cattail zones had the lowest elevation so the soils tend to stay saturated longer slowing the decomposition of dead organic matter. Cattails also focus their energy on shoot and leaf production during their three month growing season before allowing the growth to die as it refocuses its energy on lateral root development. This further enhances the percent carbon content of the soils cattails inhabit within the study area. In addition, the cattail communities within SCM dominate the areas around the channels where hydraulic activates tend to deposit more nutrients and flush toxins enhancing the growth and productivity of the cattails.

The percent carbon of the saltgrass soils were the lowest of all the soil samples that were analyzed (Fig. 9). The saltgrass pit lacked an organic horizon since saltgrass favors below ground root production verses above ground shoot and leaf production (Fig. 9). Continuing its trend as an intermediate plant, the salt rush percent carbon was higher than the salt grass pits samples but slightly lower than the cattail samples. Again, the 
presence of an O horizon of the salt rush pit was reflective of the above ground development of salt rush and the seasonal flooding which suspended decomposition of the plant litter (Table 5 and Fig. 9).

The nitrogen data confirmed that the concentration of nitrogen was low in all three soil pits as expected (Fig. 9). The tested samples indicated that the first horizon of the salt rush community had the highest nitrogen content. The lower nitrogen content of the salt grass soil sample seems to support the theory that saltgrass may utilize a portion of its nitrogen to regulate the effects of high salinity. However, based on analysis of the data, it seems that neither nitrogen nor carbon is a limiting factor in SCM on the spatial distribution or concentration of vegetation. It appears that the availability of carbon and nitrogen in SCM is dictated by the seasonal flooding and the development of the halophyte species.

\section{Conclusion}

The zoning of halophyte communities in SCM seemed most likely related to how each species has adapted to the hydrogeomorphology and salinity of the marsh. The efficient use of arenchyma to promote high radial oxygen loss allows saltgrass to inhabit higher elevations and salinity. Cattails prefer to inhabit the lower elevations around the marsh channels since it cannot tolerate high salinity. The mash channels help to flush out toxins and lower the salinity. Cattails effectively utilize adventitious roots to avoid high water tables and saline soils. The salt rush communities represented an intermediate community preferring to inhabit the middle ground and areas with mild salinity.

Therefore, based on the analysis of the data, any changes to the hydrology of Scotts Creek or the geomorphology of the marsh will ultimately change the distribution 
and concentration of halophytes. Continued investigation into the soils and plant of SCM ought to be conducted prior to bridge reconstruction in order to improve our knowledge and create a base line data set that will allow natural resource managers to monitor any changes that may occur during and after bridge reconstruction. 
Chapter 4: The Investigation of Sulfate Reduction in Scotts Creek Marsh

\section{Introduction}

Sulfur is the $14^{\text {th }}$ most abundant element on the Earth's surface and is rarely present in low enough concentrations to be considered a limiting variable for biological growth and development (Mitsch and Gosselink, 2007). Coastal salt marshes are ideal environments for the reduction of $S$ because of the abundance of $S$ to be utilized by soil microbes as an alternative terminal electron acceptor, typically high soil organic matter content, and low oxidation-reduction (redox) potentials due to daily or seasonal flooding (Rabenhorst and James, 1992). Sulfur additions, losses, transformations, and translocations play a critical role in the functions and services provided by coastal salt marshes. Sulfur typically acts as the primary electron acceptor for anaerobic microbes in coastal salt marsh soils; therefore, a major portion of the below-ground flow of energy cycles through reduced S compounds mediated by soil microbial respiration (Mitsch and Gosselink, 2007).

It has been estimated that the reduction of S can range from 1000 to $2000 \mathrm{~g}$ $\mathrm{S} / \mathrm{m}^{2} / \mathrm{yr}$ in a coastal salt marsh with S reduction accounting for $50-90 \%$ of total organic matter decomposition (Howarth and Giblin, 1983; Howarth, 1984; Howes et al., 1984). Approximately $70 \%$ the S found in natural soil systems is organic with the remaining percentage comprised of reduced inorganic sulfides like pyrite $\left(\mathrm{FeS}_{2}\right)$, dissolved $\mathrm{SO}_{4}{ }^{2-}$, and gases like hydrogen sulfide $\left(\mathrm{H}_{2} \mathrm{~S}\right)$ (Wieder and Lang, 1986, 1988; Giblin and Weider, 1992). Sulfides are anions that will typically covalently bind to another sulfides to form disulfides or react with transition metals in the environment to form octahedrally 
coordinated metal sulfides. In sulfate minerals, $\mathrm{S}$ is typically a small cation with a $6^{+}$ charge (Fanning et al., 2002).

Sulfate ions are normally tetrahedrally coordinated with four oxygens forming a valence unsatisfied molecule with a $2^{-}$charge. Like $\mathrm{N}, \mathrm{S}$ is a terminal electron acceptor and has several redox states (Mitsch and Gosselink, 2007). Therefore, the concentration and nature of sulfides and sulfates is most often dictated by the redox status of the medium they are in. Despite low S concentrations in soils, the biogeochemical cycling of the S fraction can dominate the chemistry of an environment, particularly the fate and transport of sulfide (Fanning et al., 2002).

\section{The Characteristics of Sulfide}

Sulfide $\left(\mathrm{S}^{2-}\right)$ minerals are easily oxidized in aerobic environments and are not found in high concentrations in most soils. Soils that do contain a significant amount of sulfides are usually coastal hydric soils and those that have developed over unoxidized sulfide bearing parent materials (Fanning et al., 2002). Hydric, or wetland soils, form as the result of biogeochemical processes catalyzed by soil microbes in flooded environments (USDA, 2010). To survive anaerobic environments, soil microbes utilize alternative terminal electron acceptors instead of oxygen to complete the decomposition of organic compounds for energy (Vepraskas and Faulkner, 2001).

Based on their ease of reduction and availability, if no $\mathrm{O}$ is present in the environment, microorganisms have a preference for alternative electron acceptors allowing for the predictability of coupled redox reactions in saturated soils (James and Bartlett, 2000). The order of preference for alternative electron acceptors are $\mathrm{NO}_{3}{ }^{-} / \mathrm{N}_{2}$, $\mathrm{MnO}_{2} / \mathrm{Mn}^{2+}, \mathrm{Fe}(\mathrm{OH})_{3} / \mathrm{Fe}^{2+}, \mathrm{SO}_{4}{ }^{2-} / \mathrm{H}_{2} \mathrm{~S}$ and $\mathrm{CO}_{2} / \mathrm{CH}_{4}$ (James and Bartlett, 2000). 
Therefore, transformation of sulfates to sulfides will not occur unless the conditions for reduction have been met and the pool of available $\mathrm{NO}_{3}{ }^{-}, \mathrm{Mn}^{4+}$, and $\mathrm{Fe}^{3+}$ have either been depleted or not available (Vepraskas and Faulkner, 2001).

Mediated dissimilatory reduction of sulfate by obligate sulfur anaerobes is known as sulfidization (Rabenhorst, 2001). Sulfidization pathways lead to the production of hydrogen sulfides $\left(\mathrm{H}_{2} \mathrm{~S}\right)$ (Eq. 1), organic dimethyl sulfides $\left(\left(\mathrm{CH}_{3}\right)_{2} \mathrm{~S}\right)$, and metal-based mono-, di- and polysulfides (Eqs. 2 and 3) (Rabenhorst, 2001). Monosulfides (mackinawite, $\mathrm{FeS}$ ) are a nanocrystaline sulfide that will quickly volatilize to $\mathrm{H}_{2} \mathrm{~S}$ when exposed to aerobic environments (Fanning et al., 2002). In partially oxidized environments, the ferrous $\mathrm{Fe}\left(\mathrm{Fe}^{2+}\right)$ in $\mathrm{FeS}$ can be partially oxidized to form the polysulfide, greigite $\left(\mathrm{Fe}_{3} \mathrm{~S}_{4}\right)$. Both $\mathrm{FeS}$ and $\mathrm{Fe}_{3} \mathrm{~S}_{4}$ are metastable and are often the precursors for the more thermodynamically favored disulfide, pyrite $\left(\mathrm{FeS}_{2}\right)$.

$$
\begin{gathered}
\mathrm{SO}_{4}{ }^{2-}+2 \mathrm{CH}_{2} \mathrm{O} \rightarrow \mathrm{H}_{2} \mathrm{~S}+2 \mathrm{HCO}_{3}^{-} \\
\mathrm{Fe}^{2+}+\mathrm{S}^{2-} \rightarrow \mathrm{FeS} \\
\mathrm{FeS}+\mathrm{S}^{\circ} \rightarrow \mathrm{FeS}_{2}
\end{gathered}
$$

Pyrite is a stable disulfide framboid (too small to be seen with the naked eye) with cubic habit (Fanning et al., 2002). Metal sulfides, particularly pyrite, precipitate readily in coastal soils that have contact with ocean water (Fanning et al., 2002). However, large concentrations of metal sulfide compounds can be detrimental to coastal wetland ecosystems if they are allowed to oxidize (Mitsch and Gosselink, 2007). From a natural resource perspective, the challenges of managing coastal salt marsh ecosystems with elevated concentrations of sulfide are many and often intricate (Powell and Martens, 2004). 


\section{Problems Associated with the Reduction and Oxidation of Sulfur}

The reduction of sulfates and subsequent concentration of sulfides in coastal wetlands can lead to sulfide toxicity in hydric soils (Mitsch and Gosselink, 2007). Hydrogen sulfide in high enough concentrations can be detrimental to organisms in anaerobic environments because it interferes with normal metabolic processes (Pearson and Havill, 1988; Koch et al., 1990), carbon assimilation (Pezeshki, et al., 1991), and nitrogen uptake (Bradley and Morris, 1990; Ponnamperuma, 1972). Sulfide toxicity can also inhibit both sulfur and metal micronutrient uptake in plants, such as zinc and copper, since sulfides will react quickly in solution to form metal sulfide precipitates (Mitsch and Gosselink, 2007). However, oxidation of sulfides and the production of sulfuric acid is the primary reason why most scientists and engineers study S in natural settings (Fanning

et al., 2002). Soils containing highly acidic horizons or layers affected by the oxidation of iron sulfides are known as acid sulfate soils (Powell and Martens, 2011).

When rapid oxidation of pyrite is allowed to occur, the iron disulfide is transformed and two moles of sulfuric acid is produced (Eq. 4) (Rabenhorst, 2001).

$$
\mathrm{FeS}_{2}+5 / 2 \mathrm{H}_{2} \mathrm{O} \rightarrow \mathrm{FeOOH}+2 \mathrm{H}_{2} \mathrm{SO}_{4}
$$

As a result, weathered soils and soils with low buffering capacity can become highly acidic (Rabenhorst, 2001). The acidification of coastal wetlands has become a major environmental concern in areas where anthropogenic disturbances and global climate change has disrupted the normal hydrologic regime of coastal wetlands (Lamers et al. 2013). In a review, Powells and Martens (2004) estimated that approximately 666,000 ha of Queensland, Australia, are affected by sulfuric acid soils. 
Often coastal salt marshes are destroyed to make way for development and agricultural systems that usually involves the altering of a marsh's hydrology and geomorphology. Changes to the hydrogeomorphology usually involve practices that rapidly oxidize pyrite, generating copious amounts of $\mathrm{H}_{2} \mathrm{SO}_{4}$ and dissolved iron (Powells and Martens, 2004; Burton et. al., 2011). As acidity builds and the pH drops heavy metals are dissolved and released into the soil environment. Furthermore, the hydrogeomorphology of most coastal salt marshes facilitates easy transport of heavy metals and $\mathrm{H}_{2} \mathrm{SO}_{4}$ into the surrounding environment through leaching and translocation by channels and tides. The efficient transport of these toxins can cause serious harm to organisms in the surrounding aquatic and terrestrial ecosystems (Burton et al., 2011).

\section{Research Background and Importance}

The hydrology, climate, and biogeochemistry of SCM makes it an ideal location for sulfate reduction. Historically, during the summer and fall, low flow rates of Scott's Creek and swell activities creates a sandbar which closes the mouth of the creek turning the salt marsh into an ephemeral lagoon (Hayes et al., 2008). Although the flooding of SCM is beneficial for the organisms living in the ecosystem, the rapid draining of the marsh and sudden oxidation of the saturated soils could potentially create high concentrations of sulfuric acid that can easily be transported into the surrounding ecosystem.

Furthermore, the California Department of Transportation (Caltrans) has decided that the bridge spanning the mouth of Scott's Creek along Route 1 must be replaced due to its continued degradation. To achieve their goals, changes to the hydrology of Scotts 

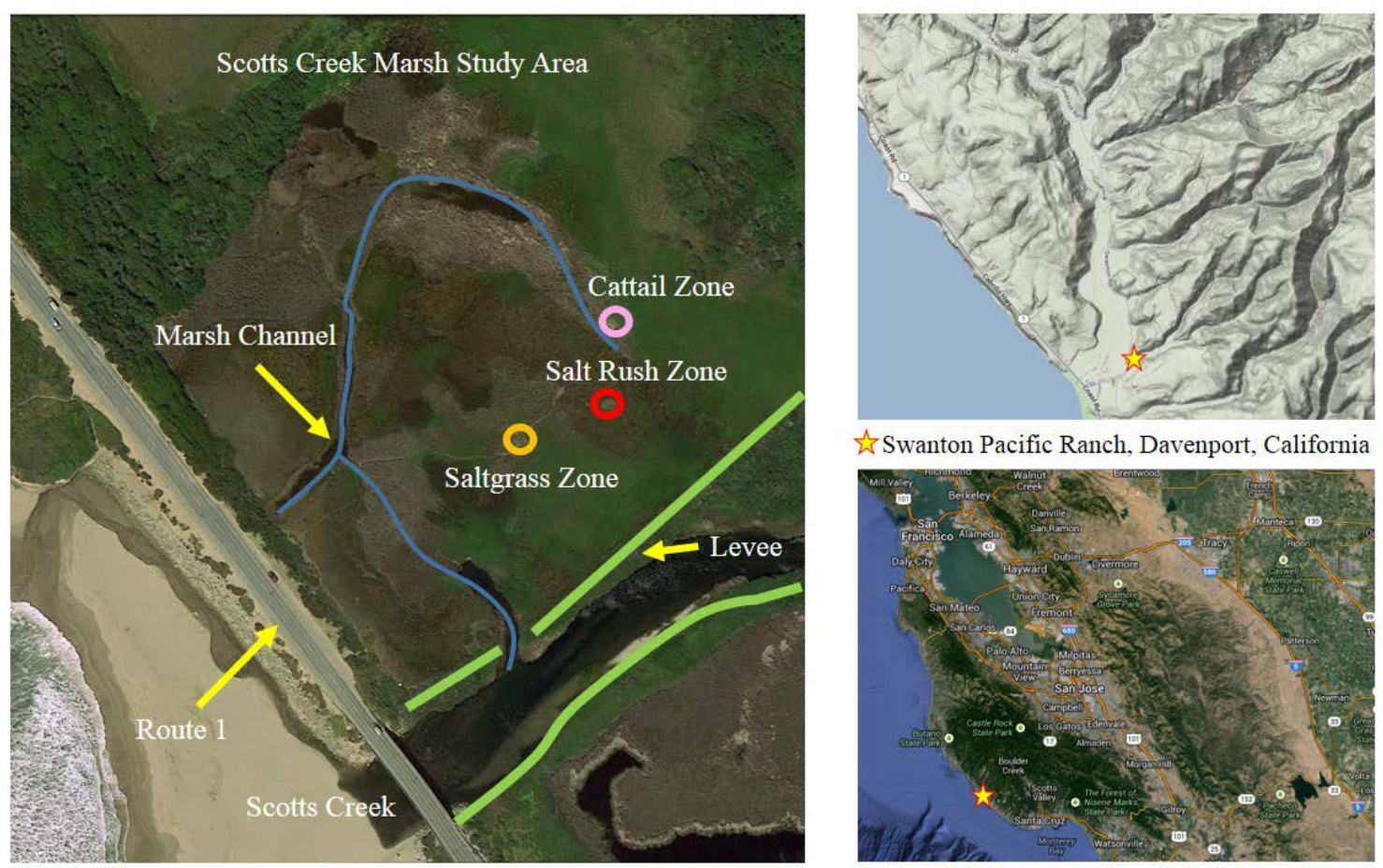

¿ Swanton Pacific Ranch, Davenport, California

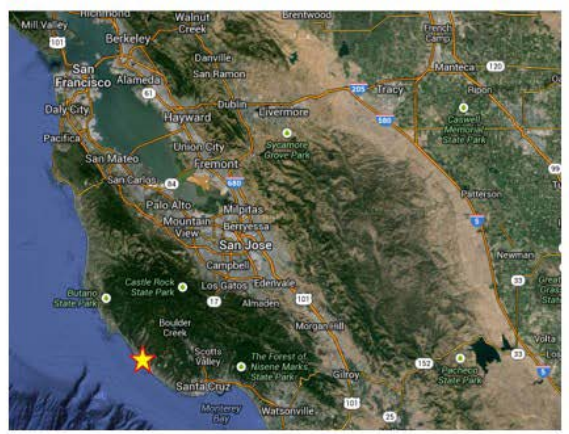

Figure 10. Location of the IRIS installation sights within the Scotts Creek Marsh study area, Swanton Pacific Ranch, Davenport, California

Creek and the geomorphology of the marsh would be required by Caltrans. Any bridge reconstruction plan should consider that any changes to the hydrogeomorphology of SCM could potentially lead to the production sulfuric acid. Given the fact that there has never been a study investigating sulfate reduction in SCM and its importance as a critical habitat, research was necessary to help develop a management plan that would improve the bridge and prevent the possible formation of acid sulfate soils.

Like most wetlands, SCM is an extremely complex ecosystem; therefore, the study focused on investigating the soil redox potential before and after the annual lagoon formation through the use an Indicators of Reduction in Soil (IRIS). Use of IRIS tubes is a simple but effective way to visually identify the redox condition in soils while mimicking the natural environment by applying synthetic iron paint onto a polyvinylchloride (PVC) tube. Since reduced iron, $\mathrm{Fe}^{2+}$, is colorless and mobile, the redox 
condition of the soil is obtained by measuring the amount of iron $\left(\mathrm{Fe}^{3+}\right)$ paint that is removed once the tubes have been extracted from the ground (Jenkinson and Franzmeier, 2005). Research conducted by Rabenhorst, Burch, and Castenson (2005) helped to improve the construction, implementation, and analysis of IRIS tubes and has since become an official technical standard for measuring redox conditions in the field by the National Technical Committee on Hydric soils (NTCHS) (USDA, 2010).

The affordability and ease of use make IRIS tubes ideal for delimitating hydric soils that are problematic and difficult to identify without the use of specialized equipment (Castenson and Rabenhorst, 2006). The ability to react with $S^{2-}$ to form iron monosulfides coatings is an additional attribute of IRIS tubes (Vasilas et al., 2013). Reported originally by Stolt in 2005, Keller, Megonigal, and Rabenhorst (2010) developed a technique to detect and measure $\mathrm{S}^{2-}$ concentrations using an IRIS panel. Iron coated panels were inserted into marsh pores for a specific period of time (5 or 60 minutes), removed, and analyzed using a scanner and imagery software (Rabenhorst et al., 2010). If standard images are prepared using a $\mathrm{Na}_{2} \mathrm{~S}$ solution adjusted to $\mathrm{pH} 7.5$, a quantitative assay can be used to determine $S^{2-}$ concentrations (Rabenhorst et al., 2010). The advantages of using IRIS tubes to measure the reduction of sulfate are the cost, low failure rate (does not require power and no moving parts), ease of installation and extraction, and practicality (Jenkinson and Franzmeier, 2005; Rabenhorst and Burch, 2006; Castenson and Rabenhorst, 2006; Vasilas, 2013).

\section{Objectives}

Since little has been published on the effectiveness of IRIS tubes to indicate the presence of monsulfides, the objective of our study was to investigate the effectiveness of 
IRIS to indicate the presence of sulfides. Based on the hydrogeomorphology of Scott's Creek Marsh and work conducted by Stolt and Rabenhorst, it was hypothesized that (i) the annual flooding of SCM would produce the right conditions for the reduction of sulfate and (ii) the use of IRIS tubes would be an effective way to investigate the redox condition of the soils within the marsh.

\section{Methods and Materials}

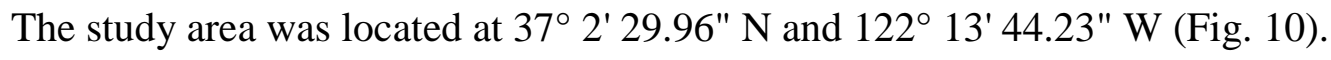
Geologically, SCM lies on the Salinian structural block bounded by Sur-Nacmiento and the San Andreas faults (Stanley, 1984). The Salinian block consists of mostly Cretaceous quartz diorite covered by Mesozoic arkosic sandstone of the Santa Maria Formation, which itself is covered by the upper Miocene Santa Cruz mudstone (Brabb, 1989; Stanley, 1984). The mean annual precipitation for Davenport, CA is $801 \mathrm{~mm}$ (32 inches) and the mean annual maximum and minimum temperatures are $20^{\circ} \mathrm{C}\left(68{ }^{\circ} \mathrm{F}\right)$ and $8{ }^{\circ} \mathrm{C}$ $\left(47^{\circ} \mathrm{F}\right)$ respectively (NOAA, 2013). The low precipitation for 2013 caused the mouth of Scott's Creek to close and transforming it into a lagoon on June $8^{\text {th }}$.

The IRIS tubes were constructed by first making synthetic iron paint prepared by following the procedures established by Jenkinson and Franzmeier (2005), Rabenhorst and Burch (2006), and Castenson and Rabenhorst (2006). Sixteen grams of anhydrous $\mathrm{FeCl}_{3}$ was dissolved and continuously stirred in $500 \mathrm{~mL}$ of distilled water. Next, approximately $370 \mathrm{~mL}$ of $1 \mathrm{M} \mathrm{KOH}$ was added to the solution until the $\mathrm{pH}$ reached 12 . After the solution sat for 30 minutes, the paint was transferred into centrifuge tubes. The paint was centrifuged three times at $1000 \mathrm{rpm}$ for five minutes at a time. Between each cycle, the supernatant was discarded and distilled water added. 
After the third centrifuge, the concentrated paint was transferred into dialysis tubing and placed into a distilled water bath for three days. Paint was then transferred into a storage container and placed in a refrigerator for a week. Next, a ten foot, 1 inch diameter, polyvinyl-chloride tube was cut into five, $60 \mathrm{~cm}$ tubes. Each tube was then sanded using 220 grit sandpaper to remove any impurities and to provide a rough surface for the iron paint to adhere to. The tubes were then cleaned with distilled water and allowed to dry. Once the paint was ready, $50 \mathrm{~cm}$ of each tube was painted onto the tubes.

Three installation zones were chosen for the study and identified based on the dominant vegetation as the saltgrass, salt rush, and cattail zones (Fig. 10). Five IRIS tubes were installed weekly in each zone and allowed to remain in the ground for minimally three weeks at a time. The installation and withdrawal began on April 6 to July 212013. Since the tubes are circular, once removed from the ground, three photographs were taken for each tube and later stitched together to form a single continuous image. The percent oxidation and reduction that occurred on each tube was analyzed by importing the IRIS images into Adobe Photoshop CS5.1. The total number of pixels that comprised the photograph was recorded first by using the histogram panel. Then, by using the color range tool, the number of pixels that represented the reduction of iron and sulfur were selected. Finally, the number of pixels selected by the color range tool was divided by the total number of pixels that comprised the image to obtain the percentage of oxidation and reduction that had occurred.

\section{Results and Discussion}

Figures 11, 12, and 13 show the percentage of iron paint that remained oxidized, percentage of iron paint that was reduced and translocated, and percentage of the reduced 
sulfate for every IRIS tube at each site. Prior to the flood event, very little iron paint reduction actually occurred. Before the lagoon phase of the marsh, the tube with the greatest reduction of iron (48\%) was tube E from week 1 located within the cattail zone (Fig. 13). Twenty four tubes showed sulfate reduction; however, the reduction that did occur was limited and the range of reduction was only 1 to $17 \%$ (Figs. 11, 12, 13).

The reduction that did proceed during the first six weeks of the study occurred mostly in the cattail zone which had a higher water table due to its location near the marsh channel and lower elevation. The tubes placed in the cattail zone reduced more during the first five weeks because it had the lowest elevation out of the three zones; therefore, the soils were saturated for a longer period of time allowing greater reduction to occur (Fig. 13). These results were expected since reduction will not occur unless the soil is saturated for a sustained period of time.

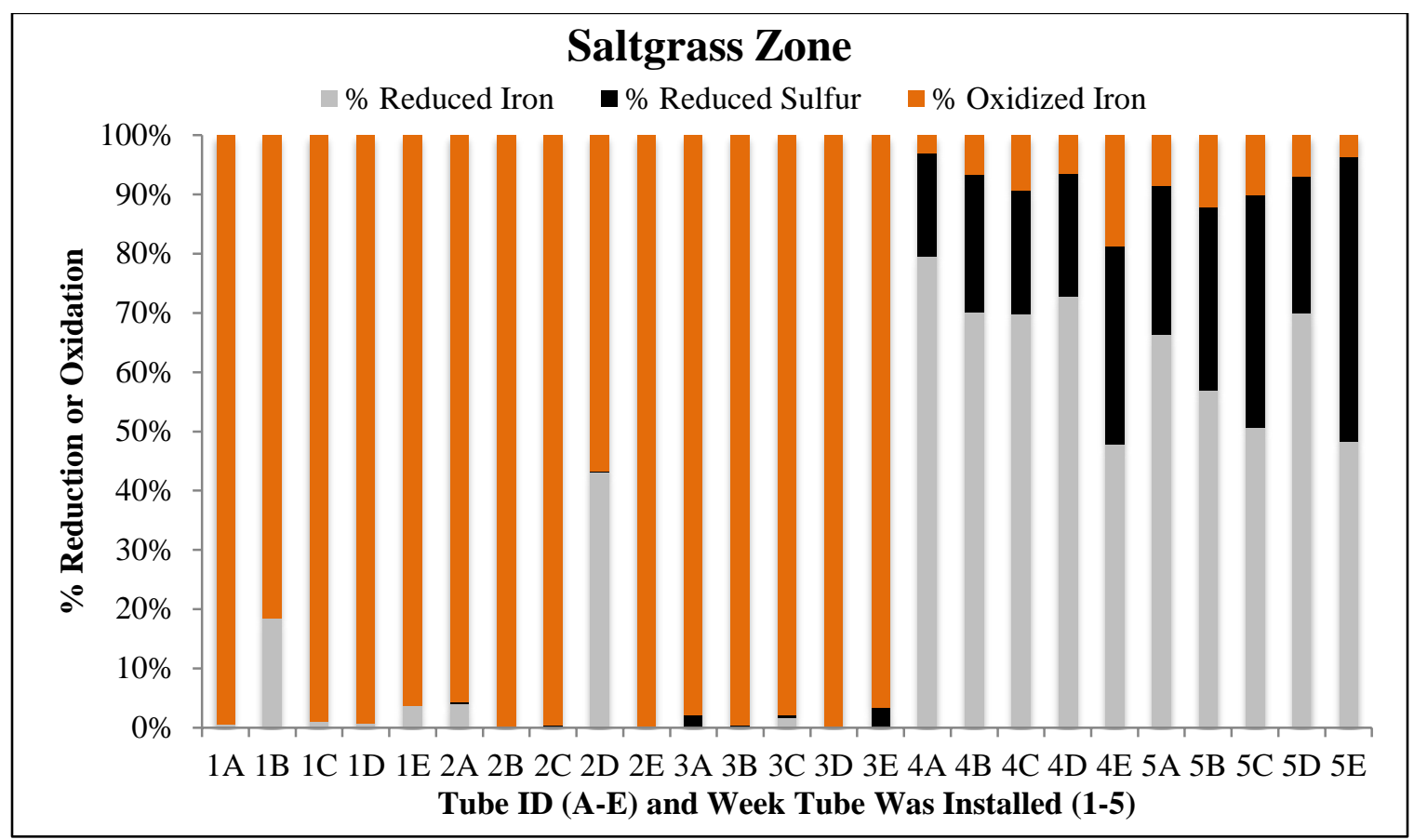

Figure 11. The results of the all the IRIS tubes by week from April 6 - July 21, 2013 within the saltgrass zone, Swanton Pacific Ranch, Davenport California 


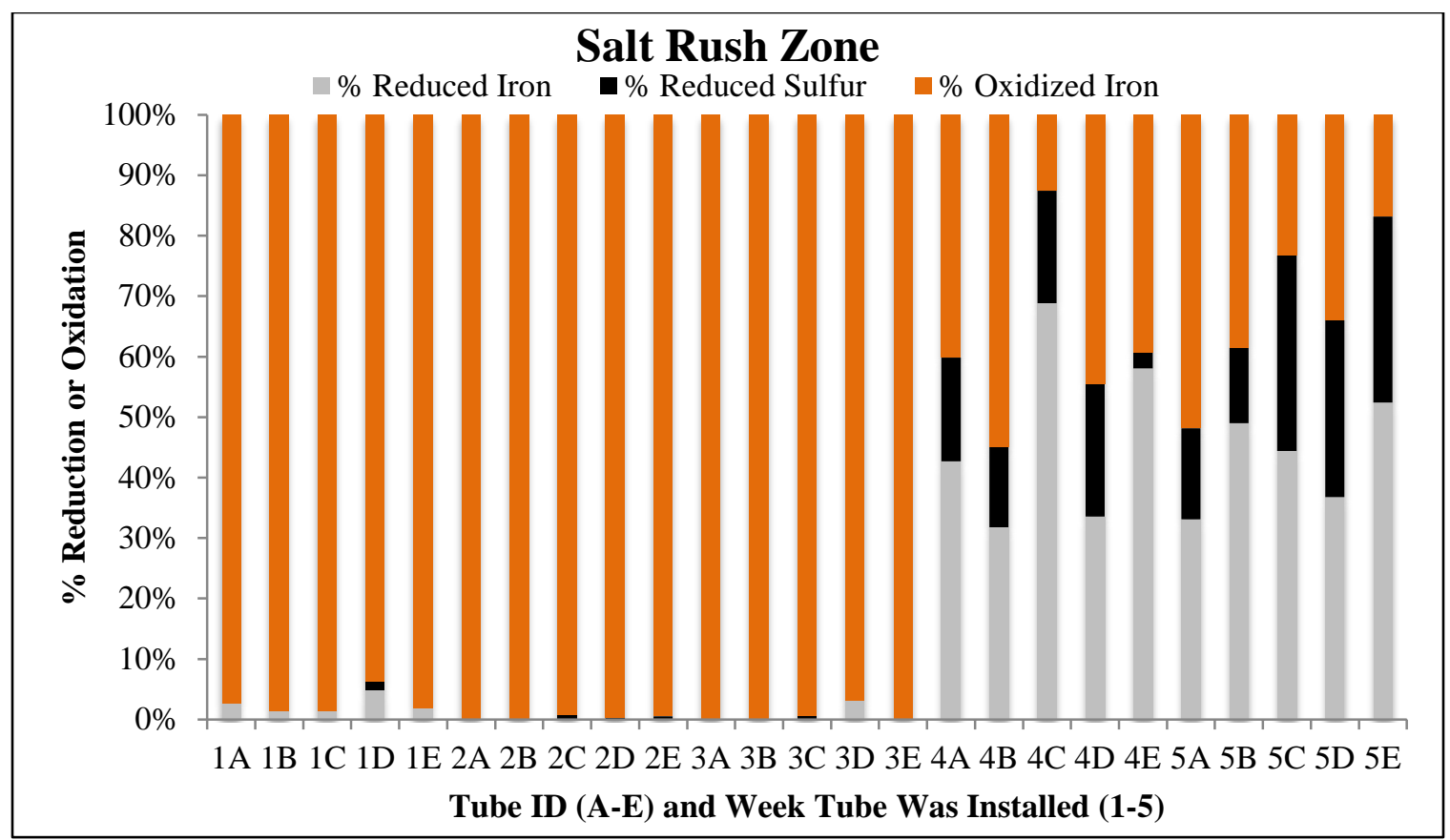

Figure 12. The results of the all the IRIS tubes by week from April 6 - July 21, 2013 within the salt rush zone Swanton Pacific Ranch, Davenport California

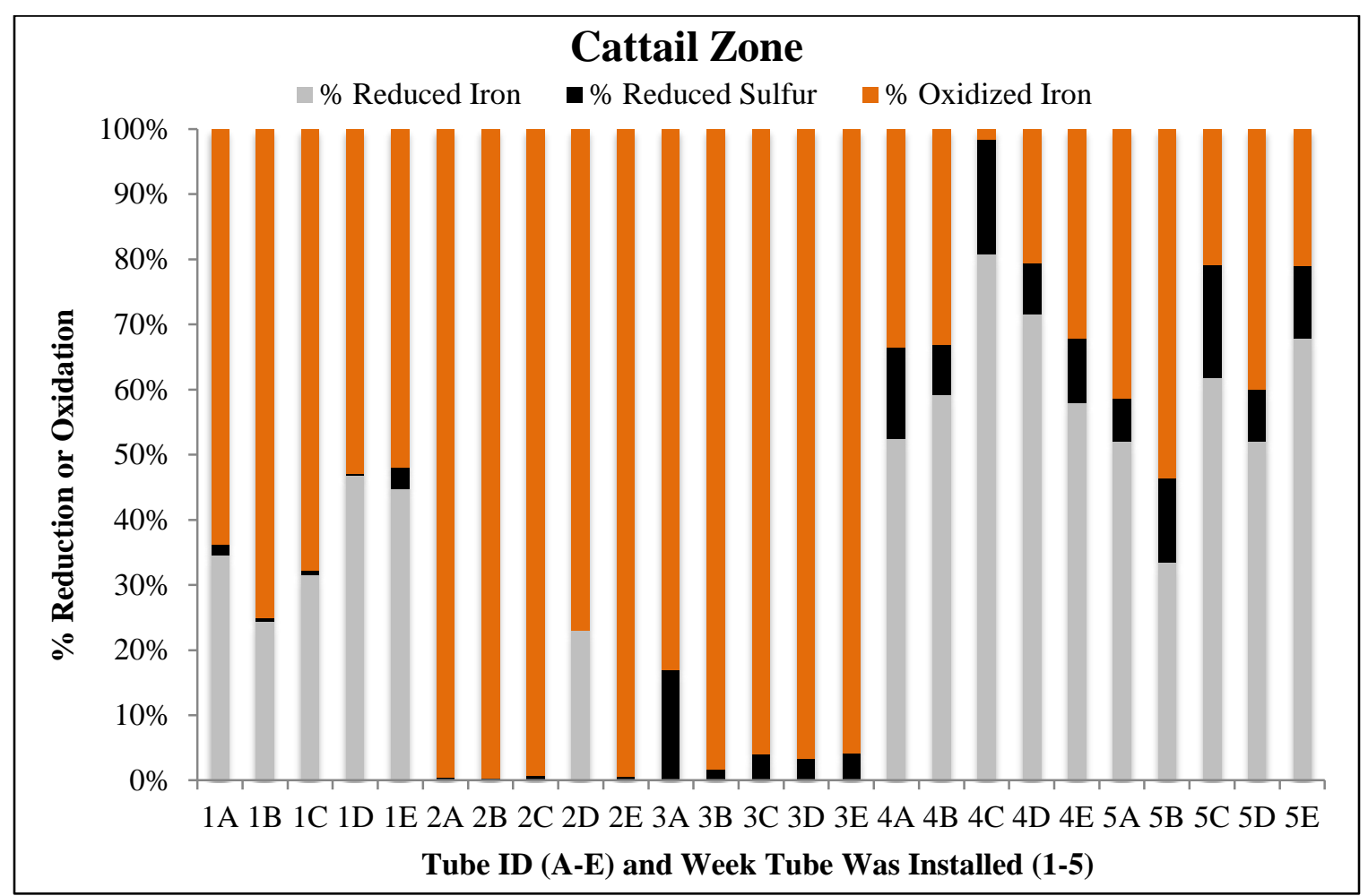

Figure 13. The results of the all the IRIS tubes by week from April 6 - July 21, 2013 within the cattail zone Swanton Pacific Ranch, Davenport California 
The tubes that were withdrawn after the mouth of Scott's Creek closed showed significant reduction since the soils of the marsh were flooded. The total average reduction that occurred for all the tubes installed during weeks 4 and 5 was $64 \%$. The average reduction for all thirty tubes indicates that approximately $45 \%$ of the reduction that occurred was iron based and 19\% sulfate. The tubes that reduced the most were those that were placed in the saltgrass zone during week five which had an average of $40 \%$, followed closely by the tubes in the cattail zone (38\%). The area that had the least amount of reduction was the salt rush zone with an average of $27 \%$.

The reduction of sulfate occurred in all three sites; however, the most occurred at the salt grass zone. The average reduction of all five tubes in the saltgrass zone for the tubes installed during week 4 and 5 were extremely high at 91 and 92\%. The first set of IRIS tubes pulled after the closure of Scott's Creek indicated that the average sulfate reduction of all 15 tubes was only $16 \%$ compared to the $60 \%$ of iron reduction. However, the percent average sulfate reduction of the second set of tubes pulled increased to 23\% compared to $52 \%$ iron reduction.

\section{Conclusion}

The hydrogeomorphology of SCM created an ideal environment for sulfate reduction. The annual conversion of the marsh in June to a lagoon created sustained saturated soil conditions which facilitated the reduction of sulfate into sulfide. Under these conditions, the IRIS tubes proved effective as an indicator of sulfate reduction. Any future study using IRIS tubes to indicate sulfate reduction ought to create a set of standards as outline by Rabenhorst et al. (2010). By creating a standard, the concentration of sulfides can be derived. Knowledge that reduction of sulfate occurs at SCM under 
saturated conditions and the challenges associated with managing such a system illuminates the need for further study. Any bridge reconstruction plan that would cause rapid oxidation to the soils is not encouraged until a further biogeochemical studies have been conducted. 
Chapter 5: Assessment of IRIS Tubes Using Adobe Photoshop CS 5.1

\section{Introduction}

Use of IRIS tubes is a simple but effective way to visually identify the redox condition in soils while mimicking the natural environment by applying synthetic iron paint onto polyvinyl-chloride (PVC) tube. Since reduced iron, $\mathrm{Fe}^{2+}$, is colorless and mobile, the redox condition of the soil is obtained by measuring the amount of iron $\left(\mathrm{Fe}^{3+}\right)$ paint that is removed once the tubes have been extracted from the ground (Jenkinson and Franzmeier, 2005). Research conducted by Rabenhorst, Burch, and Castenson (2005) helped to improve the construction, implementation, and analysis of IRIS tubes and has since become an official technical standard for measuring redox conditions in the field by the National Technical Committee on Hydric soils (NTCHS) (USDA, 2010).

The affordability and ease of use make IRIS tubes ideal for delimitating hydric soils that are problematic and difficult to identify without the use of specialized equipment (Castenson and Rabenhorst, 2006). The ability to react with $\mathrm{S}^{2-}$ to form Fe monosulfides coatings is an additional attribute of IRIS tubes (Vasilas et al., 2013). Reported originally by Stolt in 2005, Rabenhorst, Megonigal, and Keller (2010) developed a technique to detect and measure $S^{2-}$ concentrations using an IRIS panel. Iron coated panels were inserted into marsh pores for a specific period of time (5 or 60 minutes), removed, and analyzed using a scanner and imagery software (Rabenhorst et al., 2010). If standard images are prepared using a $\mathrm{Na}_{2} \mathrm{~S}$ solution adjusted to $\mathrm{pH} 7.5$, a quantitative assay can be used to determine $S^{2-}$ concentrations (Rabenhorst et al., 2010). The advantages of using IRIS tubes to measure the reduction of sulfate are the cost, low failure rate (does not require power and no moving parts), ease of installation and 
extraction, and practicality (Jenkinson and Franzmeier, 2005; Rabenhorst and Burch, 2006; Castenson and Rabenhorst, 2006; Vasilas, 2013).

The advantages of using IRIS tubes to measure the reduction of S are the cost, low failure rate (does not require power and no moving parts), ease of installation and extraction, and practicality (Jenkinson and Franzmeier, 2005; Rabenhorst and Burch, 2006; Castenson and Rabenhorst, 2006; Vasilas, 2013). However, the increased use of IRIS tubes draws attention to the need for accurate measurement of $\mathrm{Fe}^{3+}$ (Rabenhorst, 2011). Early measurements of the reduction that occurred on IRIS tubes were done by importing a stitched photograph of an IRIS tube into a visual analysis tool such as Image Tool 3 (IT3) (University of Texas Health Science Center in San Antonio, 1995). The reduction was measured by drawing polygons around reduced areas and calculating a percentage from the photograph (Rabenhorst and Burch, 2006; Castenson and Rabenhorst, 2006; Rabenhorst et al., 2007). Although effective, this method requires time and can be difficult when dealing with reduced areas that are more organic in nature and not uniform.

Berkowitz and Salle (2011) utilized a bianarization image analysis tool and counted the number of black and white pixels to get a percentage. While effective, the use of this method poses problems when investigating $S$ reduction since monosulfides are a range of black colors (Rabenhorst et al., 2010). However, by using a gray output channel filter in Adobe Photoshop CS2 version 9.0.2, Keller, Megonigal, and Rabenhorst (2010) were successful in creating a monochrome image that could then be imported into an image tool and analyzed. The most useful innovation of late has been the use of a 
transparent mylar grid with a pre-specified measurement that is placed around the top 15 cm of an IRIS tube (Rabenhorst, 2011).

The mylar is flat making it easy to record, analyze, and store (Rabenhorst, 2011). When IRIS tubs are pulled from the ground, the $15 \mathrm{~cm}$ gridded sheet of mylar is wrapped around the tube with two rubber bands (Rabenhorst, 2011). The reduced areas are marked by filling in the grid with a maker and counted giving you a percentage of reduction (Rabenhorst, 2011). This method is a quick and reliable technique designed for studies investigating and delineating hydric (wetland) soils (Rabenhorst, 2011).

With practice, Rabenhorst (2011) estimated that a 15-cm section of IRIS tube requires at least 8 minutes to complete when using a mylar gird. Since most researchers use $50 \mathrm{~cm}$ IRIS tubes, it would take approximately 25 minutes to completely analyze a single tube. Since the technical standard requires the installation and analysis of five tubes, the total time for one study site could take up to 2 hours to complete. Furthermore, when studying S reduction, time is of the essence since the oxidation of monsulfides can be extremely rapid. Though the use of mylar grids are extremely useful, there will always be a need for quick and reliable computer analysis for research and the creation of standards.

Currently there is no single standard computer method for analyzing IRIS tubes. Previously most people have used IT3; however, this program is out dated and cannot be used on computers with current operating systems (Castenson and Rabenhorst, 2006). The latest version of Adobe Photoshop CS5.1 (AP5) has several features that make the analysis of IRIS tubes fast, and easy particularly those used for S reduction experiment. Not only is AP5 an excellent tool for cleaning, cropping, and stitching IRIS photographs, 
the gray output channel filter, histogram tab, and color range selection option make it an efficient option for proper IRIS tube analysis.

\section{Objectives}

The objective of the study was to evaluate the viability of AP5 to analyze IRIS tubes utilized during a S reduction experiment. Based on research conducted by Berkowitz and Salle (2011) and Keller, Megonigal, and Rabenhorst (2010) it was hypothesized that the use of AP5 will facilitate the creation of a computer-based technical standard using pixel percentage and red, green, blue (RGB) color ranges.

\section{Methods and Materials}

The IRIS tubes were constructed by first making synthetic $\mathrm{Fe}^{3+}$ paint prepared by following the procedures established by Jenkinson and Franzmeier (2005), Rabenhorst and Burch (2006), and Castenson and Rabenhorst (2006). Sixteen grams of anhydrous $\mathrm{FeCl}_{3}$ was dissolved and continuously stirred in $500 \mathrm{~mL}$ of distilled water. Next, approximately $370 \mathrm{~mL}$ of $1 \mathrm{M} \mathrm{KOH}$ was added to the solution until the $\mathrm{pH}$ reached 12. After the solution sat for 30 minutes, the paint was transferred into centrifuge tubes. The paint was centrifuged three times at $1000 \mathrm{rpm}$ for five minutes at a time. Between each cycle, the supernatant was discarded and distilled water added.

After the third centrifuge, the concentrated paint was transferred into dialysis tubing and placed into a distilled water bath for three days. Paint was then transferred into a storage container and placed in a refrigerator for a week. Next, a ten foot, 1 inch diameter, polyvinyl-chloride tube was cut into five, $60 \mathrm{~cm}$ tubes. Each tube was then sanded using 220 grit sandpaper to remove any impurities and to provide a rough surface 
for the $\mathrm{Fe}^{3+}$ paint to adhere to. The tubes were then cleaned with distilled water and allowed to dry. Once the paint was ready, $50 \mathrm{~cm}$ of each tube was painted onto the tubes.

Three installation zones were chosen for the study and identified based on the dominant vegetation as the saltgrass, salt rush, and cattail zones (Fig. 14). Five IRIS tubes were installed weekly in each zone and allowed to remain in the ground for minimally three weeks at a time. The installation and withdrawal began on April 6 to July 212013. Since the tubes are circular, once removed from the ground, three photographs were taken for each tube and later stitched together to form a single continuous image.

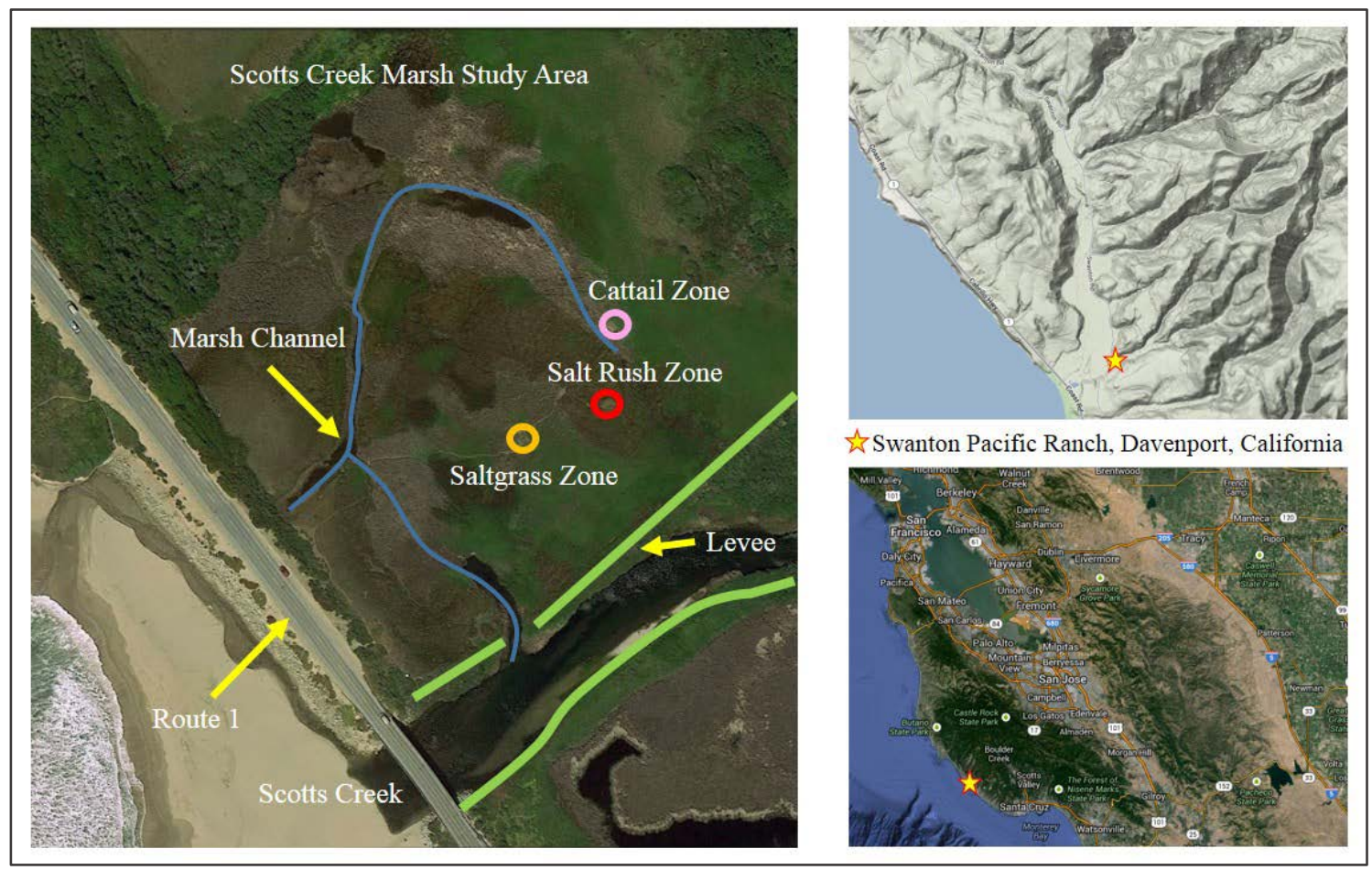

Figure 14. Location of the IRIS installation sights within the Scotts Creek Marsh study area, Swanton Pacific Ranch, Davenport, California

The percent oxidation and reduction that occurred on each tube was analyzed by importing the IRIS images into Adobe Photoshop CS5.1 (AP5). To standardize the process, a color range was established by using the color sampler tool and the histogram window (Fig. 15, 16). Since S reduction can be difficult to discern, a gray output channel 
filter was utilized as suggested by (Fig. 17, 18) (Rabenhorst et al., 2010). It was decided that monsulfides had a red, green, blue (RGB) range of $0-100$ (R), 0 - 100 (G), and 0 100 (B). The $\mathrm{Fe}^{3+}$ had a color range of $175-225$ (R), $100-125$ (G), and $20-80$ (B). The $\mathrm{Fe}^{2+}$ RGB range was 200+ (R), 200+ (G), and 200+ (B). However, after some preliminary testing, it was decided the original color range did not take into consideration the intermediate orange or black/gray colors.

Therefore, the RGB ranges were modified to include the intermediate orange/red color with a range of 200+ (R), $150-200$ (G), and $100-165$ (B). The intermediate gray/black RGB color range was more difficult to assign; however, we found the ranges to be 125 - 200 (R), 125 - 200 (G), and 125 - 200 (B). As well, all of the numbers for the intermediate gray/black RGB colors were within 5 points of each other. For example, 198 (R), 196 (G), 197 (B) are all within the same 5 points of each other.

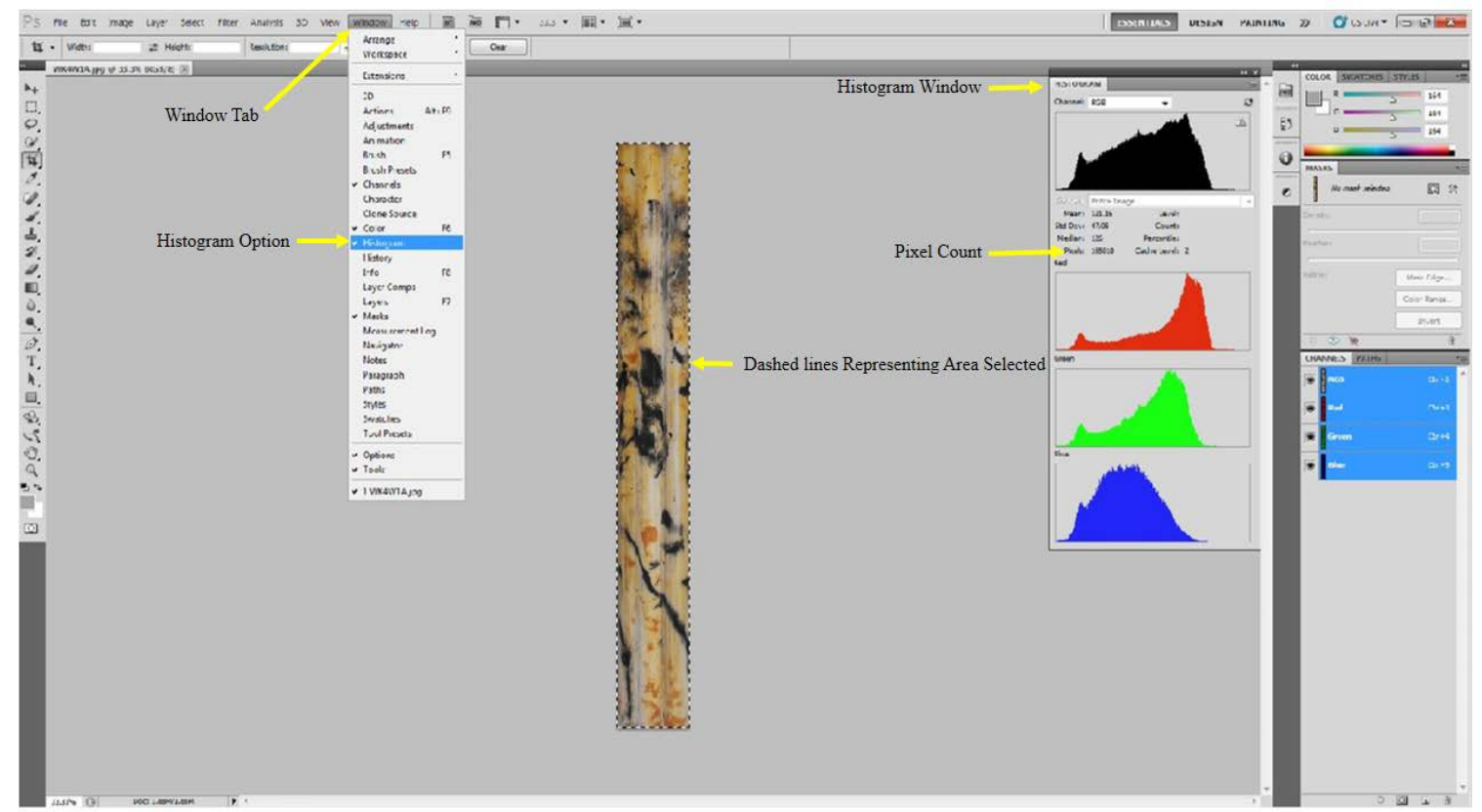

Figure 15. To obtain total pixel count of the entire IRIS image, (i) open the histogram window by clicking on the windows tab and selecting the histogram option, (ii) the press ctl+A to select the entire image, (iii) the total pixel count is located in the histogram window 


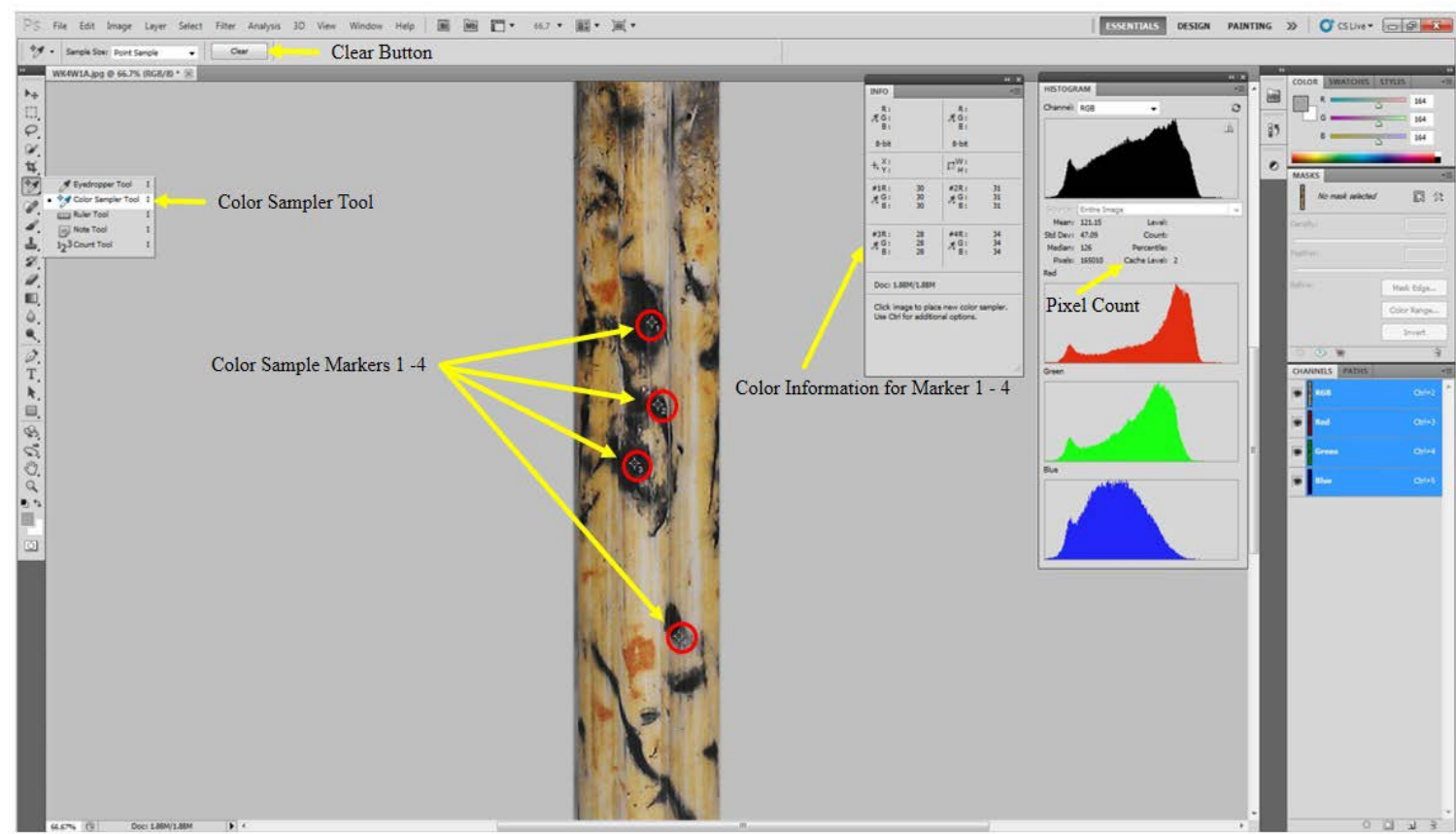

Figure 16. To identify the proper range of colors for oxidation and reduction, (i) open the color sampler tool, the color information window will open, (ii) identify the proper RGB value by gliding the eye dropper icon over the image and reading the value in the color information window, (iii) once proper value is identified, left click eye dropper and place marker, you can choose up to four

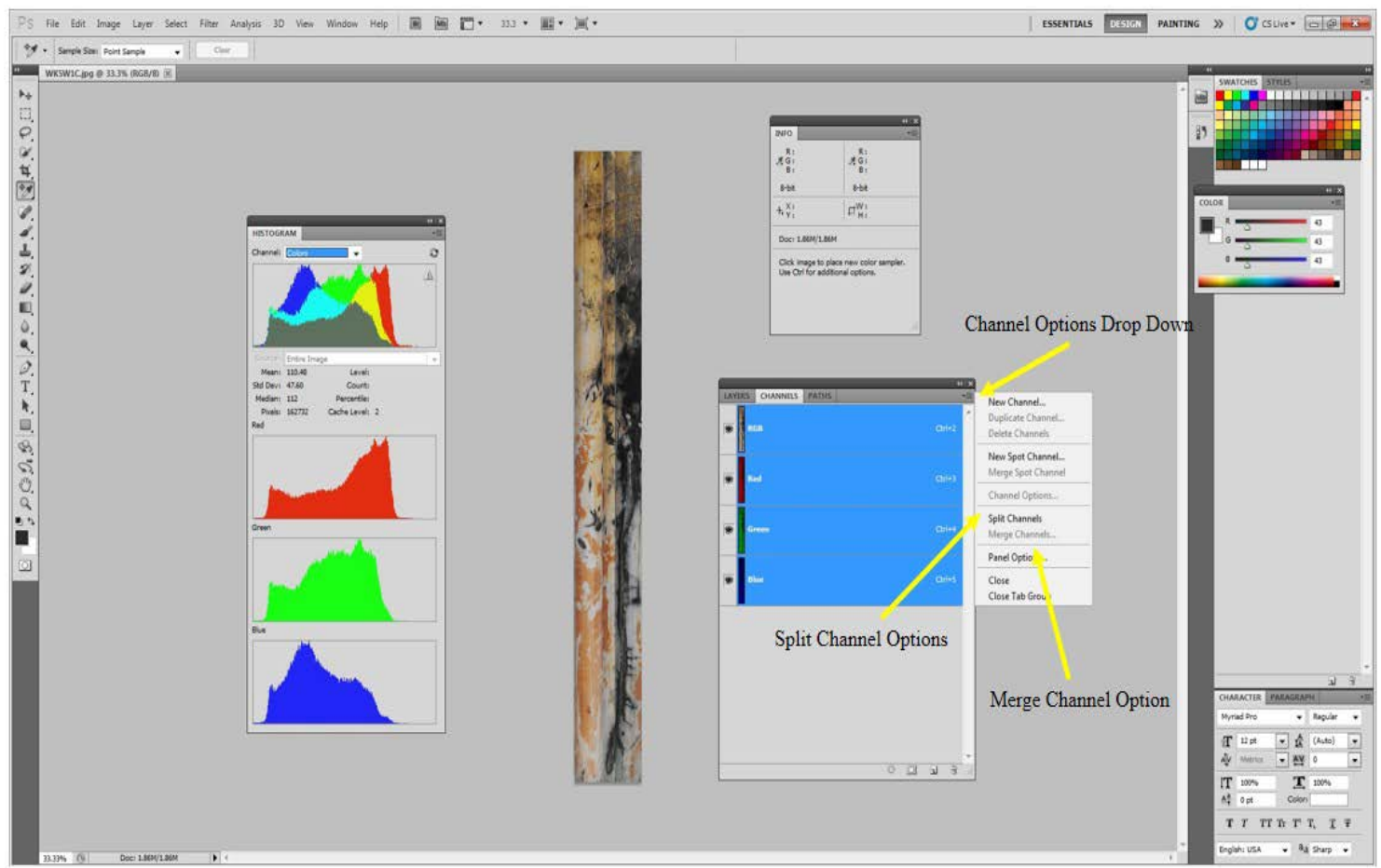

Figure 17. To obtain a more accurate representation of $\mathrm{S}$ reduction, you can create a grey channel filter, (i) click the windows tab and select channel options, (ii) once the channel window is open, click on the channel options drop down, (iii) click split channel options, (iv) once the channel has been split, click merge channel, (v) a grey channel filter will be applied 


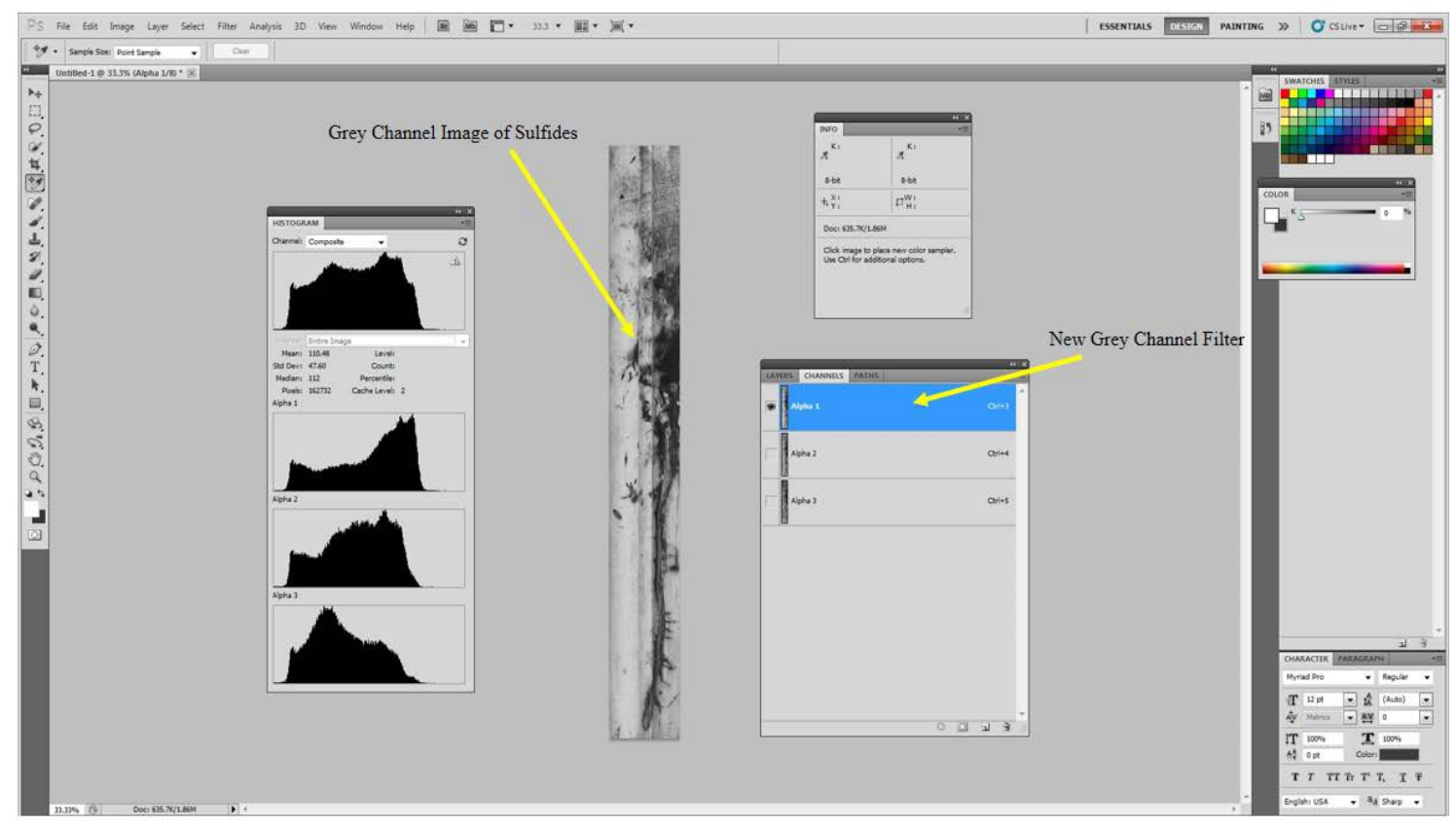

Figure 18. Once the grey channel filter has been created, the color sampler and color range tools can be used for more accurate measurements

After the range of colors had been established, the total number of pixels for the photograph was calculated by using the "select all” command and reading the pixel count on the histogram panel (Fig. 15, 19). The color range selection tool was used to select only the pixels that fell within the established range of colors for the reduction of $\mathrm{Fe}^{3+}$ and S (Fig. 19, 20). The reduction on each tube was calculated by dividing the total number of reduced pixels over the total number of pixels that comprised the photograph.

The data from the computer analysis were then compared to the responses of fifteen undergraduate soil science students. Each students was given a set of prepared IRIS images and a copy of the percent area covered guide from the Field Book for Describing and Sampling Soils version 3.0 (Schoeneberger et al., 2012). The students then visually estimated the percent $\mathrm{Fe}^{3+}$ and $\mathrm{S}$ of the images they were provided. Each IRIS image was viewed independently by three students and their averages were 
calculated. The student averages were then compared to the averages generated through the use of AP5.

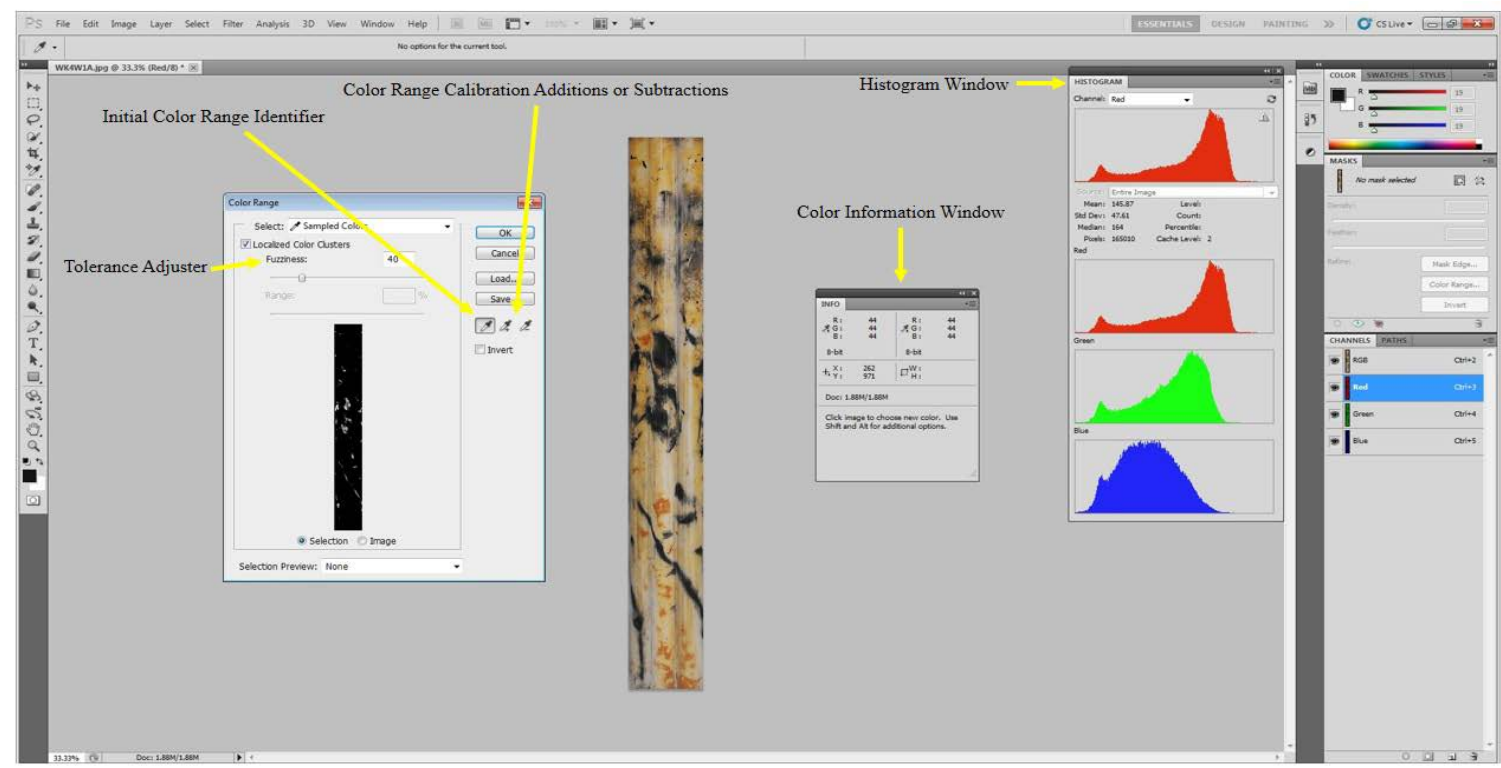

Figure 19. Once a color range has been established, the number of pixels within the color range can be quantified by using the color range selection tool, (i) click the selcetion tab and click the color range option, (ii) click on the intial color range identifier icon, (iii) glide mouse over the image and choose the desired RGB color by looking on the color information window or histogram window, once a desire value is found, click on the image to intialize the calibration, (iv) next click on the additions button and continue to add more colors within the desired RGB range, (v) once the total range of colors has been added, click OK to allow the program to select the desired pixels

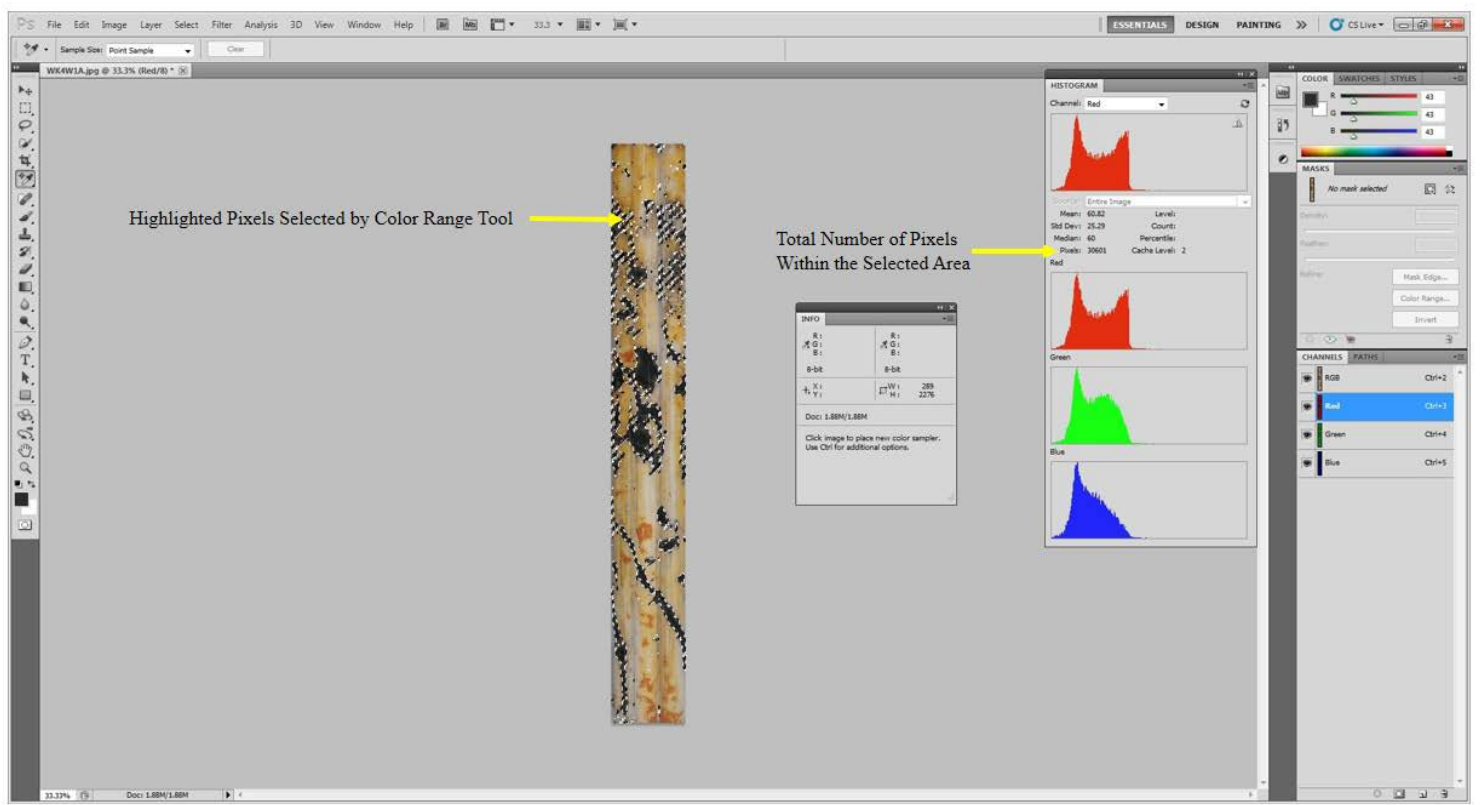

Figure 20. The color range selection tool will select and highlight the pixels entered, the total number of selected pixels within the desired color range is found in the histogram window 


\section{Results and Discussion}

Figures 21, 22, and 23 show the percentage of $\mathrm{Fe}^{3+}$, percentage of $\mathrm{Fe}^{2+}$ that was reduced and translocated, and percentage of the reduced S for every IRIS tube at each site. Prior to the flood event, little $\mathrm{Fe}^{3+}$ reduction actually occurred. Before the lagoon phase of the marsh, the tube with the greatest reduction of Fe (48\%) was tube $\mathrm{E}$ from week 1 located within the cattail zone (Fig. 23). Twenty four tubes showed S reduction; however, the reduction that did occur was limited and the range of reduction was only 1 to $17 \%$ (Figs. 21, 22, 23).

The tubes that were withdrawn after the mouth of Scotts Creek closed showed significant reduction since the soils of the marsh were flooded. The total average reduction that occurred for all the tubes installed during weeks 4 and 5 was $64 \%$. The average reduction for all thirty tubes indicates that approximately $45 \%$ of the reduction

that occurred was $\mathrm{Fe}^{2+}$ based and $19 \% \mathrm{~S}$. The tubes that reduced the most were those that were placed in the saltgrass zone during week five which had an average of $40 \%$, followed closely by the tubes in the cattail zone (38\%). The area that had the least amount of reduction was the salt rush zone with an average of $27 \%$.

The use of AP5 was effective in rapidly determining the percentage of reduction; however, modification to the initial color range was needed. It was discovered that photographic techniques played a role in the RGB ranges, particularly if a shadow was casted along the edges of the image. Shadows lowered the RGB values increasing the RGB range. With good photographic techniques and the added step of using the auto color option, we believe that the ranges of RGB can be lowered. Furthermore, the 
advancements in battery operated hand scanners could pave the way for a more rapid and accurate way of obtaining an image of IRIS tubes in the field.

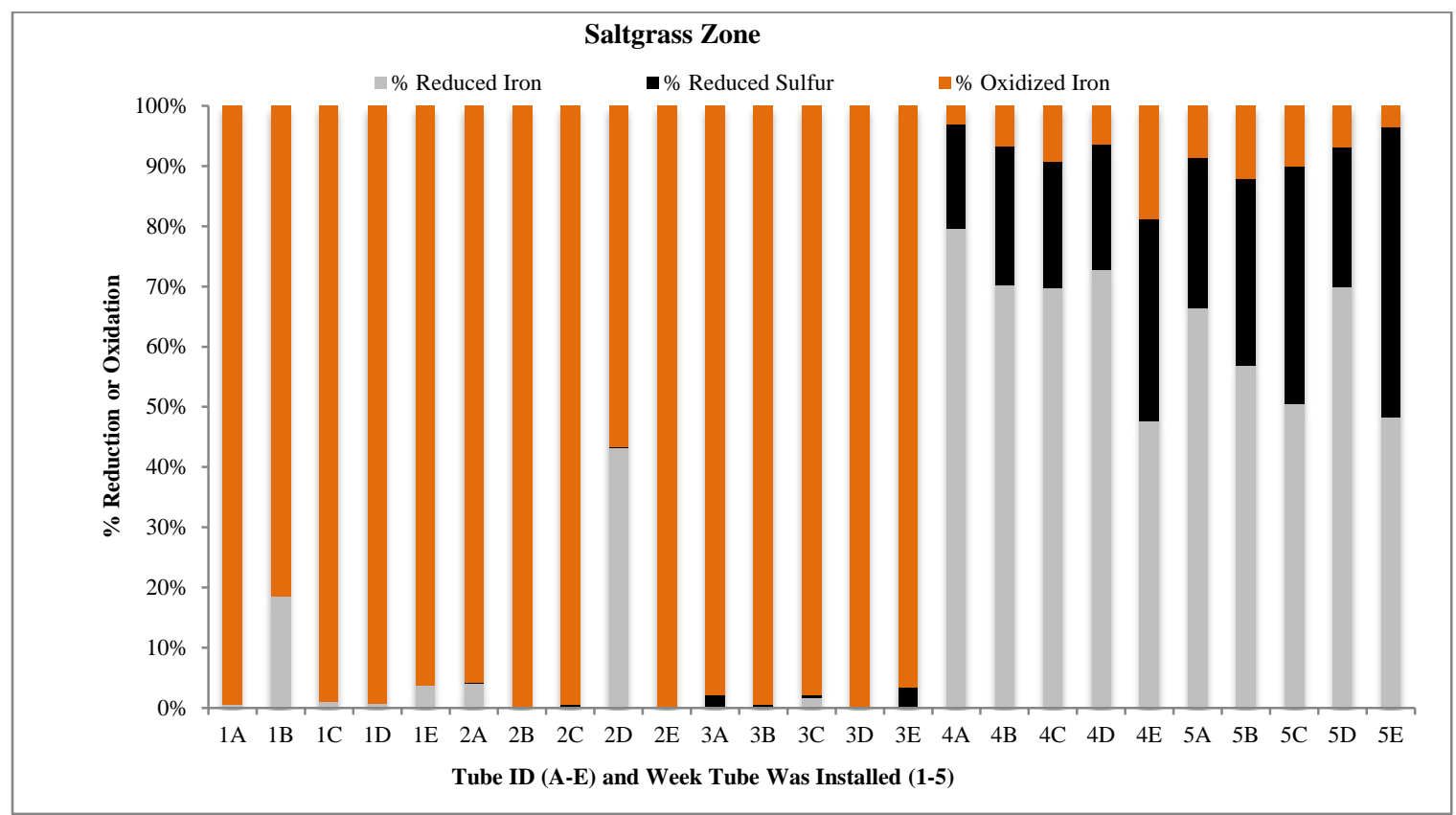

Figure 21. The results of the all the IRIS tubes by week from April 6 - July 21, 2013 within the saltgrass zone, Swanton Pacific Ranch, Davenport California

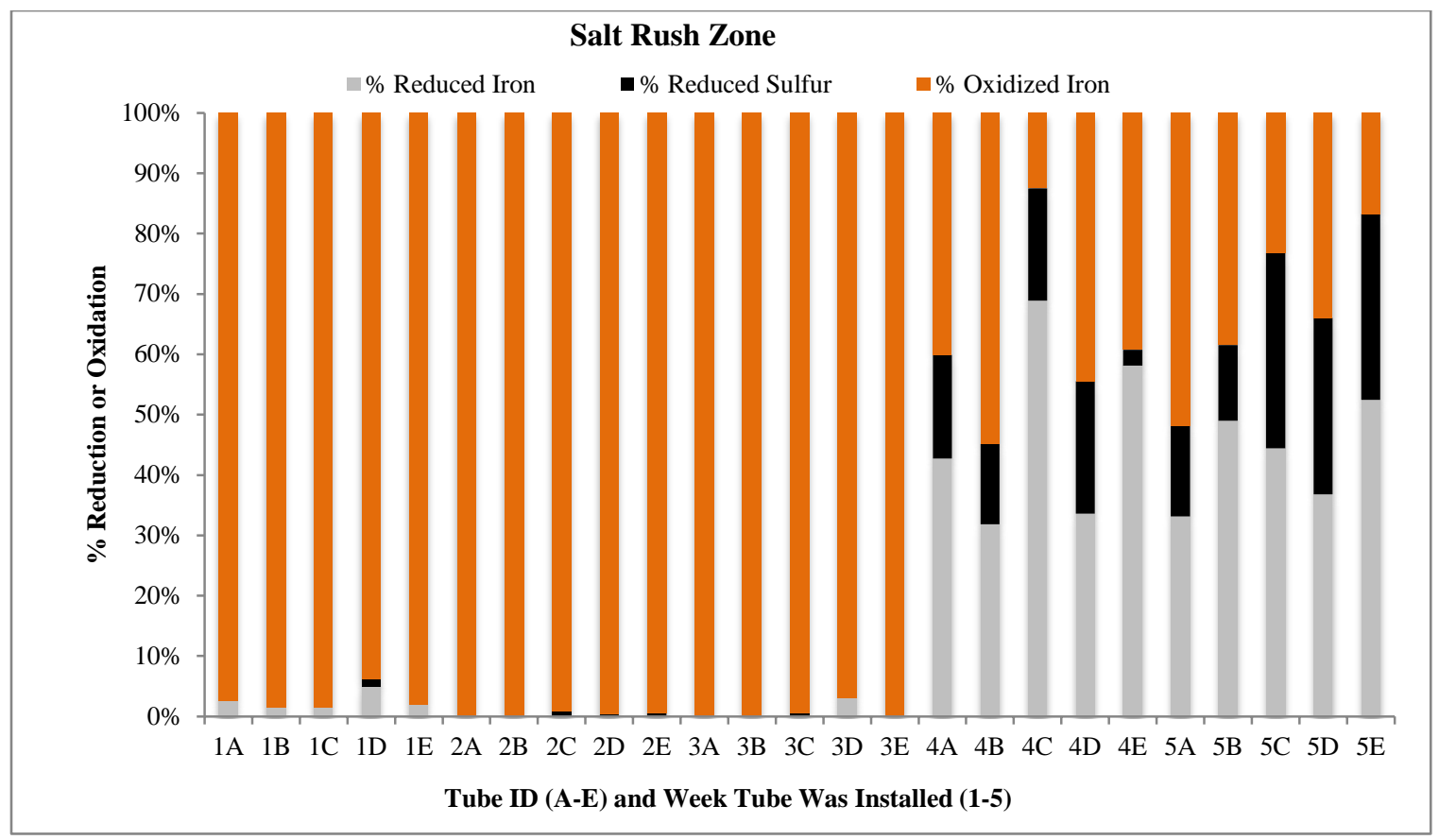

Figure 22. The results of the all the IRIS tubes by week from April 6 - July 21, 2013 within the salt rush zone Swanton Pacific Ranch, Davenport California 


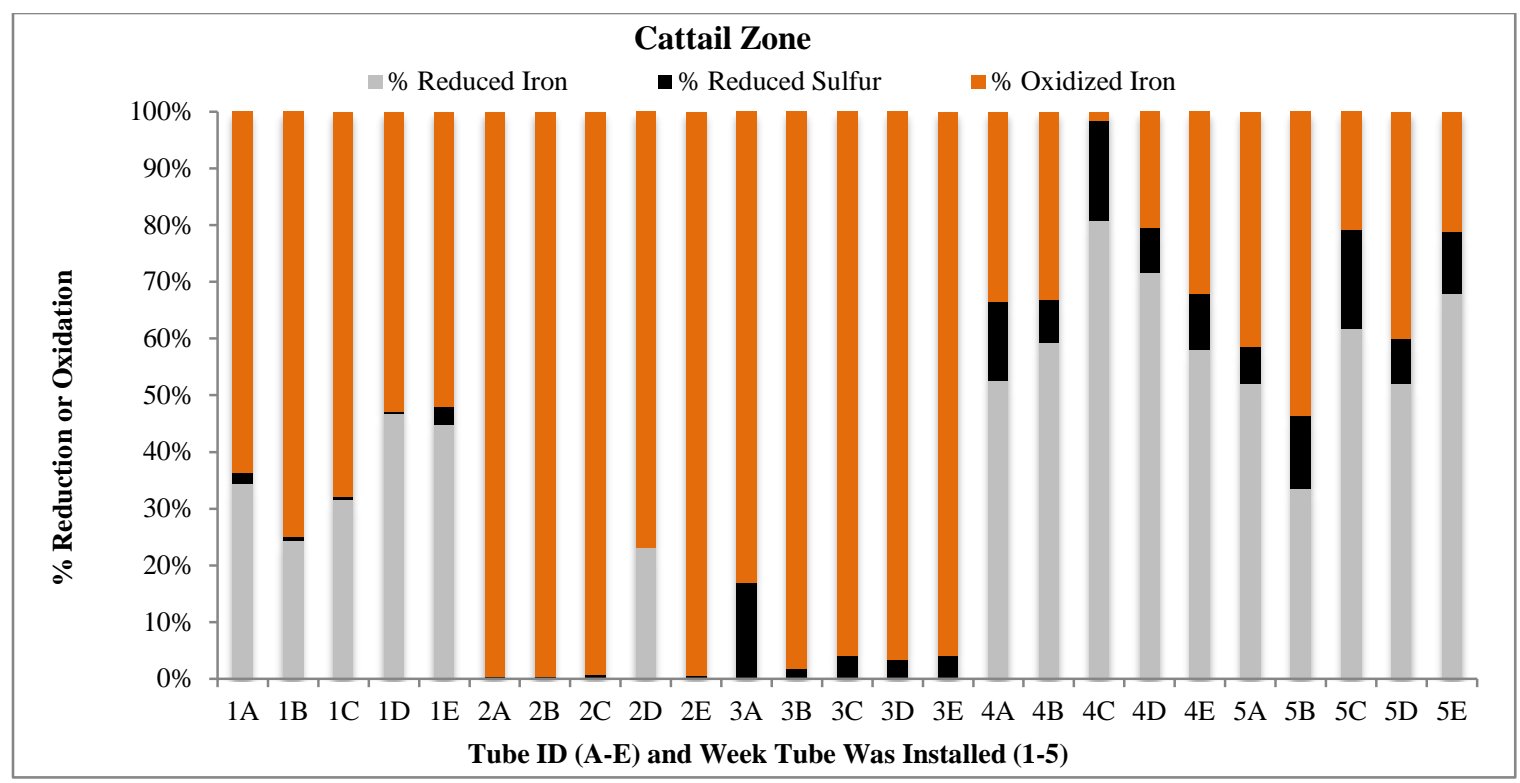

Figure 23. The results of the all the IRIS tubes by week from April 6 - July 21, 2013 within the cattail zone Swanton Pacific Ranch, Davenport California

The computed data were compared to the student estimations of reduction and some interesting trends could be found. When comparing the two methods, the $\mathrm{R}^{2}$ values for total reduction and oxidation was 0.92 for total reduction and 0.93 suggesting the two methods were equally on par with each other (Fig. 24). However, when comparing the total reduction of $\mathrm{Fe}^{3+}$ verses $\mathrm{S}$ reduction, the $\mathrm{R}^{2}$ values were 0.79 for total $\mathrm{Fe}^{3+}$ reduction and 0.87 for total S reduction (Fig. 25). The analyzed data seemed to indicate that there were a differences when trying to distinguish the reduction of $\mathrm{Fe}^{3+}$ and percent $\mathrm{S}$ reduction when utilizing the two different methods.

The results of the experiment seem to support Rabenhorst, Megonigal, and Keller's (2010) finding that the estimation and calculation of reduction is more varied in reduction percentages between 30 and 65\% (Fig. 24). Based on the comparative analysis, it was clear that more work is needed to come up with a computer based technical standard especially those designed for the analysis of S reduction. 


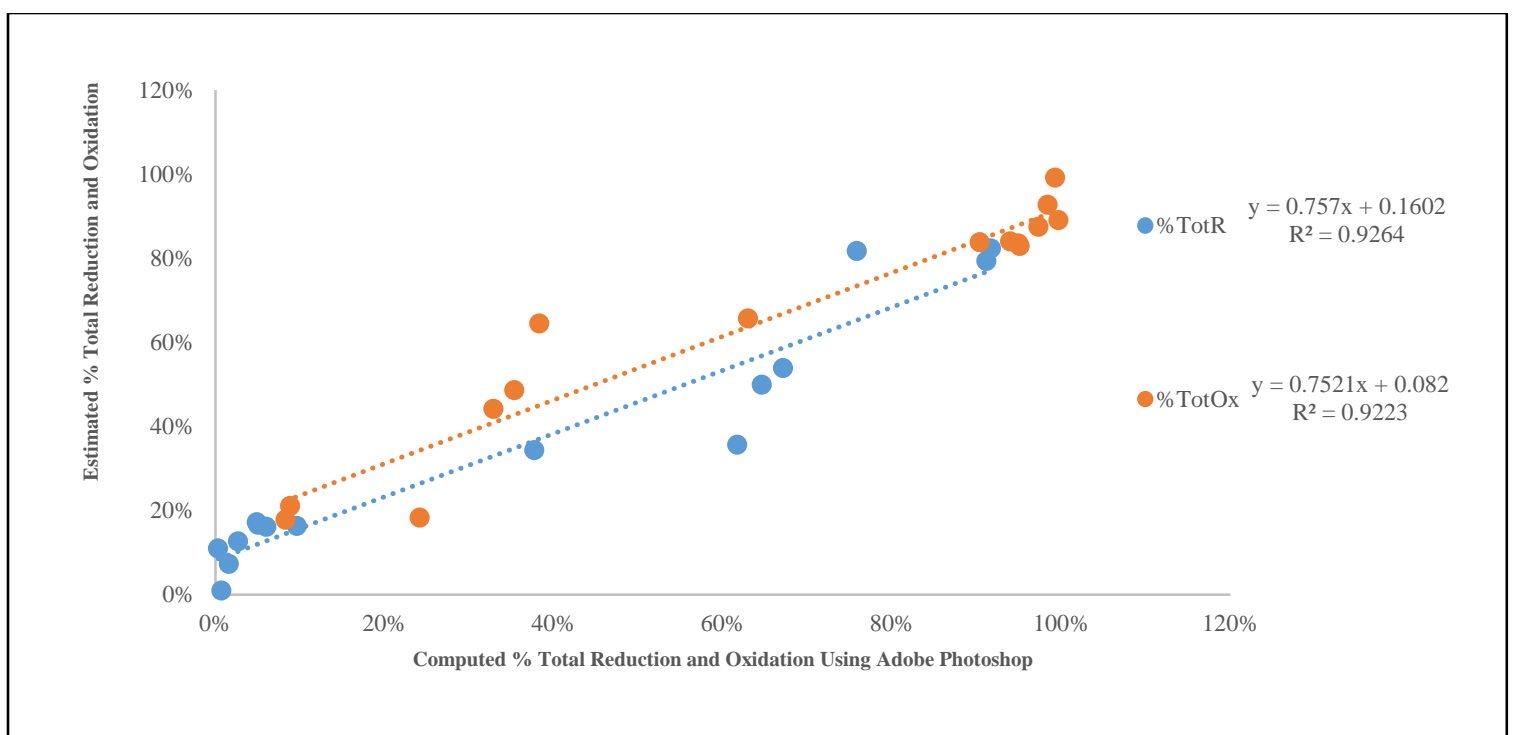

Figure 24. Comparison of the computer and student estimated total reduction (\%TotR) and oxidation (\%TotOx) of all IRIS tubes based on computer generated images

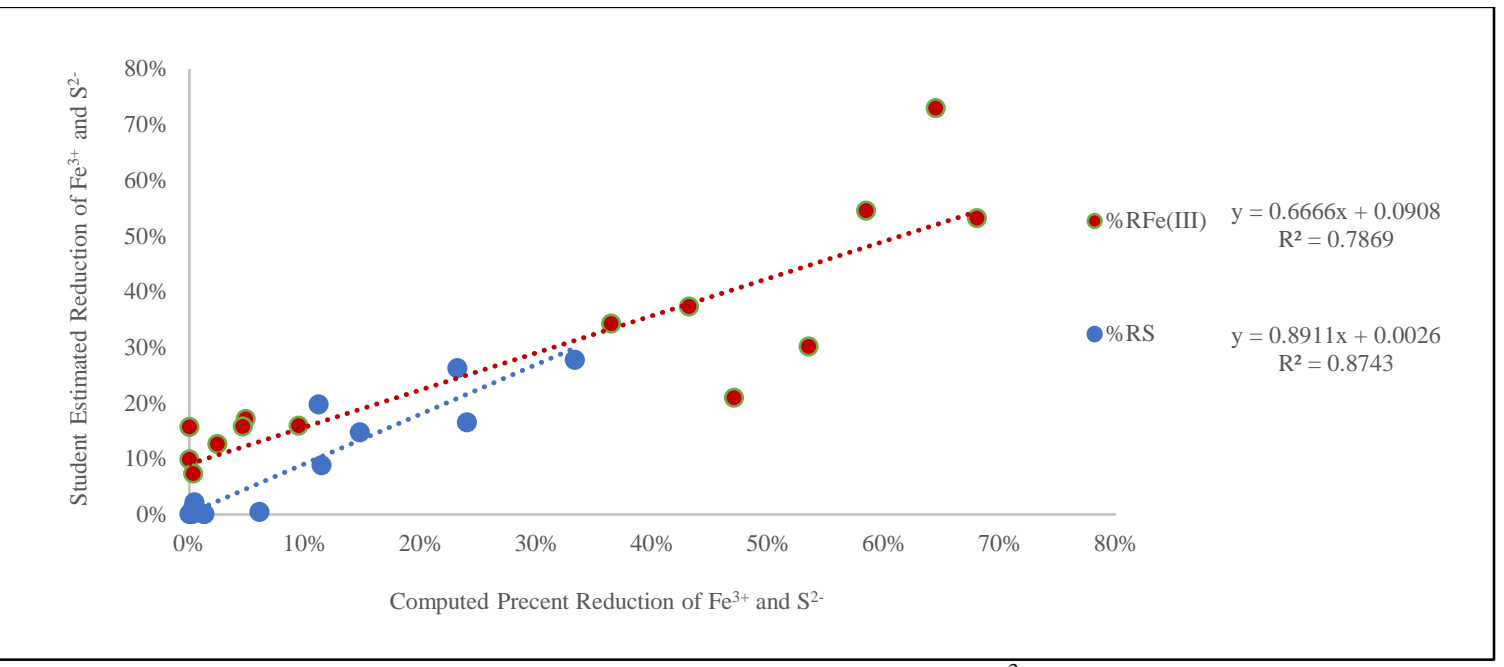

Figure 25. Comparison of the computer and student estimated percent $\mathrm{Fe}^{3+}$ reduction (\%ReFe(III)) and S reduction (\%RS) of all IRIS tubes based on computer generated images

\section{Conclusion}

The image analysis tools of AP5 offer efficient options for calculating the reduction of $\mathrm{Fe}^{3+}$ and $\mathrm{S}$ by pixel count. Although more experimentation is needed, the use of AP5 as a way to measure the reduced areas on IRIS tubes was promising and offered a way to standardize computer analysis. The time required for the total analysis seemed to depend on how well the initial photographs were taken. The more precision when taking 
photographs reduced the time required to edit. Taking good photographs in the field will eliminate much of the time required for editing and allow for more precise measurements. The development of hand scanners that run on batteries offers potential in the future for even more rapid editing and reliable color analysis. 
Chapter 6: Thesis Conclusions

The zoning of halophyte communities in SCM seemed most likely related to how each species has adapted to the hydrogeomorphology and salinity of the marsh. Cattails prefer to inhabit the lower elevations around the marsh channels since it cannot tolerate high salinity. The salt rush communities represented an intermediate community preferring to inhabit the middle ground and areas with mild salinity. Therefore, based on the analysis of the data, any changes to the hydrology of Scotts Creek or the geomorphology of the marsh will ultimately change the distribution and concentration of halophytes. The hydrogeomorphology of SCM created an ideal environment for sulfate reduction. Under these conditions, the IRIS tubes proved effective as an indicator of sulfate reduction. Finally, although more research is needed, the use of Adobe Photoshop CS5.1 proved to be an effective tool to digitally analyze the redox condition of IRIS tubes. 


\section{BIBLIOGRAPHY}

Adams, D.A. 1963. Factors influencing vascular plant zonation in North Carolina salt marsh. Ecology 44:445-456.

Anisfield, S.C., M.J. Tobin, and G. Benoit. 1999. Sedimentation rates in flow-restricted and restored salt marshes in Long Island Sound. Estuaries 22:231-244.

Armstrong, J., W. Armstrong, and P.M. Beckett. 1992. Phragmites australis: venture- and humidity-induced pressure flows enhance rhizome aeration and rhizosphere oxidation. New Phytologist 120:197-207.

Barbier, E.B., S.D. Hacker, C. Kennedy, E.W. Koch, A.C. Stier, and B.R. Silliman. 2011. The value of estuarine and coastal ecosystem services. Ecological Monographs, Ecological Society of America 81:169-193.

Bartlett, R.J. and B.R. James. 1993. Redox chemistry of soils. Advanced Agronomy 50:151-208.

Bates, R.G. 1981. The modern meaning of pH. Critical Reviews in Analytical Chemistry 10:247-278.

Beeftink, W.G. 1977. Salt marshes. In. R.K. Barnes, (ed.) The Coastline. John Wiley \& Sons, New York, NY. p. $93-121$.

Best, M., A. Massey, and A. Prior. 2007. Developing a salt marsh classification tool for the European water framework directive. Marine Pollution Bulletin 55:205-214.

Bohn, H.L. 1968. Electromotive force of inert electrodes in soil suspensions. Soil Science Society of America Proceedings. 32:211-215.

Boon, P.I. and A. Mitchell. 1995. Methanogenesis in the sediments of an Australian freshwater wetland: comparison with aerobic decay and factors controlling methanogenesis. FEMS Microbiology Ecology 26:174-190.

Bowmen, R.H. and D.C. Estrada. 1980. Soil survey of Santa Cruz County, California. USDA Soil Conservation Services.

Brabb, E.E. 1989 Geologic map of Santa Cruz County, California. USDI Geologic Survey. Misc. Investigations Series, map I-1905.

Bradley, P.M. and J.T. Morris. 1990. Influences of oxygen and sulfide concentrations on nitrogen uptake kinetics in Spartina alterniflora. Ecol. 71:282-287.

Brady, N. C. \& Weil, R. R., 2002. The nature and properties of soils. $2^{\text {nd }}$ ed. Pearson Education Inc. Upper Saddle River, NJ. 
Brady, N. C. \& Weil, R. R., 2010. The nature and properties of soils. $3^{\text {rd }}$ ed. Pearson Education Inc. Upper Saddle River, NJ.

Brown, A. and C. Bledsoe. 1996. Spatial and temporal dynamics of mycorrhizas in Jaumea carnosa, a tidal saltmarsh halophyte. Journal of Ecology 84:703-715.

Buol, S.W., R.J. Southard, R.C. Graham, and P.A. McDaniel. 2011. Soil genesis and classification. $6^{\text {th }}$ ed. John Wiley \& Sons, Inc. Chichester, West Sussex, UK.

Buresh, R.J., R.D. Delaune, and W.H. Patrick. 1980. Nitrogen and phosphorus distribution and utilization by Spartina alterniflora in a Louisiana Gulf Coast marsh. Estuaries 3:111-121.

Capone, D.G. and R.P. Kiene. 1988. Comparison of microbial dynamics in marine and freshwater sediments: Contrast in anaerobic carbon metabolism. Limnology and Oceanography 33.725-749.

Castenson, K.L. and M.C. Rabenhorst. 2006. Indicator of reduction in soil (IRIS): Evaluation of a new approach for assessing reduced conditions in soil. Soil Science Society of America Journal 70:1222-1226.

Catellan, G.W. 1983. Physical chemistry. $3^{\text {rd }}$ ed. Addison-Wesley Publishing Co., Reading, MA.

Chapman, V.J. 1974. Salt marshes and deserts of the world. In R.J. Reimold and W.H. Queen, eds. Ecology of halophytes. Academic Press, New York, NY. p. 3-19.

Chapman, V.J. 1975. The salinity problem in general: Its importance and distribution with special reference to natural halophytes. In. A. Poljakoff-Mayber and J. Gale (eds.) Plant in saline environments. Ecological studies. $5^{\text {th }}$ ed. Springer-Verlag, New York, p. 724.

Chapman, V.J. 1976a. Coastal vegetation, $2^{\text {nd }}$ ed. Pergamon Press, Oxford, UK. p. 292.

Chapman, V.J. 1976b. Wet coastal ecosystems. Elsevier, Ansterdam. p. 428.

Chapman, V.J. 1960. Salt marshes and salt deserts of the world. Interscience, New York, NY. p. 392.

Childers, D.L., J.W. Day, and H.N. McKellar. 2000. Twenty more years of marsh and estuarine flux studies: Revisiting Nixon (1980). In. M.P. Weinstein and D.A. Kreeger (eds.) International symposium: Concepts and controversies in tidal marsh ecology. Kluwer Academic Publishers, Dordrecht, the Netherlands. p. 389-421.

Colmer, T.D. and T.J. Flowers. 2008. Flooding tolerance in halophytes. New Phytologist 179:964-974. 
Compton, R.G., and G.W. Sanders. 1996. Electrode potentials. Oxford Science Publications, Oxford, NK.

Cotton, F.A., and G. Wilkinson. 1980. Advanced inorganic chemistry. John Wiley and Sons, New York, NY.

Craft, C.B. 2001. Biology of wetlands. In Wetland Soils. Richardson, J.L. and M.J. Vepraskas eds. Lewis Publishers, CRC Press LLC, Boca Raton, FL.

Ernst, W.O. 1990. Ecophysiology of plants in waterlogged and flooded environments. Aquatic Botany 38:73-90.

Eswaren, H., P. Reich, P. Zdruli, and T. Levermann. 1996. Global distribution of wetlands. American Society of Agronomy Abstract 328.

Frey, R.W. and P.B. Basan. 1985. Coastal salt marshes. In. R.A. Davis, Jr. (ed.) Coastal Sedimentary environments. Springer-Verlag, New York, NY. p. 225-301.

Gambrell, R.P. and W.H. Patrick. 1978. Chemical and microbiological properties of anaerobic soils and sediments. In. D.D. Hook and R.M. Crawford (eds.) Plant life in anaerobic environments. Ann Arbor Science, Ann Arbor, MI. Pages 375-423.

Giblin, A.E. and R.K. Wieder. 1992. Sulfur cycling in marine and freshwater wetlands. In. R.W. Howarth et al. (eds.) Sulfur cycling on the continents. Wetlands, terrestrial ecosystems, and associated ecosystems. John Wiley \& Sons, New York, NY. p. 85-117.

Hacker, S.D. and M.D. Bertness. 1995. Morphological and physiological consequences of a positive plant interaction. Ecology 76:2165-2175.

Hare, F.K. 1980. Long-term annual surface heat and water balances over Canada and the United States south of $60^{\circ} \mathrm{N}$ : Reconciliation of precipitation, runoff, and temperature fields. Atmosphere-Ocean 18:127-153.

Harter, R.D. and G. Smith. 1981. Langmuir equation and alternative methods for studying “adsorption” reactions in soils. In. D. Baker (ed.) Chemistry in soil environments. Soil Science Society of America, Madison, WI. p. 167-182.

Hayes, S.A., M.H. Bond, C.V. Hanson, and E.V. Freund. 2008. Steelhead growth in a small Central California watershed: Upstream and estuarine rearing patterns. American Fisheries Society 137:114-128.

Hernandez, M.E. and W.J. Mitsch. 2007. Denitrification in created riverine wetlands: Influence of hydrology and season. Ecological Engineering 30:78-88. 
Howes, B.L., J.H. Dacey, and G.M. King. 1984. Carbon flow through oxygen and sulfate reduction pathways in salt marsh sediments. Limnology and Oceanography 29:10371057.

Howarth, R.W. 1984. The ecological significance of sulfur in the energy dynamics of salt marsh and coastal marine sediments. Biogeochemistry 1:5-27.

Howarth, R.W. and A. Giblin. 1983. Sulfate reduction in the salt marshes at Sapelo Island, Georgia. Limnology and Oceanography 28:70-82.

James, B.R. 1989. Electron activities in soils: A key master variable. Advances in Agronomy, Abstract. p. 201.

James, B.R. and R.J. Bartlett. 2000. Redox phenomena. M.E. Sumner ed. In Hadbook of Soil Science. CRC Press LLC., Boca Raton, FL. p. B-169 - B-194.

Jenkinson, B.J., and D.P. Franzmeier. 2006. Development and evaluation of iron-coated tubes that indicate reduction in soils. Soil Science Society of America Journal 70:183191.

Jenkinson, B.J. and D.P. Franzmeier. 2005. Development and evaluation of iron-coated tubes that indicate the reduction of soils. Soil Science Society of America Journal 70:183191.

Josselyn, M. 1983. The ecology of San Francisco Bay tidal marsh: A community profile. FWS/OBS-83/23, U.S. Fish and Wildlife Service, Slidell, LA. p. 102.

Junk, W.J., P.B. Bayley, and R.E. Sparks. 1989. The flood pulse concepts in riverfloodplain systems. In. D.P. Dodge (ed.) Proceedings of the international large river symposium. Special Issue of Journal of Canadian Fisheries and Aquatic Sciences 106:11127.

Jun-Xing, Y., L. Yong, and Y. Zhi-Hong. 2012. Root-unduced changes of pH, Eh, Fe(II) and fractions of $\mathrm{Pb}$ and $\mathrm{Zn}$ in rhizosphere soils of four wetland plants with different radial oxygen losses. Pedosphere 22:518-527.

Koch, M.S., I.A. Mendelssohn, and K.L. McKee. 1990. Mechanism for the hydrogen sulfide-induced growth limitations in wetland macrophytes. Limnology and Oceanography 35:399-408.

Kubitzk, K. 1998. The families and genera of vascular plants. Springer-Verlag, Berlin, Germany.

Lefeuvre, J.C., P. Laffaille, E. Feunteum, V. Bouchard, and A. Radureau. 2003.

Biodiversity in salt marshes: From patrimonial values to ecosystem functioning. The case study of the Mont-Saint-Michel Bay. Comptes Rendus Biologies 326:125-131. 
Lindsay, W.L. 1979. Chemical equilibria in soils. Wiley-Interscience, New York, NY.

Liu, C.W. and T.N. Narasimhan. 1989. Redox-controlled multiple-species reactive chemical transport. 1. Model development. Water Resources Research. 25:869-882.

Lovley, D.R. 1991. Dissimilatory iron (III) and manganese (IV) reduction. Microbiological Review 55:259-287. Lyubenova, L., A.J. Kuhn, A. Höltkemeier, P. Schröder. 2013. Root exudation pattern of Typha latifolia L. plants after copper exposure. Plant and Soil. 370:187-195.

McBride, M.B. 1994. Environmental chemistry of soils. Oxford University Press, New York, NY.

McKnight, J.S., D.D. Hook, O.G. Langdon, and R.L. Johnson. 1981. Flood tolerance and related characteristics of trees of the bottomland forests of the southern United States. In J.R. Clark and J. Benforado, eds. Wetlands of Bottomland Hardwood Forests. Elsevier, Amsterdam. p. 29-69.

Megonigal, J.P., M.E. Hines, and P.T. Visscher. 2004. Anaerobic metabolism: Linkages to trace gases and aerobic processes. In. W.H. Schlesinger (ed.) Biogeochemistry. Elsevier-Pergamon, Oxford, UK, p. 317-424.

Mendelssohn, I.A. 1979. Nitrogen metabolism in the height forms of Spartina alterniflora in North Carolina. Ecology 60:574-584.

Mendelssohn, I.A. and J.T. Morris. 2000. Eco-physiological controls on the productivity of Spartina alterniflora Loisel. In. M.P. Weinstein and D.A. Kreeger (eds.) International Symposium: Concepts and Controversies in tidal marsh ecology. Kluwer Academic Publishers, Dordrecht, the Netherlands. p. 59-80.

Miller, D.C., R.J. Geider, and H.L. MacIntyre. 1996. Microphytobenthos: The ecological role of the "secret garden" of vegetated, shallow-water marine habitats. $2^{\text {nd }}$ ed. Role in sedimentary stability and shallow water food webs. Estuaries 19:202-212.

Mitsch, W.J. and J.G. Gosselink. 2000. Wetlands. $3^{\text {rd }}$ ed. John Wiley \& Sons, Inc., New York, NY.

Mitsch, W.J. and J.G. Gosselink. 2000. Wetlands. $4^{\text {th }}$ ed. John Wiley \& Sons, Inc., New York, NY.

Morris, J.T. 1982. A model of growth responses by Spartina alterniflora to nitrogen limitation. Journal of Ecology 70:25-42. 
Moseman-Valtierra, S.M., K. Armaiz-Nolla, L. A. Levin. 2009. Wetland response to sedimentation and nitrogen loading: Diversification and inhibition of nitrogen-fixing microbes. Ecological Applications 20:1556-1568.

National Oceanic and Atmospheric Administration, 2013. National Climatic Data Center http://www.ncdc.noaa.gov/

Neubauer, S.C., K. Givler, S.K. Valentine, and J.P. Megonigal. Seasonal patterns and plant-mediated controls of subsurface wetland biogeochemistry. Ecology 86:3334-3344.

Odum, E.P. 1968. A research challenge: Evaluating the productivity of coastal and estuarine water. Proceedings of the second sea grant conference, University of Rhode Island. p. 63-64.

Odum, E.P. 1980. The status of three ecosystem-level hypotheses regarding salt marsh estuaries: Tidal subsidy, outwelling, and detritus-based food chains. In. V.S. Kennedy (ed.) Estuarine perspective. Academic Press, New York, NY. p. 485-495.

Odum, E.P. 2000. Tidal marshes as outwelling/pulsing systems. In. M.P. Weinstein and D.A. Kreeger, (ed.) International symposium: Concepts and controversies in tidal marsh ecology. Kluwer Academic Publishers, Dordrecht, the Netherlands.

Patrick, W.H. and R.D. Delaune. 1972. Characterization of the oxidized and reduced zones in flooded soils. Proceedings of the Soil Science Society of America 36:573-576.

Patrick, W.H. and A. Jugsujinda. 1992. Sequential reduction of oxidation of inorganic and organic nitrogen, manganese, and iron in flooded soils. Soil Science Society of America Journal 56:1071-1073.

Partick, W.H., R.P. Gambrell, and S.P. Faulkner. 1996. Redox measurements of soil. In. Methods of soil analysis: Part 3 Chemical methods. Sparks, D.L. and D.L. Suarez (eds.) Soil Science Society of America Book Series 5, Soil Science Society of America, Madison, WI. p. 1255-1273.

Pearson, J. and D.C. Havill. 1988. The effect of hypoxia and sulfide on culture grown wetland and nonwetland plants. 2. Metabolic and physiological changes. Journal of Experimental Botany 39:431-439.

Pezeshki, S.R., R.D. DeLaune, and S.Z. Pan. 1991. Relationship of soil hydrogen sulfide level to net carbon assimilation of Panicum hemitomon and Spartina patens. Vegetatio 95:159-166.

Pomeroy, L.R., L.R. Shelton, and R.J. Reimold. 1972. Nuteirent flux in estuaries. In. G.E. Likens (ed.) Nutrients and eutrophication. American Society of Limnology and Oceanography Special Symposium. Allen Press, Lawrence, KS, p. 274-291. 
Ponnamperuma, F.N. 1972. The chemistry of submerged soils. Advanced Agronomy 24: 29-96.

Rabenhorst, M.C. 2005. Biological zero: A soil temperature concept. Wetlands 25:616 621.

Rabenhorst, M.C. and S.N. Burch. 2006. Synthetic iorn oxides as an indicator of reduction in soils (IRIS). Soil Science Society of America Journal 70:1227-1236.

Rabenhorst, M.C., R.R. Bourgault, and B.R. James. 2007. Iron oxyhdroxide reduction in simulated wetland soils: Effects of mineralogical composition of IRIS paint. Soil Science Society of America Journal 72:1838-1842.

Rabenhorst, M.C., J.P. Megonigal, and J. Keller. 2010. Synthetic iron oxides for documenting sulfide in marsh pore water. Soil Science Society of America Journal 74:1383-1388.

Rabenhorst, M.C. 2010. Visual assessment of IRIS tubes in field testing for soil reduction. Wetlands 30:847-852.

Rabenhorst, M.C. 2011. Simple and reliable approach for quantifying IRIS tube data. Soil Science Society of America Journal 76:307-308.

Reddy, K.R. and W.H. Patrick. 1984. Nitrogen transformation and loss in flooded soils and sediments. CRC Critical Reviews in Environmental Controls 13:273-309.

Reddy, K.R. and D.A. Graetz. 1988. Carbon and nitrogen dynamics in wetland soils. In D.D. Hook et al. (eds.) The ecology and management of wetlands, Vol. 1, Ecology of wetlands. Timber Press, Portland, OR. p. 307-318

Reddy, K.R. and E.M. D’Angelo. 1994. Soil processes regulating water quality in wetlands. In, W.J. Mitch, (ed.) Global wetlands: Old world and new. Elsevier, Amsterdam, the Netherlands. p. 309-324.

Redfield, A.C. 1972. Development of a New England salt marsh. Ecological Monographs 42:201-237.

Robert, W.L., N.C. Melvin, M. L. Butterwick, W. N. Kirchner. 2012. National Wetland Plant List: Indicator rating definitions. Wetland Regulatory Assistance Program, U.S. Army Corps of Engineers, Washington, DC.

Ryan, A.B and K.E. Boyer. 2012. Nitrogen further promotes a dominant salt marsh plant in an increasingly saline environment. Journal of Plant Ecology 5:429-441. 
Sexstone, A.J., N.P. Revsbech, T.B. Parkin, and J.M. Tiedje. 1985. Direct measurement of oxygen profiles and denitrification rates in soil aggregates. Soil Science Society of America Journal 49: 645-651.

Siegal, D.I. 1988a. A review of the recharge-discharge function of wetlands. In. D.D. Hook et al. (eds.) The ecology and management of wetlands, Vol. 1, Ecology of Wetlands. Timber Press, Portland, OR. p. 59-67.

Sillén, L.G. 1967. In Equilibrium concepts in natural water systems. American Chemical Society, Advances in Chemistry Series No. 67, Washington, DC.

Silliman, B.R., and M.D. Bertness. 2002. A trophic cascade regulates salt marsh primary production. Proceedings of the National Academy of Science USA 99:10500-10505.

Smart, R.M. and J.W. Barko. 1980. Nitrogen nutrition and salinity tolerance of Distichlis spicata and Spartina alterniflora. Ecology 61:630-638.

Smith, J.L. and J.W. Doran. 1996. Measurements and use of $\mathrm{pH}$ and electrical conductivity for soil quality analysis. In. Methods for assessing soil quality. Soil Science Society of America Special Publications 49:169-185.

Sparks, D.L. 1985. Kinetics of ionic reactions in clay minerals and soils. Advanced Agronomy 38:231-265.

Sparks, D.L. 2003. Environmental soil chemistry. $2^{\text {nd }}$ ed. Academic Press, San Diego CA. p. 245-265.

Sprecher, S.W. 2008. Installing monitoring wells in soils, Version 1.0. Natural Resources Conservation Service, National Soil Survey Center, Lincoln, NE.

Sposito, G. 1981. The thermodynamics of soil solutions. Oxford University Press, New York, NY.

Sposito, G. 1989. The chemistry of soils. Oxford University Press, New York, NY.

Sousa, A.I., A.I. Lillebø, I. Caçador, and M.A. Pardal. 2008. Contributions of Spartina maritima to the reduction of eutrophication in estuarine systems. Environmental Pollution 156:628-635.

Sousa, A.I., A.I. Lillebø, M.A. Pardal, and I. Caçador. 2010. Productivity and nutrient cycling in salt marshes: Contribution to ecosystem health. Estuarine, Coastal and Shelf Science 87:640-646.

Stanley, R.G. 1984. Middle tertiary sedimentation and tectonic of the La Honda Basin, Central California. Ph.D. Dissertation UC Santa Cruz. University Microfilms International, Ann Arbor, MI. pp 471. 
Streever, E.Z. , R.S. Warren, and W.A. Niering. 1976. Tidal energy subsidy and standing crop production of Spartina alterniflora. Estuarine, Coastal and Marine Science 4: 473478.

Stumm, W., and J.J. Morgan. 1996. Aquatic chemistry. $3^{\text {rd }}$ Ed. Wiley-Interscience, New York, NY.

Townend, Ian, C. Fletcher, M. Knappen, and K. Rossington. 2011. A review of salt marsh dynamics. Water and Environmental Journal 25: 477-488.

Tuner, R.E. 1976. Geographic variations in salt marsh macrophytes production: A review. Contributions to Marine Science 20:47-68.

United States Department of Agriculture. 2003. M. Stevens and M. K. Anderson (eds.) Plant guide: Salt rush. USDA, NRCS, http://plants.usda.gov.

United States Department of Agriculture. 2006. M. Stevens et al. (eds.) Plant guide: Broad-leaf cattail. USDA, NRCS, http://plants.usda.gov United States Department of Agriculture, Natural Resources Conservation Service. 2005. S.D. Newman et al. (eds.) Plant guide: Salt grass. USDA, NRCS, http://plants.usda.gov.

United States Department of Agriculture, Natural Resources Conservation Service. 2010. Field indicators of hydric soils in the United States, Version 7.0. L.M. Vasilas et al. (eds.). USDA, NRCS, in cooperation with the National Technical Committee for Hydric Soils.

United States Department of Agriculture, Natural Resources Conservation Service. 2012. P.J. Schoeneberger et al. (eds.) Field book for describing and sampling soils, Version 3.0. Natural Resources Conservation Service, National Soil Survey Center, Lincoln, NE.

USDA natural Resource Conservation Services. 2011. Soil quality indicators. Electrical conductivity. Washington DC.

Valiela, I. and J.M. Teal. 1974. Nutrient limitation in salt marsh vegetation. In R.J. Reimold and W.H. Queen, eds. Ecology of Halophytes. Academic Press, New York, NY. p. 547-563.

Valiela, I. and J.M. Teal. 1979. The nitrogen budget of a salt marsh ecosystem. Nature 280: 652-656.

Vepraskas, M.J. 1995. Redoximorphic features for identifying aquatic conditions. Technical Bulletin 301. North Carolina Agricultural Research Services, North Carolina State University, Raleigh, NC. p. 33. 
Vepraskas, M.J., and S.P. Faulkner. 2001. Redox chemistry of hydric soils. In. Wetland soils. Richardson, J.L. and M.J. Vepraskas (eds.) Lewis Publishers, CRC Press LLC, Boca Raton, FL.

Weinstein, M.P. and D.A. Kreeger. 2000. Concepts and controversies in tidal marsh ecology. International symposium: Concepts and controversies in tidal marsh ecology, Cumberland College, Vineland, NJ, April 5-9, 1998. Kluwer Academic Publishers, Dordrecht, the Netherlands.

Wieder, R.K. and G.E. Lang. 1986. Fe, Al, Mn, and S chemistry of sphagnum peat in four peatlands with different metal and sulfur input. Water, Air, and Soil Pollut. 29:309320.

Wieder, R.K. and G.E. Lang. 1988. Cycling of inorganic and organic sulfur in peat from big run bog, West Virginia. Biogeochemistry 5:221-242.

Wilson, A.M. and J.T. Morris. 2012. The influence of tidal forcing on groundwater flow and nutrient exchange in a salt marsh-dominated estuary. Biogeochemistry 108:27-38.

Woo, M.K. and T.C. Winter. 1993. The role of permafrost and seasonal frost in the hydrology of northern wetlands in North America. Journal of Hydrology 141: 5-31.

Yoshida, T. 1975. Microbial metabolism of flooded soils. pp. 83-123. In. E.A. Paul and A.D. Maclaren (eds.) Soil biogeochemistry. Marcel Dekker Inc. New York, NY. Zedler, J.B. 1980. Algae mat productivity: Comparisons in a salt marsh. Estuaries 3:122131.

Zedler, J.B. 1982. The ecology of Southern California costal salt marshes: A community profile. FWS/OBS-81/54, U.S. Fish and Wildlife Services, Washington, DC.

Zedler, J.B. 1988. Salt marsh restoration: Lessons from California. In, J. Cairns (ed.) Rehabilitating damaged ecosystems, Vol. I. CRC Press, Boca Raton, FL, p. 123-138.

Zedler, J.B. 1991. The challenge of protecting endangered species habitat along the southern California coast. Coastal Management 19: 35-53.

Zedler, J.B. 1996. Tidal wetland restoration: A scientific perspective and Southern California focus. Report T-038, California Sea Grant College System, University of California, La Jolla. 129 pp. 